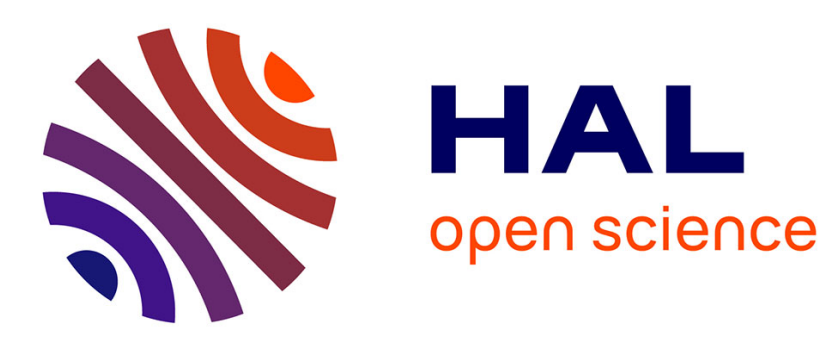

\title{
A Review of Vanadium Dioxide as an Actor of Nanothermochromism: Challenges and Perspectives for Polymer Nanocomposites
}

Jenny Faucheu, Elodie Bourgeat-Lami, Prévot Vanessa

\section{- To cite this version:}

Jenny Faucheu, Elodie Bourgeat-Lami, Prévot Vanessa. A Review of Vanadium Dioxide as an Actor of Nanothermochromism: Challenges and Perspectives for Polymer Nanocomposites. Advanced Engineering Materials, 2019, 21 (2), pp.1800438. 10.1002/adem.201800438 . hal-02131942

\author{
HAL Id: hal-02131942 \\ https://hal.science/hal-02131942
}

Submitted on 13 Nov 2020

HAL is a multi-disciplinary open access archive for the deposit and dissemination of scientific research documents, whether they are published or not. The documents may come from teaching and research institutions in France or abroad, or from public or private research centers.
L'archive ouverte pluridisciplinaire HAL, est destinée au dépôt et à la diffusion de documents scientifiques de niveau recherche, publiés ou non, émanant des établissements d'enseignement et de recherche français ou étrangers, des laboratoires publics ou privés. 


\title{
A review of Vanadium Dioxide as an actor of nanothermochromism: challenges and perspectives for polymer nanocomposites.
}

Jenny Faucheu, ${ }^{1}$ Elodie Bourgeat-Lami, ${ }^{2}$ Vanessa Prevot ${ }^{3}$

\author{
${ }^{1}$ Mines Saint-Etienne, Univ Lyon, CNRS, UMR 5307 LGF, Centre SMS, F - 42023 Saint-Etienne France \\ ${ }^{2}$ Univ. Lyon, Université Claude Bernard Lyon 1, CPE Lyon, CNRS, UMR 5265, Chemistry, Catalysis, Polymers and \\ Processes (C2P2), 43 Bvd. du 11 Novembre 1918, F-69616 Villeurbanne, France \\ ${ }^{3}$ Univ. Clermont Ferrand, CNRS, SIGMA-Clermont, UMR 6296 ICCF, F-63171 Aubière, France
}

\begin{abstract}
:
$\mathrm{VO}_{2}$ has been intensively studied as a model system for Metal-Insulator Transition, ever since its phase switching behavior at relatively low temperature $\left(T_{c}=68^{\circ} \mathrm{C}\right)$ was discovered. Its thermo-active characteristics have been studied for applications in thermal solar collectors to prevent overheating of the fluid absorber, smart windows and smart tiles to optimize thermal comfort in buildings. In the last decades, strong efforts were made to develop protocols to process $\mathrm{VO}_{2}$-based material into thin films, coatings, porous layers and glazings in order to provide thermo-active properties to common substrates. A selection of complementary works in both the synthesis of $\mathrm{VO}_{2}$ nanoparticles and formulation of $\mathrm{VO}_{2}$-polymer nanocomposites is proposed in the present review. The perspective of this work is to provide an easy entry to the thermochromic nanocomposite research field as a tutorial to tackle future challenges such as improving the application-oriented properties, in particular transition temperature $T_{\mathrm{c}}$ and solar transmittance modulation $\Delta T_{\text {sol }}$. Synthesis techniques to fabricate $\mathrm{VO}_{2}$ particles and nanoparticles and strategies to insert $\mathrm{VO}_{2}$ particles in a polymer matrix are presented.
\end{abstract}

\section{Introduction}

Among the different $\mathrm{VO}_{2}$ polymorphs, the monoclinic $\mathrm{M}$ or $\mathrm{M}_{1}$ phase and the tetragonal rutile-type $\mathrm{R}$ phase have attracted a lot of attention due to the reversible Metal-Insulator Transition (MIT) that takes place between these two phases. ${ }^{[1]}$ The phase transition changes the behavior from semiconducting $\left(\mathrm{VO}_{2}(\mathrm{M})\right)$ to metallic $\left(\mathrm{VO}_{2}(\mathrm{R})\right)$ and thus modifies the electrical conductivity and the optical properties. The nature of the MIT has been much debated, but recent work indicates a Mott transition. ${ }^{[2][3][4]}$ The reversible phase transition is a first order transition that results in a change of crystallographic structure at a transition or critical temperature $T_{\mathrm{c}}$. $\mathrm{VO}_{2}$ has been intensively studied as a model system for MIT, ever since its phase switching behavior around $T_{\mathrm{c}}=68^{\circ} \mathrm{C}$ was discovered ${ }^{[2]}$. Under heating conditions, the material starts at $T<T_{c}$ in its semiconductor state $\mathrm{VO}_{2}(\mathrm{M})$ and sees the metallic phase $\mathrm{VO}_{2}(\mathrm{R})$ germinate during the MIT transition. Under cooling conditions, the material starts at $T>T_{\mathrm{c}}$ in its metallic state $\mathrm{VO}_{2}(\mathrm{R})$ 
and sees the semiconductor phase germinate during the transition. Note that this transition exhibits a hysteresis meaning that the transition under heating conditions occurs at a slightly different temperature than the transition under cooling conditions. The optical properties of $\mathrm{VO}_{2}$ such as reflectance, ${ }^{[5]}$ emittance ${ }^{[6]}$ or transmittance ${ }^{[7]}$ are modified during the phase transition. Its thermo-active characteristics have been studied for coating applications related to solar-irradiation on substrates that can be either transparent or absorbent materials for instance, $\mathrm{VO}_{2}$ coatings could be efficient in thermal solar collectors to prevent overheating of the fluid absorber ${ }^{[8]}$, and in smart windows $^{[7][9][10][11][12][13][14]}$ and smart tiles ${ }^{[15]}$ to optimize thermal comfort in buildings. Solar irradiation onto the atmospheric envelope can be approximated by blackbody-like radiation from the surface of the sun and falls at $0.2<$ $\lambda<3 \mu \mathrm{m}$. Visible light is governed by the luminous efficiency of the eye, which is given by a bell-shaped curve falling at $0.4<\lambda<0.8 \mu \mathrm{m}$ with a peak around $\lambda=0.55 \mu \mathrm{m}$. Solar transmittance modulation $\Delta T_{\text {sol }}(\lambda)$ of a thermoactive coating depends on the wavelength and is defined as the difference between the transmittance spectrum at low temperature and the transmittance spectrum at high temperature for $0.2<\lambda<3 \mu \mathrm{m}$ (the transmittance modulation $\Delta T_{\mathrm{IR}}(\lambda)$ can also be defined for the IR part of the solar spectrum i.e. $\left.0.8<\lambda<3 \mu \mathrm{m}\right)$. The solar transmittance modulation $\Delta T_{\text {sol }}$ is defined as the integrated value over the wavelength range. In particular, $\mathrm{VO}_{2}$-glazings have been the subject of intensive research efforts in recent years due to their potential application as smart windows. Numerical calculations ${ }^{[16][7]}$ show that 0.1-0.3 $\mu \mathrm{m}$ thick films exhibit solar transmittance modulations $\Delta T_{\text {sol }}$ around 15$20 \%$ (Figure $2 \mathrm{a}, \mathrm{b}, \mathrm{c}$ ). These characteristics can induce up to $45 \%$ energy consumption improvement with $\mathrm{VO}_{2}$ coated-glass compared to plain float glass. ${ }^{[17]}$ In particular, the MIT involves an abrupt change in near-infrared transmittance that makes $\mathrm{VO}_{2}$ an attractive thermochromic material to intelligently adjust the near infrared radiation according to the environment temperature. ${ }^{[18][19][20][21][22]}$

Transmittance modulation by $\mathrm{VO}_{2}$-based coatings of various morphologies has motivated the bulk of the work in this field with three main challenges. ${ }^{[13]}$ The first challenge was to reduce the transition temperature $T_{\mathrm{c}}$ of $\mathrm{VO}_{2}$ in order to be more adequate for applications related to Human thermal comfort such as smart windows. The second challenge was to maximize the solar transmittance modulation specifically in the IR region. And finally, the third challenge specific to smart windows applications in which transparency is mandatory - was to maximize the transmittance in the visible range. These limitations can be alleviated by the elaboration of composite film materials containing $\mathrm{VO}_{2}$ nanoparticles or nanodomains. Indeed, several experimental results and calculations indicate that nanocomposites containing $\mathrm{VO}_{2}$ particles embedded in a dielectric matrix such as polymers or metal oxides have superior properties, that combine high luminous transmittance and high solar transmittance modulation, than $\mathrm{VO}_{2}$-thin continuous solid films (Erreur! Source du renvoi introuvable.), ${ }^{[23][24][25][26][27][28]}$ in particular, due to the triggering of plasmonic absorption by $\mathrm{VO}_{2}$ nanoparticles in their metallic state. "Nanothermochromism" is a term that was first coined by Li et al. ${ }^{[7]}$ to describe the approach consisting in mixing $\mathrm{VO}_{2}$ nanoparticles with a glass or a polymer matrix. This term is now commonly used. ${ }^{[29]}$ Besides these functional constraints, stability and durability in outdoor environments are still open questions that will take advantage of the huge empirical and research works on durability of composites that are available. 


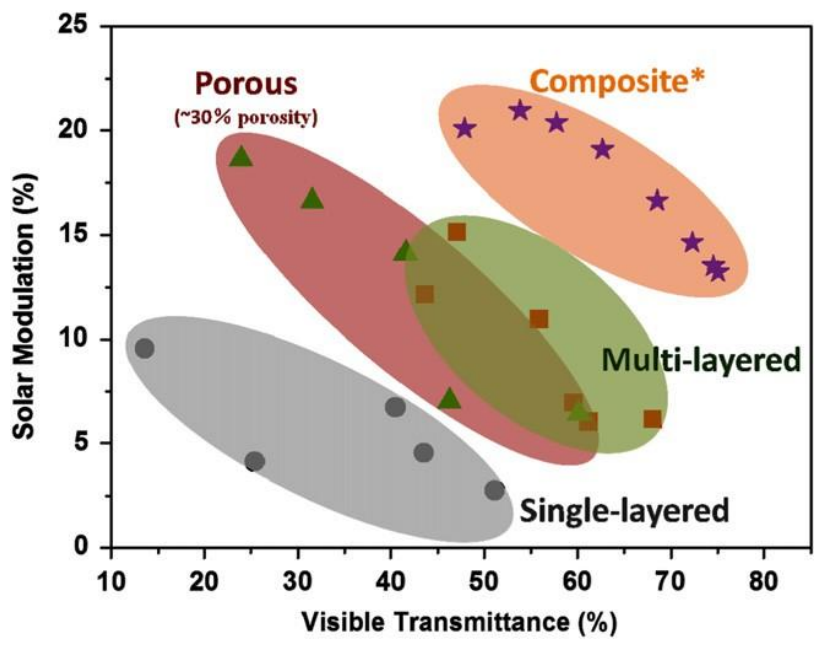

Figure 1. Main performances of $\mathrm{VO}_{2}$ films prepared by different methods. The results for composite films were made from numerical calculations. ${ }^{[7]}$

This review intends to extract papers dedicated to thermochromism provided by $\mathrm{VO}_{2}$ nanoparticles in order to draw the challenges and perspectives of using these nanoparticles into polymer matrices. If such challenges were overcome, a wide range of applications related to adaptive passive control of thermal properties would become industrially realistic (thermal comfort in buildings, thermal stealth in military applications, thermal sensors...). A selection of complementary works in both the synthesis of $\mathrm{VO}_{2}$ nanoparticles and formulation of $\mathrm{VO}_{2}$-polymer nanocomposites is proposed in the present review. The perspective of this work is to provide an easy entry to the thermochromic nanocomposite research field as a tutorial to tackle future challenges. Section 2 describes the existing strategies for improving the application-oriented properties, in particular transition temperature $T_{\mathrm{c}}$ and solar transmittance modulation $\Delta T_{\text {sol }}$. Section 3 is dedicated to synthesis techniques adequate for fabricating $\mathrm{VO}_{2}$ particles and nanoparticles. Section 4 collects the existing approaches to insert $\mathrm{VO}_{2}$ particles in a polymer matrix. Section 4 will wrap up perspectives and challenges of using $\mathrm{VO}_{2}$-polymer coatings as smart architectural coatings for buildings and urban structures and more generally for adaptive passive thermal coatings.

\section{2. $\mathrm{VO}_{2}$ a model material}

This work is dedicated to polymer- $\mathrm{VO}_{2}$ nanoparticles composite paints. A comprehensive review of strategies explored to improve the thermochromic properties of $\mathrm{VO}_{2}$-based materials is presented. The $\mathrm{VO}_{2}$ topic has already drawn interest in several reviews ${ }^{[30][31][32]}$ under different scope in the past. In particular, Warwick and Binions ${ }^{[30]}$ presented the fundamental physical and chemical principles underlying the electronic structure and properties of $\mathrm{VO}_{2}$, and the chronological developments in the theory behind the thermochromic transitions such as, the effects of electron-electron interactions and structural phase changes due to lattice distortions. An extensive discussion and observations on the current understanding of the nature of MIT exhibited by $\mathrm{VO}_{2}$ investigated via computational, experimental and theoretical studies, were detailed. This previous review also provides a panorama of techniques for thin film deposition such as sol-gel and solution, pulsed laser deposition, physical vapor deposition, atomic layer 
deposition, chemical vapor deposition, atmospheric pressure chemical vapor deposition or aerosol assisted chemical vapor deposition. A more complete review on thin film deposition techniques is provided by Wang et al. ${ }^{[31]}$ To date, gas-phase deposition methods, such as sputtering and chemical vapor deposition and solution-based deposition are the most common methods for the fabrication of $\mathrm{VO}_{2}$ films. Gao et al. ${ }^{[32]}$ reviewed the state-of-the-art solution processes used to prepare $\mathrm{VO}_{2}$ films, with a special emphasis on polymer-assisted deposition methods. The resulting $\mathrm{VO}_{2}$ films are compared in terms of optical properties and transmittance modulation. Gao's review suggests that chemical preparation is inexpensive, easy to scale up, and best suited for the practical applications of the fabricated materials. $\mathrm{VO}_{2}$ films prepared by these methods show controllable morphology and thickness but complex optical properties compared with those prepared by gas-phase methods. These methods are not best suited to produce nanoparticles to be further used as pigments in a polymer matrix. However, the final properties and the strategies explored to reach these final properties of the deposited coatings are interesting insights to be considered in a nanoparticle/polymer system. In particular, under specific experimental conditions, the final morphology exhibits nanostructured $\mathrm{VO}_{2}$ films such as nanoporous films or films made of partial sintering of nanoparticles.

\subsection{Properties of discontinuous $\mathrm{VO}_{2}$ coatings: towards polymer-VO $\mathrm{V}_{2}$ nanocomposites}

Among the variety of elaboration processes explored to fabricate $\mathrm{VO}_{2}$ coatings, some were specifically explored in order to form "discontinuous" coatings ${ }^{[33][34]}$ such as porous coatings ${ }^{[35][36][37][38][39]}$ or etched films ${ }^{[40][41]}$. These works were primarily motivated by the need for increasing luminous transmittance without degrading the infrared modulation. For instance, freeze-drying was employed as an efficient way to avoid aggregation phenomena in the

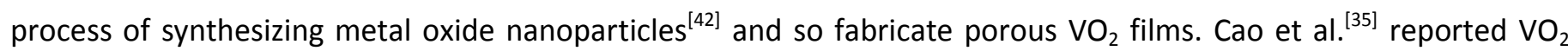
nanostructures with porosities from $16 \%$ to $45 \%$ fabricated using freeze-drying. With a decreasing pre-freezing temperature, grain sizes and pores of $\mathrm{VO}_{2}$ films tended to be slightly increased. The solar transmittance modulation and the visible transmittance were increased with the increase in pore sizes and porosity. Wang et al. ${ }^{[36]}$ reported the preparation of $\mathrm{VO}_{2}$ films with different nanostructures using sol-gel processes. Compared to a conventional $\mathrm{VO}_{2}$ sintered films, the nanoporous structure formed exhibited improved thermochromic properties, with a 16\% increase in the visible transmittance. Ding et al. ${ }^{[37]}$ prepared $\mathrm{VO}_{2}$ films with a micro/nano hierarchical porous structure through a nanoparticle assembly, with cetyl trimethyl ammonium-vanadate (CTAV) as a precursor. The obtained $\mathrm{VO}_{2}$ films exhibited a visible transmittance significantly increased (+25\%) compared to continuous films. Wang et al. ${ }^{[0]}$ reported the use of surface engineering methods, including acid etching and self-patterning to enhance the thermochromic performance of $\mathrm{VO}_{2}$ thin films. Two different morphologies, i.e. dense-packed and nanograin-array patterned continuous $\mathrm{VO}_{2}$ thin films could be obtained by controlling the thickness of the $\mathrm{VO}_{2}$ thin film. The selfpatterning-induced nanograin-array patterned $\mathrm{VO}_{2}$ thin film exhibited much larger $T_{\text {lum }}$ than the dense-packed counterpart, which should be mainly ascribed to the antireflection effect. With acid etching, the dense-packed surface could be changed to patterned surface, which showed improved $T_{\text {lum }}$ and $\Delta T_{\text {sol. }}$ Li et al. ${ }^{[41]}$ compared a nanostructured $\mathrm{VO}_{2}$ film with a grain size of about $8 \mathrm{~nm}$ and a microstructured $\mathrm{VO}_{2}$ film with grain sizes of about 1-2 $\mu \mathrm{m}$. They observed a transition temperature $T_{c}$ of $35^{\circ} \mathrm{C}$ for the nanostructured film compared to $68^{\circ} \mathrm{C}$ for the 
microstructured one. Xu et al. ${ }^{[38][39]}$ reported the fabrication of porous nanostructured $\mathrm{VO}_{2}$ films with sphere-shaped and rod-shaped nanocrystals using a surfactant-assisted sol-gel method. Different surfactants have been used as the nanostructure directing agents including cetyl trimethyl ammonium bromide, polyethylene glycol and sodium dodecyl sulfate. They noted that the $T_{c}$ of the nanostructured films was lower than the one of dense $\mathrm{VO}_{2}$ films. In addition, the hysteresis width was also much wider. However, among the nanostructured films, the films with rodshaped nanostructures exhibited a narrower hysteresis probably due to improved contacts between particles, which favored phase transition propagation.

DC reactive magnetron sputtering process was investigated to produce granular coatings ${ }^{[33]}$. Zhang et al. ${ }^{[34]}$ prepared $\mathrm{VO}_{2}$ films with spheroidal nanoparticles of different sizes, from 45 to $80 \mathrm{~nm}$ diameter, by using $\mathrm{DC}$ reactive magnetron sputtering process to investigate the effect of grain size on the hysteresis. Adjusting the annealing time controlled the size of the $\mathrm{VO}_{2}$ nanoparticles. It was observed that the hysteresis width was inversely proportional to the average grain size.

Besides, several authors have shown that the thermochromic performances of $\mathrm{VO}_{2}$ films can be significantly increased by controlling the morphology of the nanostructure of the film material using silica templates, ${ }^{[43][44][45]}$ latex templates ${ }^{[46][47][18][48]}$ or other micro-patterned templates. ${ }^{[49][50]}$ For instance, Zhou et al. ${ }^{[47]}$ reported a twodimensional periodic $\mathrm{VO}_{2}$ structure. The resulting porous thermochromic film exhibited a very high $T_{\text {lum }}$ of $81 \%$ but a moderate $\Delta T_{\text {sol }}$ of $7.9 \%$ due to the large pore size $(200 \mathrm{~nm})$.

In summary, the variety of processes explored to fabricate discontinuous $\mathrm{VO}_{2}$ films highlights the advantages and drawbacks compared to continuous films. Indeed, both the luminous transmittance and the solar transmittance modulation are efficiently improved with addition of porosity. This effect is ascribed to interfacial scattering phenomena that limit direct surface reflection. However, discontinuity in the films also tends to lower $T_{c}$ but widen the hysteresis. It appears that there is still room for a convenient and large-scale method to produce optimized discontinuous $\mathrm{VO}_{2}$ films. Consistently, $\mathrm{VO}_{2}$ nanoparticles have attracted much interest in recent years, because they provide additional optical effects that could reinforce the optical properties provided by the thermochromic characteristics. Besides intrinsic optical properties of bulk $\mathrm{VO}_{2}$, the optical properties of $\mathrm{VO}_{2}$ nanoparticles embedded in a dielectric medium are impacted by scattering and absorption that can both be strongly influenced by the plasmon resonance. The fact that $\mathrm{VO}_{2}$ nanoparticles in their metallic state can undergo a plasmon resonance has been demonstrated both numerically ${ }^{[51][52]}$ and experimentally. ${ }^{[33][54][55]}$ Lopez et al. ${ }^{[54]}$ showed that the MIT of the nanophase precipitates turns on the classical surface plasmon resonance, with specific features that depend on the size and aspect ratio of the $\mathrm{VO}_{2}$ particles. Bai et al. ${ }^{[51]}$ performed numerical calculations of the optical scattering efficiencies of $\mathrm{VO}_{2}$ nanoparticles with three different shapes (sphere, cube, porous aggregate) using Mie theory and Discrete Dipole Approximation (DDA). All three model nanoparticles contained the same volume of $\mathrm{VO}_{2}$, that of a sphere of $200 \mathrm{~nm}$ radius. In all three cases, scattering of the $\mathrm{VO}_{2}$-metallic $(\mathrm{R})$ peaked in the near-infrared due to a broad plasmon resonance at about $1.4 \mu \mathrm{m}$. Granqvist, et al. ${ }^{[16][7]}$ performed a numerical study that focused on a nanocomposite approach considering $\mathrm{VO}_{2}$ nanoparticles embedded in a dielectric matrix (Figure 2d, e). The calculations used a rather low volume fraction of $\mathrm{VO}_{2}$ of $f=0.01$ and a thickness of $5 \mu \mathrm{m}$. The most salient feature is the pronounced absorption band in the near-infrared that is centered at a wavelength of $1.2 \mu \mathrm{m}$. This transmittance 
minimum, which corresponds to an absorption maximum in the infrared is due to localized plasmon resonance of free electrons in $\mathrm{VO}_{2}$ nanoparticles.
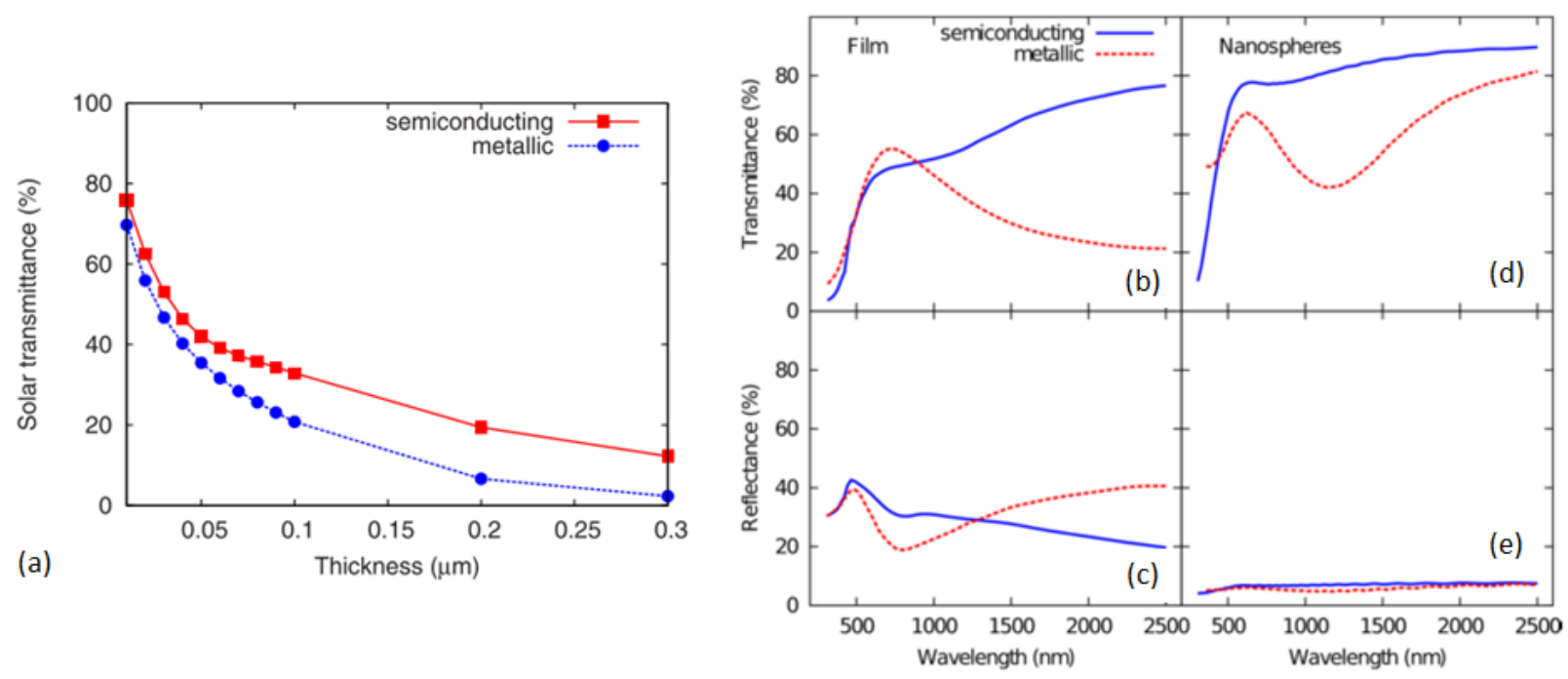

Figure 2. (a) Computed data of solar transmittance as a function of thickness of $\mathrm{VO}_{2}$ films in semiconducting and metallic states, (b, d) Spectral transmittance and (c, e) reflectance for a $50 \mathrm{~nm}$-thick thin film of $\mathrm{VO}_{2}(\mathrm{~b}, \mathrm{c})$ and for a layer comprising a dilute dispersion of $\mathrm{VO}_{2}$ nanospheres, with an equivalent $\mathrm{VO}_{2}$ thickness of $50 \mathrm{~nm}$, in a medium mimicking transparent glass or polymer (d, e). Adapted with permission from ref. ${ }^{[16][7]}$ Copyright 2016 and 2010, MDPI and AIP Publishing.

The calculations demonstrate that embedding $\mathrm{VO}_{2}$ nanoparticles in a dielectric second phase is a reasonable strategy combining a high luminous transmittance and a significantly enhanced solar energy transmittance modulation. This strategy overcomes the drawbacks of thin films such as low transmittance that induce an unfavorable yellow color, which is unpleasant to human eyes and low solar transmittance modulation. In addition, it has been shown numerically that the difference in solar transmittance between the semiconducting and metallic phases is $20 \%$ for dispersions of spheres while the corresponding number for the film is about 7\%. Random distributions of nanoparticles show that the highest transmittance levels are found for the spherical particles, compared to rod-like and platelet-like particles ${ }^{[7]}$. Finally, this numerical study shows that efficient thermochromic polymer- $\mathrm{VO}_{2}$ nanocomposites, quasi-spherical $\mathrm{VO}_{2}(\mathrm{M})$ nanoparticles with uniform sizes seem to be ideal to achieve good visible transmittance and high modulation of infrared light. However, the formation of spherical $\mathrm{VO}_{2}$ particles and the control of the transition characteristics (hysteresis width and $T_{c}$ ) remain a challenge.

\subsection{Effect of elemental doping on transition and optical characteristics}

The physical origin of the Mott transition ${ }^{[2][3][4]}$ is the interplay between the Coulomb repulsion of electrons and their degree of localization (electronic band width). Several studies have focused on strategies to decrease the transition temperature to nearer room temperature. The most common strategy to alter the transition temperature is elemental doping, which involves the intentional incorporation of atoms or ions of suitable elements into the host 
lattice. ${ }^{[56][57]}$ Two main mechanisms are considered to explain the altering of $T_{\mathrm{C}}$ by elemental doping in $\mathrm{VO}_{2}$. If the interatomic distance is large, the electrons remain localized in the energy bands separated by the band gap. If the electron density increases by elemental doping for example, delocalization of the electrons can occur and the material transits to a metallic state. It is also considered that elemental doping modifies the density of defectnucleation sites, which in turn influences the transition propagation and so the transition temperature. Hu et al. ${ }^{[58]}$ studied the band gap widening provided by $\mathrm{Mg}$-dopants into the $\mathrm{VO}_{2}$ lattice. They managed to reach a qualitative agreement between experimental and computational data which opens insights to discover alternative dopants to widen band gaps in thermochromic materials. Tan et al. ${ }^{[59]}$ unveiled the atomic structure evolutions of $\mathrm{W}$ dopant and their role in tailoring the $T_{\mathrm{c}}$ of $\mathrm{VO}_{2}$ transition. They found that the local structure around the $\mathrm{W}$ atom is intrinsically symmetric with a tetragonal-like structure. Using synchrotron radiation X-ray absorption spectroscopy combined with first-principles calculations, they gave the experimental evidence that the symmetric $\mathrm{W}$ core drives the detwisting of the nearby asymmetric monoclinic $\mathrm{VO}_{2}$ lattice to form rutile-like $\mathrm{VO}_{2}$ nuclei, and the propagations of these $\mathrm{W}$-encompassed nuclei through the matrix lower the thermal energy barrier for phase transition. Thus, besides elemental doping, other strategies were explored to alter the transition temperatures based on the modification of the density of defect-nucleation sites. Internal stresses can be introduced by elemental doping ${ }^{[60]}$ but also by film preparation processes. ${ }^{[61]}$ The transition temperature has also been shown to be affected by film strain $^{[62]}$ and it has been demonstrated that strain can be introduced by a careful choice of deposition conditions. ${ }^{[63]}$ Therefore, it is interesting to note that doped $\mathrm{VO}_{2}$ elaborated by different techniques can lead to contradictory conclusions. For instance, the doping by $\mathrm{Al}(+\mathrm{III})$ of $\mathrm{VO}_{2}$ films obtained by pulsed laser leads to a decrease in $\mathrm{T}_{\mathrm{c}}$ $\left(40^{\circ} \mathrm{C}\right),{ }^{[64]}$ whereas the use of sol-gel demonstrates its increase $\left(80^{\circ} \mathrm{C}\right) .{ }^{[56]}$ The effect of internal stresses (more compressive during laser ablation than for sol-gel) could play a role in the transition temperature in addition to the elemental doping.

Wan et al. ${ }^{[65]}$ performed a theoretical study of doping processes and investigated the M-doped monoclinic M1 phase of $\mathrm{VO}_{2}$ with $\mathrm{M}=\mathrm{B}, \mathrm{C}, \mathrm{N}$ at $\mathrm{O}$ site, and $\mathrm{M}=\mathrm{B}, \mathrm{Mg}$, $\mathrm{Al}$ at $\mathrm{V}$ site. This study showed that all these doping elements enabled to decrease $\mathrm{T}_{\mathrm{c}}$ and highlighted that the $\mathrm{C}$-doped $\mathrm{VO}_{2}$ could be the best effective doping element in $\mathrm{M}$-doped $(\mathrm{M}=\mathrm{B}, \mathrm{C}, \mathrm{N}, \mathrm{Al}, \mathrm{Mg}) \mathrm{VO}_{2}$. From an experimental point of view, the most effective route for appreciable reduction of $T_{\mathrm{C}}$ is doping some donor impurity atoms, which could be easily realized by chemical substitution methods. ${ }^{[6]}$ Considering the $\mathrm{V}$ site for doping, the doping of $\mathrm{VO}_{2}$ films with cations of $(+\mathrm{V})$ and $(+\mathrm{VI})$ valences leads to a reduction

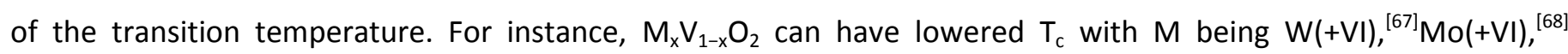
$\mathrm{Ta}(+\mathrm{V}),{ }^{[69]} \mathrm{Nb}(+\mathrm{V}),{ }^{[70]} \mathrm{Sb}(+\mathrm{V}) \cdot{ }^{[71][72]}$ Note that the elemental doping can also impact the optical properties of the films. Hanlon et al. ${ }^{[68]}$ reported the doping of $\mathrm{VO}_{2}$ films with $\mathrm{Mo}(+\mathrm{VI})$ and at a doping level of 7 atomic percentage (at\%) the transition temperature was measured at $24^{\circ} \mathrm{C}$. They noted that the optical reflectance in the semiconductor state increased slightly with additional dopant, while the reflectance in the metallic state remained constant. It was found that the most effective metal ion dopant was tungsten $\mathrm{W}(+\mathrm{VI})$ which lowers the transition temperature by $25^{\circ} \mathrm{C}$ for every atomic percent of incorporated dopant. ${ }^{[73]}$ Zhang et al. ${ }^{[74]}$ prepared $\mathrm{W}$-doped $\mathrm{VO}_{2}(\mathrm{M})$ nanobelts by hydrothermal treating $\mathrm{VO}_{2}(\mathrm{~B})$ nanobelts in the presence of tungstic acid. The $\mathrm{T}_{\mathrm{c}}$ of $\mathrm{W}$-doped $\mathrm{VO}_{2}(\mathrm{M})$ nanobelts was reduced to $50^{\circ} \mathrm{C}$ in the heating cycle and to $42^{\circ} \mathrm{C}$ in the cooling cycle. The transmittance modulation was also 
increased compared to undoped $\mathrm{VO}_{2}$. Shi et al. ${ }^{[75]}$ reported a successful synthesis of W-doped $\mathrm{VO}_{2}$ particles by hydrolysis of vanadyl sulfate mingled with a small amount of sodium tungstate dihydrate and subsequent calcination. Chen et al. ${ }^{[76]}$ prepared thermochromic W-doped $\mathrm{VO}_{2}$ nanopowders by solution-based method using ammonium tungstate. It was shown that tungsten dopant concentration has almost no effect on the morphology of the nanoparticles and the granular particles were about $20-60 \mathrm{~nm}$. The reduction of transition temperature was estimated to be about $17^{\circ} \mathrm{C}$ per 1 at $\%$ of $\mathrm{W}$ doping with the tungsten extents of $\leq 1$ at\%, only about $9.5 \mathrm{~K}$ per 1 at\% with the tungsten extents of $>1$ at\%. ${ }^{[73]}$ With 3 at\% W-doped $\mathrm{VO}_{2}$, the phase transition temperature could be reduced to $35^{\circ} \mathrm{C}$. Binions et al. ${ }^{[77]}$ and Piccirillo et al. ${ }^{[78]}$ indicated that tungsten doping could significantly decrease hysteresis loop widths to about $10^{\circ} \mathrm{C}$.

Mlyuka et al. compared $\mathrm{Mg}$ and $\mathrm{W}$ doping in thermochromic films of $\mathrm{M}_{\mathrm{x}} \mathrm{V}_{1-\mathrm{x}} \mathrm{O}_{2}(\mathrm{M}=\mathrm{Mg}$ or $\mathrm{W})$ made by reactive $\mathrm{DC}$ magnetron sputtering onto heated glass ${ }^{[79]}$. The transition temperature decreased by $\sim 3^{\circ} \mathrm{C} / \mathrm{at} \% \mathrm{Mg}$, while the optical transmittance increased concomitantly. Specifically, both the luminous and the solar transmittance were enhanced by $\sim 10 \%$ when the $\mathrm{Mg}$ content was $\sim 7$ at\%. They showed that a similar decrease of $\mathrm{T}_{\mathrm{c}}$ needs a higher $\mathrm{Mg}$ content than W content (Figure 3).
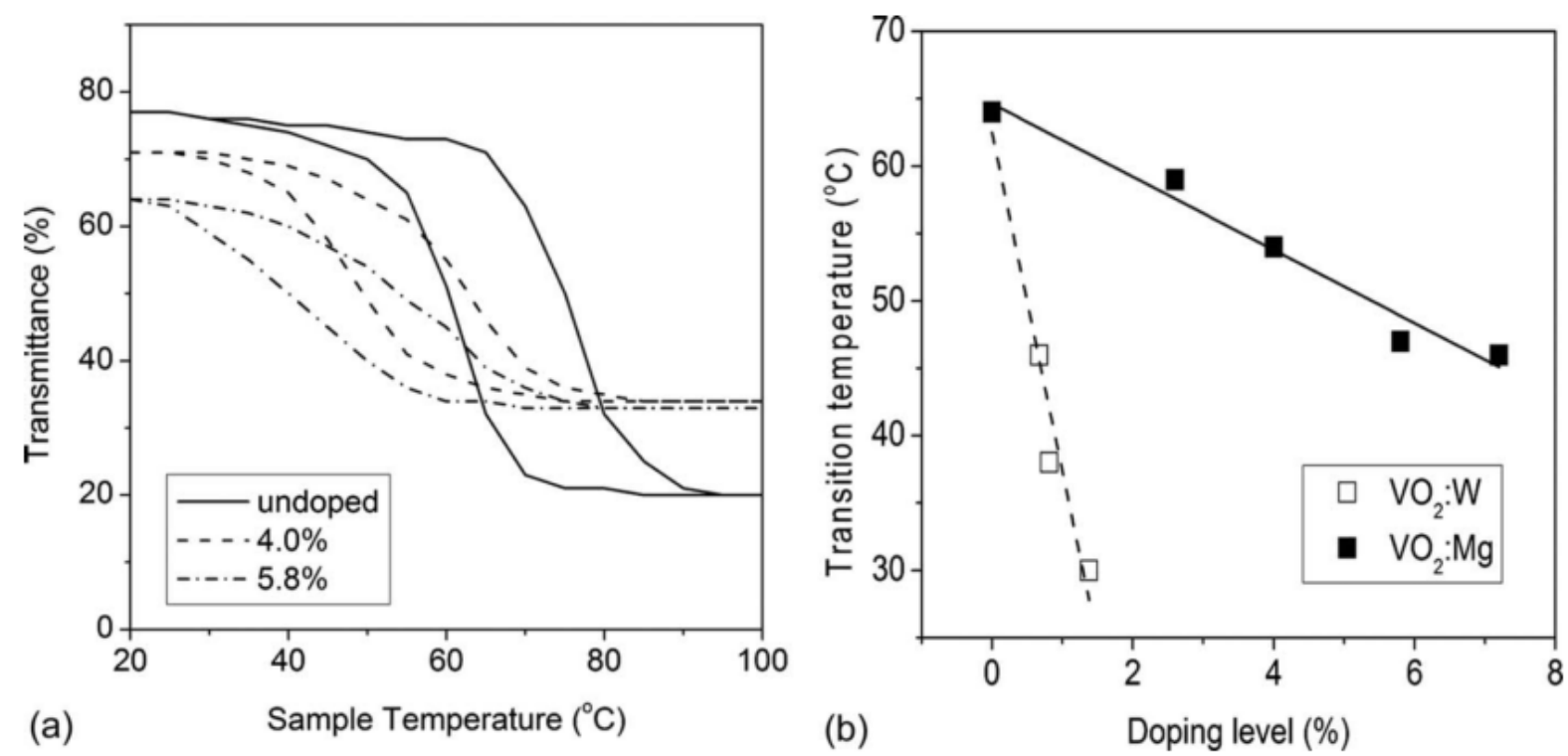

Figure 3. (a) Transmittance at $\lambda=2300 \mathrm{~nm}$ vs. temperature and (b) $\mathrm{T}_{\mathrm{c}}$ vs. doping level for $50-\mathrm{nm}$-thick $\mathrm{VO}_{2}$, $\mathrm{Mg}_{\mathrm{x}} \mathrm{V}_{1-\mathrm{x}} \mathrm{O}_{2}$ films and $\mathrm{W}_{\mathrm{x}} \mathrm{V}_{1-\mathrm{x}} \mathrm{O}_{2}$ films, the lines are solely to guide the eyes. Adapted with permission from ref. ${ }^{[79]}$ Copyright 2009, AIP Publishing.

Zhou et al. ${ }^{[80]}$ reported the successful preparation of $\mathrm{Mg}$-doped $\mathrm{VO}_{2}$ nanoparticles via hydrothermal synthesis. The transition temperature $\left(\mathrm{T}_{\mathrm{c}}\right)$ decreased by approximately $2^{\circ} \mathrm{C}$ per at\% $\mathrm{Mg}$. The $\mathrm{T}_{\mathrm{c}}$ decreased to $54^{\circ} \mathrm{C}$ with 7.0 at\% dopant. Li et al. ${ }^{[27]}$ reported undoped and $\mathrm{Mg}$-doped thermochromic $\mathrm{VO}_{2}$ films with atom ratios up to 21 at\% deposited by reactive $\mathrm{DC}$ magnetron sputtering onto heated glass and carbon substrates. It was found that $\mathrm{VO}_{2}$ films with less than 6 at\% $\mathrm{Mg}$ dopant and judiciously chosen thicknesses, can have much improved luminous transmittance and solar energy modulation than pure $\mathrm{VO}_{2}$ films. The addition of single-layer anti-reflection coatings 
on the top of the $\mathrm{VO}_{2}$-based films was shown to further enhance the performance of Mg-doped films. Moreover, modeling of nanoparticle composites confirmed that nanoparticle composites are superior to films but suggested that undoped $\mathrm{VO}_{2}$ nanoparticles are more favorable than Mg-doped ones.

Doping by cations of small sizes and valences less than or equal to that of $\mathrm{V}$ leads to higher transition temperatures at $68^{\circ} \mathrm{C}$. For instance, an increase of $\mathrm{T}_{\mathrm{c}}$ is observed with $\mathrm{M}$ being $\mathrm{Ge}(+\mathrm{IV}),{ }^{[70]} \mathrm{Al}(+\mathrm{III}),{ }^{[81]} \mathrm{Sn}(+\mathrm{IV}),{ }^{[82]} \mathrm{Ti}(+\mathrm{IV}),{ }^{[83]}$ or $\mathrm{Sb}(+\mathrm{III}) .{ }^{[71]}$ Various efforts have been conducted to study the effects of Ti doping on $\mathrm{VO}_{2}{ }^{[56][84][85]}$ It was found that the transition temperature increased as the Ti contents increased. Comparative studies also suggest that Ti doping significantly decreased the hysteresis loop width. Du et al. ${ }^{[86]}$ prepared Ti-doped $\mathrm{VO}_{2}$ films with different Ti/V ratios by polymer assisted deposition. The transition temperature increased and the hysteresis loop width was narrowed from 38.2 to $3.5^{\circ} \mathrm{C}$. This was qualitatively analyzed using nucleation theory proposed by Lopez et al. ${ }^{[64]}$ that suggested that the driving force for the transition of undoped $\mathrm{VO}_{2}$ thin films was the extrinsic defects introduced during the film preparation process, contrary to Binions' et al. ${ }^{[63]}$ approach that relates the hysteresis loop width to crystallographic orientations. Indeed, Du et al. ${ }^{[86]}$ prepared Ti-doped $\mathrm{VO}_{2}$ films that had a large size distribution without any changes in crystallographic orientations. Ti doping could probably enhance the density of defectnucleation site. Undoped films had small particle sizes $(130 \mathrm{~nm})$. Hence the small volume resulted in a lack of nucleation sites in each particle for undoped $\mathrm{VO}_{2}$ films, inducing a large hysteresis loop width. For doped films, the particles were even smaller. According to Lopez's nucleation theory, the hysteresis loop width should be widened. However, a comparatively large doping concentrations $(x>2 \%)$ would greatly increase the density of defect-induced nucleation sites, which would play a leading role compared to particle size. As a result, in spite of the diminishing particle sizes, a high density of defect-induced nucleation sites would significantly reduce the hysteresis loop width.

\subsection{Effect of elemental doping on nanoparticle phase and morphology}

The monoclinic $\mathrm{VO}_{2}(\mathrm{M})$ has a preferential orientation along the [110] direction and is prone to grow to onedimensional nanostructures, such as nanowires, nanorods and nanobelts. ${ }^{\text {[87][88][89][90][91] }}$ Doping has also been studied as a way to control sphericity of nanoparticles. ${ }^{[80][90][71]}$ Doping has the ability to control the size and morphology of nanocrystals using various mechanisms, such as competitive nucleation and dipole polarization of the dopant ion. Zhou et al. ${ }^{[80]}$ reported the successful preparation of $\mathrm{Mg}$-doped $\mathrm{VO}_{2}$ nanoparticles via hydrothermal synthesis. The morphology changed from nanorods for undoped $\mathrm{VO}_{2}$ to irregular nanoparticles for the $\mathrm{Mg}$-doped $\mathrm{VO}_{2}$, revealing the Mg-doping's strong impact on the morphological evolution of the nanoparticles. Baik et al. ${ }^{[90]}$ reported that the observed transition temperatures, which ranged between 62 and $70^{\circ} \mathrm{C}$ for the nanowires measured, trended downward with decreasing nanowire width. Gao et al. ${ }^{[71]}$ reported the preparation of crystalline Sb-doped $\mathrm{VO}_{2}$ nanoparticles with tunable sizes via a one-pot hydrothermal method. This doping strategy enabled the simultaneous control of the size, morphology and phase of the outcome material. Without $\mathrm{Sb}(+\mathrm{III})$ doping, $\mathrm{VO}_{2}(\mathrm{~A})$ nanorods grew with a preferential orientation along the [001] direction. For the sample $\mathrm{x}=0.91$ at $\%$ of $\mathrm{Sb}(+\mathrm{III}), \mathrm{VO}_{2}(\mathrm{~A})$ was still a 
major phase with $\mathrm{VO}_{2}(\mathrm{M})$ being a minor phase. As $\mathrm{x}$ increased to 2.68 at\%, $\mathrm{VO}_{2}(\mathrm{M})$ became the main phase. Pure $\mathrm{VO}_{2}(\mathrm{M})$ was obtained for $\mathrm{x}=4.69$ at\%, 13.60 at\% and 33.10 at\%. TEM observations provided evidence that the size of the nanocrystals was gradually reduced and that the size distribution tended to be more homogeneous with increasing $\mathrm{Sb}(+\mathrm{III})$ contents. They suggested that $\mathrm{Sb}(+\mathrm{III})$ doping promoted the formation of $\mathrm{VO}_{2}(\mathrm{M})$ nanoparticles from the rod-like $\mathrm{VO}_{2}$ nuclei at about $240-250^{\circ} \mathrm{C}$. As the temperature was increased to $260^{\circ} \mathrm{C}$ and/or the reaction time was prolonged, the $\mathrm{VO}_{2}(\mathrm{~A})$ rods transformed into $\mathrm{VO}_{2}(\mathrm{M})$ nanoparticles most likely due to dissolutionrecrystallization. Gao et al. ${ }^{[71]}$ proposed the following mechanism. With $\mathrm{Sb}(+\mathrm{III})$ doping, the substitution of two ions of $\mathrm{Sb}(+\mathrm{III})$ for $\mathrm{V}(+\mathrm{IV})$ in $\mathrm{VO}_{2}$ requires an extra oxygen vacancy for charge compensation, and higher surface energy of nanoparticles favors oxygen vacancies to aggregate on their surfaces, which may induce transient electric dipoles with their positive poles outward. These transient electric dipoles hinder the diffusion of $\mathrm{VO}^{2+}$ as well as other charged nuclei to the grain surface, thus retarding the growth of $\mathrm{VO}_{2}$ particles. The above discussion suggests that an extra repulsion force induced by dopant-resultant defects plays a significant role in the modification of particle sizes. This mechanism was confirmed by using other dopants in $\mathrm{VO}_{2}$ systems. Using a high-valence ion dopant, such as $\mathrm{Sb}(+\mathrm{V})$, to substitute for $\mathrm{V}(+\mathrm{IV})$ sites in the $\mathrm{VO}_{2}(\mathrm{M})$ lattice may induce negatively charged defects for the charge balance. The concentration of these defects on the grain surfaces causes an electric dipole that can accelerate the diffusion of $\mathrm{VO}^{2+}$ ions in solution to promote the grain growth. In addition, the impacts of $\mathrm{Bi}(+\mathrm{III})$ and $\mathrm{Ti}(+\mathrm{III})$ doping on the growth of $\mathrm{VO}_{2}$ nanocrystals under the analogous solution conditions were studied to directly validate the proposed mechanism. $\mathrm{Bi}(+\mathrm{III})$ and $\mathrm{Ti}(+\mathrm{III})$ ions possess the same valence as $\mathrm{Sb}(+\mathrm{III})$ and are speculated to induce similar effects in $\mathrm{VO}_{2}$ crystal growth. As expected, both dopants benefit the formation of hexahedral $\mathrm{VO}_{2}(\mathrm{M})$ nanocrystals with significantly smaller sizes. These results confirmed that doping is able to induce the transformation of $\mathrm{VO}_{2}$ polymorphs.

\subsection{Effect of "interfacial doping" on transition and optical characteristics}

In a larger extent than elemental doping, the integration of a secondary domain of inorganic components into $\mathrm{VO}_{2}$ films or onto $\mathrm{VO}_{2}$ particles has been proven effective in modulating the optical properties of the films. Core-shell particles with enhanced thermochromic properties include $\mathrm{VO}_{2} @ \mathrm{SiO}_{2},{ }^{[92][93][94][95][96][97][48]} \mathrm{VO}_{2} @ \mathrm{ZnO},{ }^{[98]} \mathrm{VO}_{2} @ \mathrm{Al}-\mathrm{O},{ }^{[99]}$ or $\mathrm{VO}_{2} @ \mathrm{TiO}_{2}{ }^{[100]}$ as well as inverted core-shell structures such as $\mathrm{SiO}_{2} @ \mathrm{VO}_{2} \cdot{ }^{[101][102]} \mathrm{Li}$ et al. ${ }^{[100]}$ reported the synthesis of $\mathrm{VO}_{2} / \mathrm{TiO}_{2}$ nanorods highlighting an approach to control the optical and transition properties by modifying the surface/interface state and microstructure of $\mathrm{VO}_{2}$ particles with core/shell nanotechnology. $\mathrm{TiO}_{2}$ coating can not only enhance the chemical stability of $\mathrm{VO}_{2}$ but also exhibits the potential to control the transition temperature and hysteresis by designed "interfacial doping" with Ti through annealing. Such "interfacial doping" has the advantage of avoiding the introduction of a large amount of defects as compared with bulk doping. Bulk defect deteriorates the modulation ability of $\mathrm{VO}_{2}$ to a large degree. Other cationic or anionic ions for example, Mo, $\mathrm{W}, \mathrm{Cr}, \mathrm{F}$ etc, are expected to be able to adjust the transition property by bulk doping and may also be designed to achieve "interfacial doping" through core/shell nanotechnology, thus to modify the phase transition of $\mathrm{VO}_{2}$ without bringing in excessive defects and retain a comparably sound switching efficiency as in pure $\mathrm{VO}_{2}$. Qureshi et al. ${ }^{[103]}$ reported composite 
$\mathrm{TiO}_{2}-\mathrm{VO}_{2}$ films showing a significant reduction in the thermochromic transition temperature $\left(54^{\circ} \mathrm{C}\right)$. It was shown that composite films of this kind did not interfere with the functionality of each individual component and that solid solutions were not formed. The films exhibited both photocatalytic properties from $\mathrm{TiO}_{2}$ and thermochromic properties from $\mathrm{VO}_{2}$. Du et al. ${ }^{[104]}$ reported the preparation of $\mathrm{VO}_{2}-\mathrm{ZrV}_{2} \mathrm{O}_{7}$ composite films on silica glass substrates by polymer-assisted deposition. The addition of $\mathrm{ZrOCl}_{2}$ in the precursor solution greatly influenced the film microstructure and transition characteristics. The composite films with similar thickness of about $95 \mathrm{~nm}$ showed decreased particle sizes and significantly enhanced luminous transmittances with increasing $\mathrm{Zr} / \mathrm{V}$ ratios, from $32.3 \%$ to $53.4 \%$ at $Z r / V=0$ and 0.12 respectively. The transition temperature $T_{c}$ was about $60^{\circ} \mathrm{C}$ for all samples, which is $8^{\circ} \mathrm{C}$ lower than that of the single crystal. Miyazaki et al. ${ }^{[102]}$ reported $\mathrm{W}$-doped $\mathrm{VO}_{2}$ coated $\mathrm{SiO}_{2}$ nanoparticles with monodispersion fabricated by the chemical solution deposition method. The resulting particle size was about $40 \mathrm{~nm}$. The transition temperature of non-doped $\mathrm{VO}_{2}$ coated $\mathrm{SiO}_{2}$ particles was $68^{\circ} \mathrm{C}$, and the transition temperature of 1.1 atomic $\% \mathrm{~W}$-doped $\mathrm{VO}_{2}$ coated $\mathrm{SiO}_{2}$ particles was $52^{\circ} \mathrm{C}$. For instance, noble metals ${ }^{[105][106]}$ such as $\mathrm{Au}$ and $\mathrm{Ag}$ can be combined with $\mathrm{VO}_{2}$ films resulting in high absorption but low reflectance. Kana Kana et al. ${ }^{[107]}$ reported on the preparation of highly nanocrystalline $\mathrm{Au}-\mathrm{VO}_{2}$ composite thin films by RF-inverted cylindrical magnetron sputtering. The plasmonic properties and thermochromic behavior of the synthesized nanocomposite films of $A u-\mathrm{VO}_{2}$ by ICMS are comparable to those seen previously with $\mathrm{Au}-\mathrm{VO}_{2}$ thin films grown by laser ablation ${ }^{[53]}$ or chemical vapor deposition. ${ }^{[108]}$ Kang et al. ${ }^{[109]}$ reported a study that involves the optical properties of $\mathrm{Pt} / \mathrm{VO}_{2}$ composite films, with a Pt top layer and a $\mathrm{VO}_{2}$ bottom layer. It was shown that the deposition of Pt layers substantially enhanced the infrared reflection of the film while retaining its thermochromic properties. At the same time, the transition temperatures of the heating semi-cycles were reduced by $9.3^{\circ} \mathrm{C}$ after a $9 \mathrm{~nm}$ Pt coating. The visible transmittance, which was diminished by the Pt layers, was effectively boosted by the addition of $\mathrm{SiO}_{2}$ antireflection coatings. These

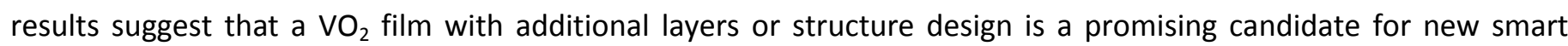
windows. Li et al. ${ }^{[110]}$ reported the preparation of nanofibers of $\mathrm{VO}_{2}(\mathrm{~A})$ with $100 \mathrm{~nm}$ diameter and 10-20 $\mu \mathrm{m}$ length via a one-step hydrothermal method. The obtained $\mathrm{VO}_{2}(\mathrm{~A})$ was coated by $\mathrm{SiO}_{2}$ to form $\mathrm{VO}_{2}(\mathrm{~A}) @ \mathrm{SiO}_{2}$ core-shell nanocomposites, which were then transformed into $\mathrm{VO}_{2}(\mathrm{M}) @ \mathrm{SiO}_{2}$ by annealing under nitrogen atmosphere. The resulted composites maintained the original fibrous morphology, particularly with a large amount of pores emerging inside the fiber due to the volume shrinkage during the phase transition, which may improve its thermal insulation ability in real applications. The $\mathrm{VO}_{2}(\mathrm{M}) @ \mathrm{SiO}_{2}$ nanofibers were arranged into a self-supporting film by filtration, which showed excellent thermochromic properties. The transmittance modulation at $2500 \mathrm{~nm}$ was more than $30 \%$, indicating an excellent thermochromic property of the fibers. Furthermore, the film showed a relatively high luminous transmittance over $50 \%$ probably due to the fibrous structure with small fiber radius and inter firad spaces for light transmission. Interestingly, the film did not show the intrinsic yellow color of $\mathrm{VO}_{2}(M)$, rather being grayish because of a structure effect, which will be beneficial for visual perception.

These results enrich the fact that doped-nanoparticles or composite-nanoparticles embedded in a polymer matrix can combine improved optical properties (narrow hysteresis, high luminous transmittance and high solar 
modulation), convenient process deposition according to polymer coatings technologies and low transition temperature.

\section{Synthesis techniques for preparing $\mathrm{VO}_{2}$ (nano) particles}

As previously described, the final properties of $\mathrm{VO}_{2}(\mathrm{M})$ are strongly related to the sample quality, stoichiometry, purity, crystallinity and morphology. Consequently, the development of various synthetic strategies for the synthesis of $\mathrm{VO}_{2}(\mathrm{M})$ with improved thermochromic properties has attracted a great attention these last two decades. It is worth noticing that the high temperature used during the reported synthesis leads to the direct formation of $\mathrm{VO}_{2}(\mathrm{R})$ which is spontaneously converted through the fully reversible transition into $\mathrm{VO}_{2}(\mathrm{M})$ at room temperature. $\mathrm{VO}_{2}(\mathrm{M})$ is thus mainly formed from the rutile $\mathrm{VO}_{2}$ thanks to the fully reversible $\mathrm{MIT}$ of $\mathrm{VO}_{2}(\mathrm{R})$. As outlined above, both physical and chemical deposition methods have been reported to prepare $\mathrm{VO}_{2}$-based coatings including sputtering, pulsed laser deposition, chemical vapor deposition and sol-gel processes. These deposition methods leading to $\mathrm{VO}_{2}$ film preparation have been extensively reviewed ${ }^{[111][31][112][113][30]}$ and will not be described here. Keeping in mind that the main idea of this paper is to focus on $\mathrm{VO}_{2}$ nanocomposites for thermochromic applications, we will mainly review in this section the chemical methods allowing the elaboration of $\mathrm{VO}_{2}(\mathrm{M}) / \mathrm{VO}_{2}(\mathrm{R})$ particles and/or nanoparticles, suitable to be further dispersed within a polymer matrix without significant aggregation. Interestingly, as previously underlined, decreasing the $\mathrm{VO}_{2}$ particle size can not only facilitate material processing but can also affect in a positive way the phase transition temperature and hysteresis properties. ${ }^{[114][60]}$ Controlling the thermochromic properties of $\mathrm{VO}_{2}$ nanocrystals by playing on the synthetic conditions is clearly a challenging task.

One possibility to decrease the $\mathrm{VO}_{2}(\mathrm{M})$ particle size and produce particles easy to disperse into a matrix involved mechanical ball-milling. ${ }^{[155][116][75]}$ Liu et al. ${ }^{[115]}$ described the preparation of $\mathrm{VO}_{2}(\mathrm{M})$ nanoparticles with an average size of $20 \mathrm{~nm}$ simply by milling a micro-sized commercial $\mathrm{VO}_{2}(\mathrm{M})$ dispersed in an organic solvent containing a dispersing agent for $4 \mathrm{~h}$. In parallel, the possibility of obtaining nanoparticles directly during the $\mathrm{VO}_{2}(\mathrm{M})$ structure formation has also been deeply investigated. Two main synthetic approaches can be distinguished in the literature involving either direct synthesis or multistep processing in which the last step is usually based on annealing of vanadium-based material precursors. Obviously, many experimental parameters including the reaction time, the temperature, the annealing conditions the $\mathrm{pH}$, the filling volumetric percentage, and the nature or morphology of the precursors play a key role on the structure and purity of the vanadium oxide formed as well as on its morphology and optical properties. These different factors are reviewed in the following paragraphs.

\subsection{Direct synthesis of $\mathrm{VO}_{2}(\mathrm{M}) / \mathrm{VO}_{2}(\mathrm{R})$ in solution}

Direct synthetic protocols in solution are particularly attractive being simpler, with lower costs and allowing direct functionalization compared to methods involving solid-state transformations and annealing processes. However even if the rutile structure of $\mathrm{VO}_{2}$ is the most stable phase from the thermodynamic point of view, only a few of onestep strategies in solution have been reported to successfully prepare $\mathrm{VO}_{2}(\mathrm{R})$ nanomaterials. Clearly, stabilization of 
the $\mathrm{VO}_{2}(\mathrm{M})$ phase directly from molecular precursors or solid phases in solution is challenging. This can be explained by the high valence state of vanadium $\left(\mathrm{V}^{4+}, \mathrm{V}^{5+}\right)$ and its tendency to form condensed polyvanadates rather than detached $\mathrm{VO}_{6}$ octahedra critical for rutile structure formation. ${ }^{[117]}$ However, it is still possible to directly produce pure nanostructured $\mathrm{VO}_{2}(\mathrm{M})$ in a cost effective and scalable way thanks to a fine tuning of the synthesis parameters and the nature of the precursors.

Table 1 sums up some of the direct solution protocols described in the literature. Systematically, a careful control of the synthetic parameters including the nature of the precursors, the heating method, the temperature, the reaction time, the type of reductant, the $\mathrm{pH}$ and the presence of further additives is required to obtain $\mathrm{VO}_{2}(\mathrm{M})$ directly in solution. As described previously, the addition of doping element can induce distortion into the structure in favor of the stabilization of the rutile phase playing then a key role in the polymorph transformation facilitating the one-step preparation of $\mathrm{VO} 2(\mathrm{M})$ by solution based approach. Numerous studies are still under progress to define an easy and reproducible way to form the thermochromic $\mathrm{VO}_{2}(\mathrm{M})$ phase from precursors by solution processing.

The hydrothermal method has been efficiently applied for the direct formation of $\mathrm{VO}_{2}(\mathrm{M})$ even if most of hydrothermal syntheses involving vanadium materials yield particles of metastable $\mathrm{VO}_{2}(\mathrm{~B})$ or other vanadium oxides phases rather than $\mathrm{VO}_{2}(\mathrm{M}) .^{[118][29]}$ Vanadium sources such as $\mathrm{V}_{2} \mathrm{O}_{5}, \mathrm{~V}_{2} \mathrm{O}_{4}, \mathrm{VOSO}_{4}$ and $\mathrm{NH}_{4} \mathrm{VO}_{3}$ have been used as precursors.

Starting from commercial $\mathrm{V}_{2} \mathrm{O}_{4}, \mathrm{VO}_{2}(\mathrm{M})$ nanowires were synthesized by hydrothermal treatment in the presence of aliphatic alcohols such as methanol, 2-propanol and 1,3-butanediol through a hydration/cleavage/exfoliation of the bulk precursor. The phase transition temperature could be decreased down to $32^{\circ} \mathrm{C}$ for the shorter nanowires obtained by the addition of 1,3-butanediol after 7 days at $210^{\circ} \mathrm{C}$ evidencing the interest of controlling $\mathrm{VO}_{2}(\mathrm{M})$ particle shape and size. ${ }^{[119]} \mathrm{VO}_{2}(\mathrm{M})$ nanorods were also prepared using $\mathrm{V}(\mathrm{OH})_{2} \mathrm{NH}_{2}$ as $\mathrm{V}^{3+}$ precursor. Such low valence appeared suitable compared to high valence states $\left(\mathrm{V}^{4+} \mathrm{V}^{5+}\right)$ to promote the formation of $\mathrm{VO}_{2}(\mathrm{M})$ at quite low temperatures $\left(200^{\circ} \mathrm{C}\right)$ in dilute $\mathrm{HNO}_{3}$ solution providing suitable acidic conditions in favor of both detached $\mathrm{VO}_{6}$ formation and weak oxidation conditions. ${ }^{[120]}$

$\mathrm{V}_{2} \mathrm{O}_{5}$ was also involved in $\mathrm{VO}_{2}(\mathrm{M})$ one-step solution synthesis by hydrothermal reaction. In general, $\mathrm{V}_{2} \mathrm{O}_{5}$ is reduced in a first step in the presence of oxalic acid or hydrazine, leading to a change of the vanadium oxidation state from $\mathrm{V}^{5+}$ to $\mathrm{V}^{4+}$. Son et al. ${ }^{[46]}$ thoroughly studied the influence of precipitation conditions such as $\mathrm{pH}$ and reactant concentration on the direct hydrothermal synthesis of $\mathrm{VO}_{2}(\mathrm{M})$ starting from $\mathrm{V}_{2} \mathrm{O}_{5}$ as vanadium precursor and $\mathrm{N}_{2} \mathrm{H}_{4}$ as reducing agent. Interestingly, varying the reaction conditions controlled the size, the shape and the purity of the resulting $\mathrm{VO}_{2}$ particles. For instance an increase of $\mathrm{pH}$ tuned the morphology from asterisk-shaped microcrystals to nanocrystals (Figure 4 ) as did an increase of temperature. ${ }^{[4]}$ 

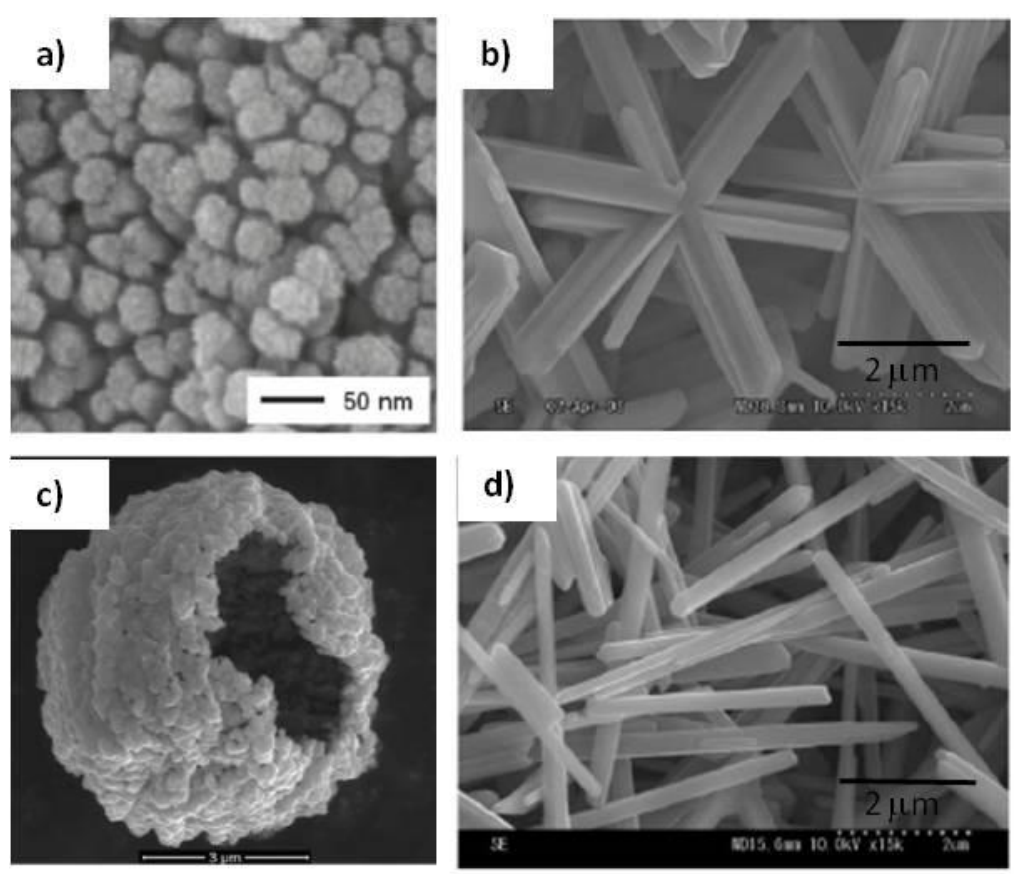

Figure 4. SEM images of various $\mathrm{VO}_{2}(M)$ morphologies prepared by hydrothermal synthesis starting from $\mathrm{V}_{2} \mathrm{O}_{5}$. Adapted with permission from a) ref., ${ }^{[46]}$ b, d) ref. ${ }^{[121]}$ and d) ref. ${ }^{[122]}$ Copyright 2010, 2014, American Chemical society and Elsevier.

Using a similar synthetic approach that used $\mathrm{V}_{2} \mathrm{O}_{5}$ and $\mathrm{N}_{2} \mathrm{H}_{4}$ as precursors, a clear solution of $\mathrm{VO}^{2+}$ was prepared in acidic solution, and further submitted to an hydrothermal treatment. ${ }^{[19]}$ Such a treatment induced the decomposition of the molecular precursors. As illustrated in Figure 5, X-Ray diffraction (XRD) patterns evidenced crystal structure transformation with the formation of $\mathrm{VO}_{2}(\mathrm{M})$ nanoparticles above $240^{\circ} \mathrm{C}$ with particle sizes ranging from 25 to $45 \mathrm{~nm}$ depending on the hydrothermal temperature applied. ${ }^{[26]}$

Interestingly in the presence of $\mathrm{H}_{2} \mathrm{O}_{2}, \mathrm{~V}_{2} \mathrm{O}_{5}$ is able to form a gel, ${ }^{[123]}$ which improved $\mathrm{V}_{2} \mathrm{O}_{5}$ dissolution and its subsequent full reduction. ${ }^{[124]}$ Vanadium gels were reported as suitable vanadium precursors to react with $\mathrm{N}_{2} \mathrm{H}_{4}$ acting as a strong reductant in basic conditions and producing pure single phase $\mathrm{VO}_{2}(\mathrm{M})$ nanoparticles. In such approach the control of the $\mathrm{V}_{2} \mathrm{O}_{5} / \mathrm{N}_{2} \mathrm{H}_{4}$ molar ratio appears essential to prepare $\mathrm{VO}_{2}(\mathrm{M})$ nanoparticles. ${ }^{[125]}$
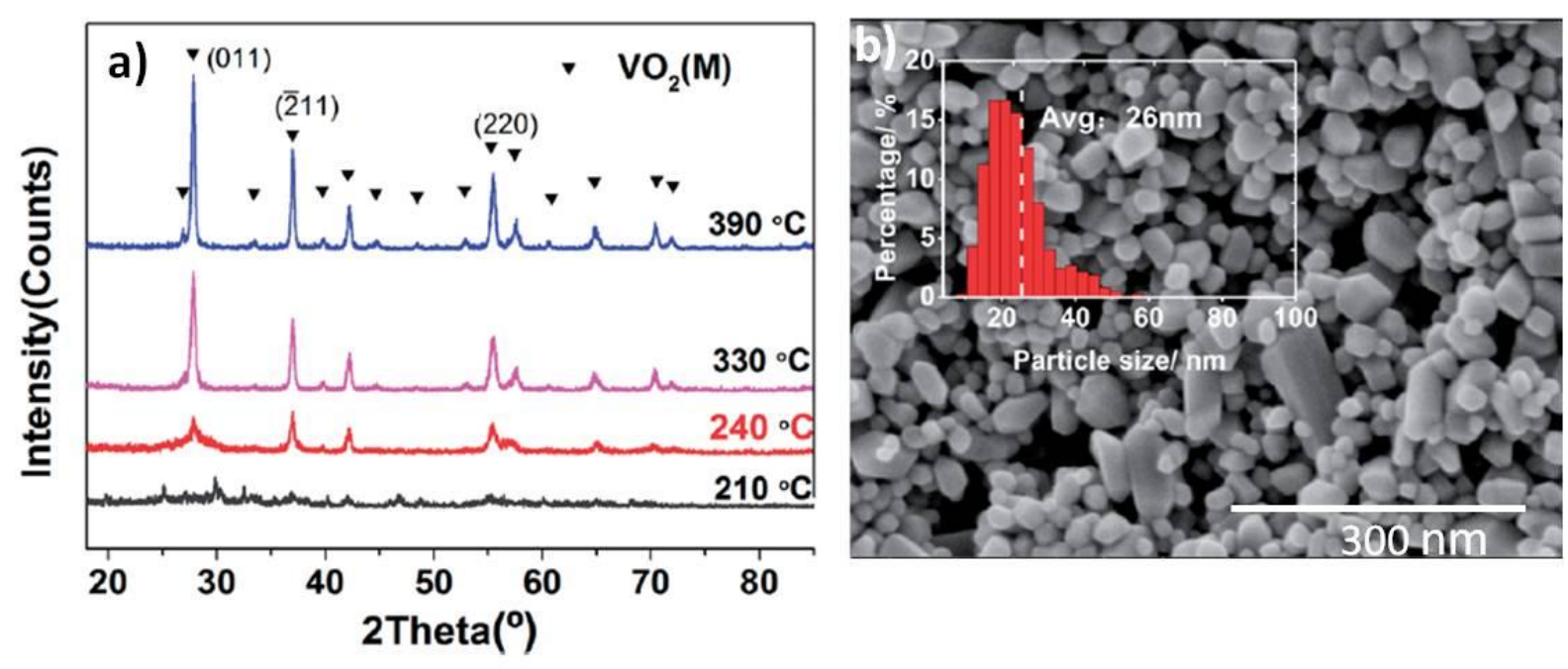
Figure 5. a) XRD patterns of the particles prepared at different temperature from $\mathrm{V}_{2} \mathrm{O}_{5}, \mathrm{~N}_{2} \mathrm{H}_{4}$ and $\mathrm{HCl}$ and b) SEM images of VO2(M) nanoparticles prepared by hydrothermal synthesis at $330^{\circ} \mathrm{C}$. Adapted with permission from ref. ${ }^{[26]}$ Copyright 2014 , The Royal Society of Chemistry.

Oxalic acid was also reported to be an efficient reducing agent for the synthesis of $\mathrm{VO}_{2}(\mathrm{M})$ starting from $\mathrm{V}_{2} \mathrm{O}_{5}$ through the formation of $\mathrm{VOC}_{2} \mathrm{O}_{4}$ as an intermediate phase. ${ }^{[121][122][126][127][128][125][129]}$ Again, VO${ }^{2}$ (M) formation appeared to be very sensitive to the synthesis parameters. Ji et al. ${ }^{[121]}$ reported that for low hydrothermal treatment temperatures, the $\mathrm{VO}_{2}(\mathrm{~B})$ polymorph was preferentially formed, while increasing the temperature to $260^{\circ} \mathrm{C}$ induced a phase transition from $\mathrm{VO}_{2}(\mathrm{~B})$ to $\mathrm{VO}_{2}(\mathrm{R})$. Longer reaction times had a similar effect as increasing the temperature. Such phase transition from $\mathrm{VO}_{2}(\mathrm{~B})$ to $\mathrm{VO}_{2}(\mathrm{R})$ nanorods under hydrothermal treatment at $260^{\circ} \mathrm{C}$ was further explored. ${ }^{[126]}$ Figure 6 shows the XRD patterns of $\mathrm{VO}_{2}$ samples prepared for increasing reaction times from $4 \mathrm{~h}$ to $20 \mathrm{~h}$, revealing the progressive transformation of $\mathrm{VO}_{2}(\mathrm{~B})$ to $\mathrm{VO}_{2}(\mathrm{R})$ with increasing the hydrothermal reaction time. This evidenced a mechanism based on nanobumps nucleation and growth on the surface of $\mathrm{VO}_{2}(\mathrm{~B})$ until complete conversion to $\mathrm{VO}_{2}(\mathrm{M})$ as the reaction time increases. ${ }^{[126]}$

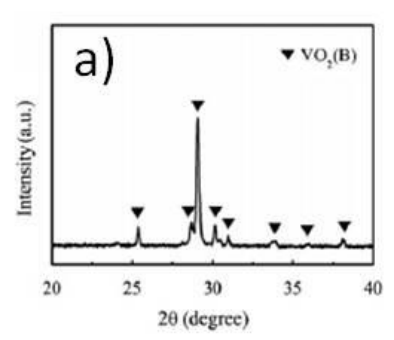

e)
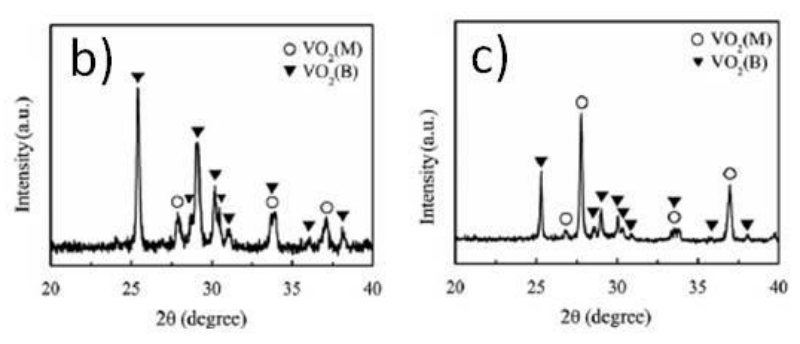

$\mathrm{VO}_{2}(\mathrm{~B})$

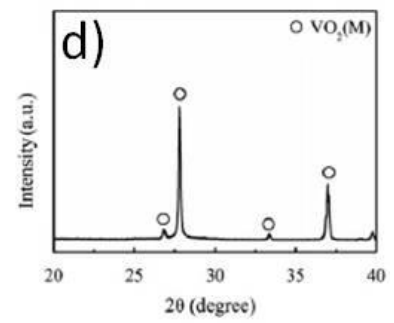

$\mathrm{VO}_{2}(\mathrm{M})$

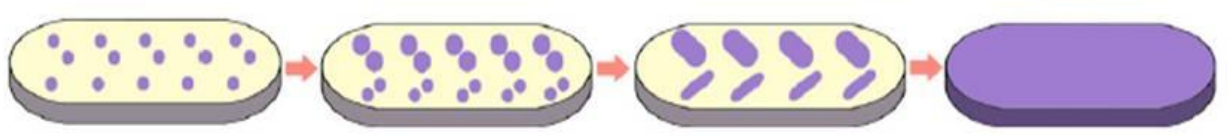

Figure 6. XRD patterns of $\mathrm{VO}_{2}$ samples prepared by hydrothermal treatment at $260^{\circ} \mathrm{C}$ for a) $2 \mathrm{~h}, \mathrm{~b}$ ) $\left.16 \mathrm{~h}, \mathrm{c}\right) 18 \mathrm{~h}$ and d) $20 \mathrm{~h}$ and e) scheme of the mechanism. Adapted with permission from ref. ${ }^{[126]}$ Copyright 2011, Elsevier.

It is also of significance to note that the presence of additives into the reaction medium allowed controlling the structure and morphology of the final particles. ${ }^{[121][129]} \mathrm{H}_{2} \mathrm{SO}_{4}$ addition promotes modification of zeta potential value and crystallization/dissolution equilibrium of $\mathrm{VO}_{2}(\mathrm{R})$. While $\mathrm{VO}_{2}(\mathrm{R})$ asterisk-shaped microcrystal were formed in absence of $\mathrm{H}_{2} \mathrm{SO}_{4}(\mathrm{pH} 3.5)$, a decrease of $\mathrm{pH}$ to 1.8 by the addition of $\mathrm{H}_{2} \mathrm{SO}_{4}$ promoted nanorods formation (Figure 4). ${ }^{[121]}$ The importance of controlling the $\mathrm{NH}_{3}$ addition to favor the formation of the $\mathrm{VO}_{2}(\mathrm{M})$ polymorph was highlighted by Dong et al. ${ }^{[130]}$ who described an hydrothermal method involving an amorphous precursor $\left[\mathrm{VO}(\mathrm{OH})_{2}\left(\mathrm{OH}_{2}\right)_{3}\right]$. The presence of $\mathrm{NH}_{4}^{+}$influenced the synthesis of pure $\mathrm{VO}_{2}(\mathrm{M})$ allowing the formation of a $\left(\mathrm{NH}_{4}\right)_{2} \mathrm{~V}_{4} \mathrm{O}_{9}$ intermediate rather than the direct crystallization of $\mathrm{VO}_{2}(\mathrm{~B})$. Polyvinylpyrrolidone in the reaction medium containing $\mathrm{V}_{2} \mathrm{O}_{5}$ and oxalate can act as a soft template to promote $\mathrm{VO}_{2}(\mathrm{R})$ hollow microsphere preparation based on nanorod self-assembly through a single-step assisted hydrothermal process. ${ }^{[129]}$ 
$\mathrm{VOSO}_{4}$ was also involved as vanadium precursor in hydrothermal reactions to directly produce $\mathrm{VO}_{2}(\mathrm{M})$ in the presence of hydrazine as reducing agent and urea as $\mathrm{pH}$ controller. In these conditions, the higher was the vanadium precursor concentration, the lower was the particle sizes. ${ }^{[131]}$ By playing on the filling ratio during the hydrothermal treatment, Ji et al. ${ }^{[128]}$ confirmed that the phase transition from $\mathrm{VO}_{2}(A)$ to $\mathrm{VO}_{2}(\mathrm{R})$ was pressure sensitive as suggested by the calculation of the ground state energies for $\mathrm{VO}_{2}(A), \mathrm{VO}_{2}(B)$ and $\mathrm{VO}_{2}(\mathrm{R})$ (Figure 7).

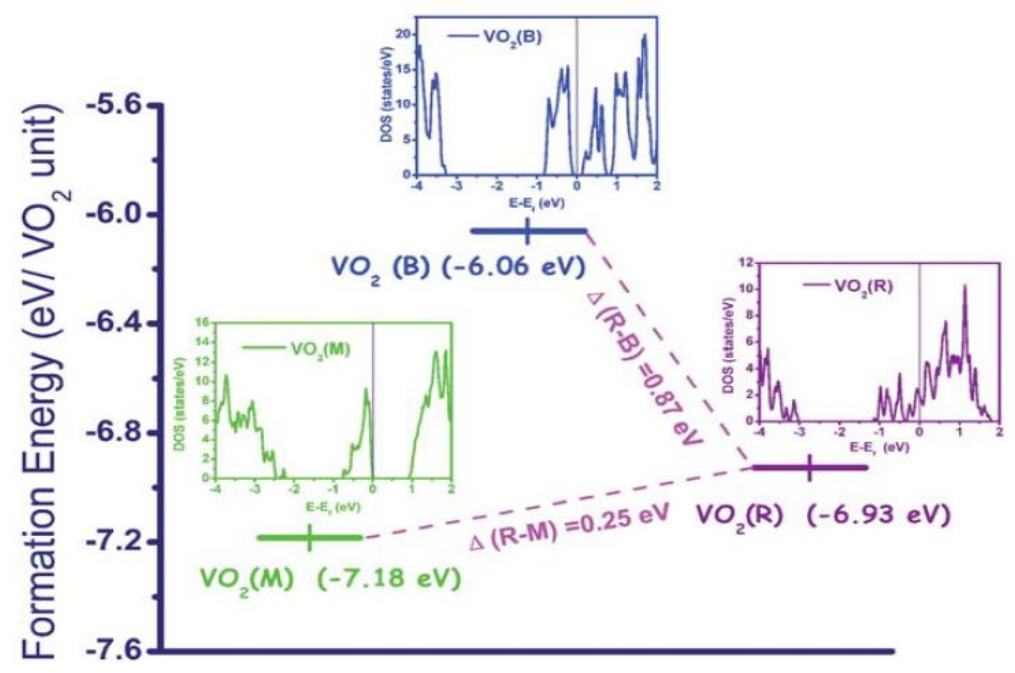

Figure 7. The calculated formation energy of different vanadium oxides according to the hybrid density functional theory. Adapted with permission from ref. ${ }^{[120]}$ Copyright 2011, The Royal Society of Chemistry.

Alternatively, $\mathrm{VO}_{2}(\mathrm{M})$ nanocrystals were also prepared using a solvothermal method involving $\mathrm{V}^{5+}$ diperoxo alkylammonium complexes as vanadium precursors in the presence of aliphatic amine acting as capping agents to limit the crystal growth. During solvothermal treatment at $180^{\circ} \mathrm{C}$ in organic medium, the complex precursors decomposed generating vanadium oxide nuclei. Figure 8 shows the TEM images of the obtained nanocrystals with various morphologies synthesized from vanadium diperoxo tetraoctylammonuim complexes in oleylamine at $180^{\circ} \mathrm{C}$ for $5 \mathrm{~h}$ with increasing water/toluene volume ratios from $0 / 40$ to $20 / 40 .{ }^{[132]}$ At low water content, monodisperse particles were formed in the dispersed water pools of a water/toluene microemulsion while an increase in water content induced a water/toluene phase separation and nanorods and aligned nanorods formation at the water/toluene interface. The SAED pattern revealed single-crystalline nanorods with a preferential elongated axis along the [101] direction. Varying the reaction conditions such as water/toluene ratio, stearic ligands of complexes, alkyl chain length of capping amines and nature of solvent could therefore control the shape and size of the nanocrystals from nanospheres to nanoplatelets, nanocubes and nanorods.

Another alternative synthetic strategy to the hydrothermal reaction has consisted in a direct combustion in a confined space of vanadium oxide acetylacetonate precursors $\mathrm{VO}(\mathrm{acac})_{2}$ dispersed in ethanol $\mathrm{VO}_{2}(\mathrm{M})$ leading to the formation of pure $\mathrm{VO}_{2}(\mathrm{M})$. Such approach provided in a short time suitable thermal energy to induce $\mathrm{VO}_{2}(\mathrm{M})$ formation and reducing/inert atmosphere to avoid further $\mathrm{VO}_{2}$ oxidation. ${ }^{[133]}$ In a similar approach, $\mathrm{VO}_{2}(\mathrm{M})$ was prepared in a short time by the combustion of $\mathrm{NH}_{4} \mathrm{VO}_{3}$ dissolved in a mixture of ethylene glycol and EtOH in air. The mechanism of formation involves the formation of a vanadyl ethylene glycolate intermediate whose complete pyrolysis strongly depends on both the volume involved and the curvature of the container. ${ }^{[134]}$ 


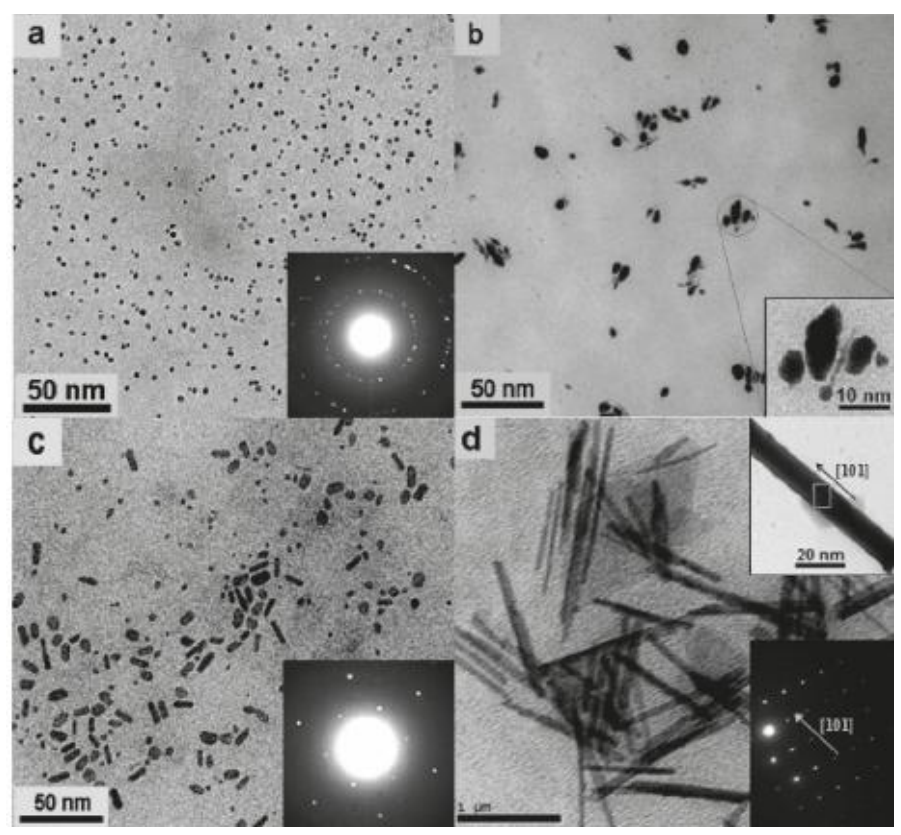

Figure 8. Effect of the increase of water content on the morphology of $\mathrm{VO}_{2}(\mathrm{M})$ nanocrystals obtained from VO $\left(\mathrm{O}_{2}\right)_{2}(\mathrm{TOA})$ in oleylamine at $180^{\circ} \mathrm{C}$ for $5 \mathrm{~h}$. Adapted with permission from ref. ${ }^{[132]}$ Copyright 2009 , American Chemical Society. 


\begin{tabular}{|c|c|c|c|}
\hline Ref. & Vanadium precursor & Additives and conditions & Morphology, Size \\
\hline [119] & $\mathrm{V}_{2} \mathrm{O}_{4}$ (commercial) & Water, 1,3-butanediol, hydrothermal, $210^{\circ} \mathrm{C}, 7$ days & Nanowires (<10 $\mu \mathrm{m}$ in length and $160 \mathrm{~nm}$ in diameter) \\
\hline [46] & $\mathrm{V}_{2} \mathrm{O}_{5}$ & $\mathrm{H}_{2} \mathrm{SO}_{4}$, hydrazine, $\mathrm{NaOH}$, hydrothermal, $220^{\circ} \mathrm{C}, 48 \mathrm{~h}$ & $\begin{array}{l}\text { Asterisk-shaped microcrystals (1-20 ?m); elongated microrods; } \\
\text { nanocrystals (20-100 nm) }\end{array}$ \\
\hline [121] & $\mathrm{V}_{2} \mathrm{O}_{5}$ & Oxalic acid, $\mathrm{H}_{2} \mathrm{SO}_{4}$, hydrothermal, $240-260^{\circ} \mathrm{C}, 16 \mathrm{~h}-48 \mathrm{~h}$ & Asterisk-shaped microcrystals; nanorods (several $\mu \mathrm{m} \times 200 \mathrm{~nm}$ ) \\
\hline [130] & $\mathrm{V}_{2} \mathrm{O}_{5}$ & Oxalic acid, $\mathrm{NaOH}, \mathrm{NH}_{3}$, hydrothermal, $280^{\circ} \mathrm{C}$ & Nanorods (150 nm); nanoparticles (50 nm) \\
\hline [135] & $\mathrm{V}_{2} \mathrm{O}_{5}$ & Oxalic acid, PVP, hydrothermal, $300^{\circ} \mathrm{C}, 0-6 \mathrm{~h}$ & Microspheres \\
\hline [125] & $\mathrm{V}_{2} \mathrm{O}_{5}$ & $\mathrm{H}_{2} \mathrm{O}_{2}, \mathrm{~N}_{2} \mathrm{H}_{4}$, hydrothermal, $260^{\circ} \mathrm{C}, 24 \mathrm{~h}$ & Nanoparticles $(<50 \mathrm{~nm})$ \\
\hline [26] & $\mathrm{V}_{2} \mathrm{O}_{5}$ & $\mathrm{~N}_{2} \mathrm{H}_{4}, \mathrm{HCl}$, hydrothermal, $300-390^{\circ} \mathrm{C}, 15 \mathrm{~h}$ & Nanoparticles (24-45 nm) \\
\hline$[136][137]$ & $\mathrm{NH}_{4} \mathrm{VO}_{3}$ & $\mathrm{~N}_{2} \mathrm{H}_{4}, \mathrm{HCl}$, hydrothermal, $280^{\circ} \mathrm{C}, 18 \mathrm{~h}$ & Nanoparticles (30-80 nm) \\
\hline [95] & $\mathrm{VOSO}_{4}$ & $\mathrm{~N}_{2} \mathrm{H}_{4}, \mathrm{NaOH}$, hydrothermal, $240^{\circ} \mathrm{C}, 36 \mathrm{~h}$ & Nanoparticles (19 nm) \\
\hline [131] & $\mathrm{VOSO}_{4}$ & $\mathrm{~N}_{2} \mathrm{H}_{4} \mathrm{CO}\left(\mathrm{NH}_{2}\right)_{2}$, hydrothermal, $260^{\circ} \mathrm{C}, 24 \mathrm{~h}$ & Nanoparticles (20-50 nm); nanorods (500 x 100 nm) \\
\hline [132] & $\begin{array}{l}\mathrm{VO}(\mathrm{O} 2)_{2}(\mathrm{CTA}) \mathrm{VO}\left(\mathrm{O}_{2}\right)_{2} \\
(\mathrm{TPA}) \mathrm{VO}\left(\mathrm{O}_{2}\right)_{2}(\mathrm{TOA})\end{array}$ & Toluene, oleylamine, hydrothermal, $180^{\circ} \mathrm{C}, 5 \mathrm{~h}$ & Spherical particles (4 nm); nanorods (300 x $20 \mathrm{~nm})$ \\
\hline [120] & $\mathrm{V}(\mathrm{OH})_{2} \mathrm{NH}_{2}$ & $\mathrm{HNO}_{3}$ aqueous solution, hydrothermal $200^{\circ} \mathrm{C}, 36 \mathrm{~h}$ & Nanorods (400-800 nm in length and $30-120 \mathrm{~nm}$ in diameter) \\
\hline [138] & $\mathrm{NH}_{4} \mathrm{VO}_{3}$ & $\mathrm{~N}_{2} \mathrm{H}_{4}, 210^{\circ} \mathrm{C}$, hydrothermal, $24-72 \mathrm{~h}$ & Nanoparticles (44 $\pm 30 \mathrm{~nm})$ \\
\hline [134] & $\mathrm{NH}_{4} \mathrm{VO}_{3}$ & Ethylene glycol, EtOH, combustion & Spherical particles (100-300 nm) \\
\hline [133] & $\mathrm{VO}(\mathrm{acac})_{2}$ & EtOH, combustion $\left(648-930^{\circ} \mathrm{C}\right)$ & Film \\
\hline
\end{tabular}

PVP : Polyvinylpyrolidone ; CTA : cetyl trimethylammonium ; TOA : tetraoctylammonium ; TPA : tetrapropylammonium 


\subsection{Solid-state conversion of vanadium oxides to prepare $\mathrm{VO}_{2}(\mathrm{M}) / \mathrm{VO}_{2}(\mathrm{R})$ particles}

Apart from the direct solution-based process, a widely used approach to obtain $\mathrm{VO}_{2}(\mathrm{M})$ consists in a post-thermal treatment of a precursor phase, typically other vanadium dioxide polymorphs or vanadyl complexes. In a preliminary step, the vanadium precursor phase is prepared using appropriate synthetic methods such as hydrothermal synthesis, ${ }^{[89]}$ continuous hydrothermal flow synthesis, ${ }^{[139]}$ the sol-gel process ${ }^{[111]},{ }^{[30]}$ or the polyol method. ${ }^{[140]}$ Then, the vanadium-based precursor is converted into $\mathrm{VO}_{2}(\mathrm{M})$ by annealing. $\mathrm{VO}_{2}(\mathrm{M})$ formation is found to be strongly dependent on the annealing parameters that highly impact the phase transition. By heating vanadium oxide precursors, the vanadium atoms displacement within the lattice is promoted leading to the desired $\mathrm{VO}_{2}(\mathrm{M}) / \mathrm{VO}_{2}(\mathrm{R})$ by taking advantage of the structural similarity. Since vanadium atoms cover different valence states ranging from +2 to $+5, \mathrm{VO}_{2}$ in a valence state $4+$ appears very sensitive to oxydo-reduction reactions. That is why during the thermal treatment or annealing, a special attention should be paid to the nature and the flow rate of the gas atmosphere used. $\mathrm{VO}_{2}(B), \mathrm{VO}_{2}(\mathrm{~A})$, paramontroseite, nsutite-type $\mathrm{VO}_{2}, \mathrm{VO}_{2}(\mathrm{D})$ or $\mathrm{VOOH}$ were successfully involved as precursors in solid state conversion upon thermal treatment to obtain $\mathrm{VO}_{2}(\mathrm{M})$. Some of the annealing conditions for these different precursor phases are reported in Table 2. Depending on the nature of the metastable precursors, the annealing temperature could be varied from $250^{\circ} \mathrm{C}$ to $550^{\circ} \mathrm{C}^{[141]}$ which influenced the particle morphology.

$\mathrm{VO}_{2}(\mathrm{~B})$ has been widely used as precursor to produce $\mathrm{VO}_{2}(\mathrm{R}) /(\mathrm{M})$. For instance, Popuri et al. ${ }^{[142]}$ evidenced by in situ high temperature XRDP (Figure 9a) the full transformation of $\mathrm{VO}_{2}(\mathrm{~B})$ prepared by hydrothermal synthesis to $\mathrm{VO}_{2}(\mathrm{M})$ above $550^{\circ} \mathrm{C}$ under vacuum, preventing the $\mathrm{VO}_{2}$ unstability under oxidizing conditions. ${ }^{[143]}$ Similar results were obtained using FTIR (Figure 9b) and in situ transmission electron microscopy ${ }^{[144]}$ confirming a complex mechanism of transformation involving an intermediate disordered phase with a reduced symmetry. On the FTIR spectra, the characteristic $\mathrm{VO}_{2}(\mathrm{M})$ double band located at $680-730 \mathrm{~cm}^{-1}$ appeared above $540^{\circ} \mathrm{C}$. The study of the transition behavior of $\mathrm{VO}_{2}(\mathrm{~B})$ nanorods evidenced that the low MIT transition temperature observed after annealing at a lower temperature and shorter time was related to the presence of $\mathrm{VO}_{2}(\mathrm{M})$ grains in the strain environment of $\mathrm{VO}_{2}(\mathrm{~B})$ nanorods rather than a size effect. ${ }^{[145]}$
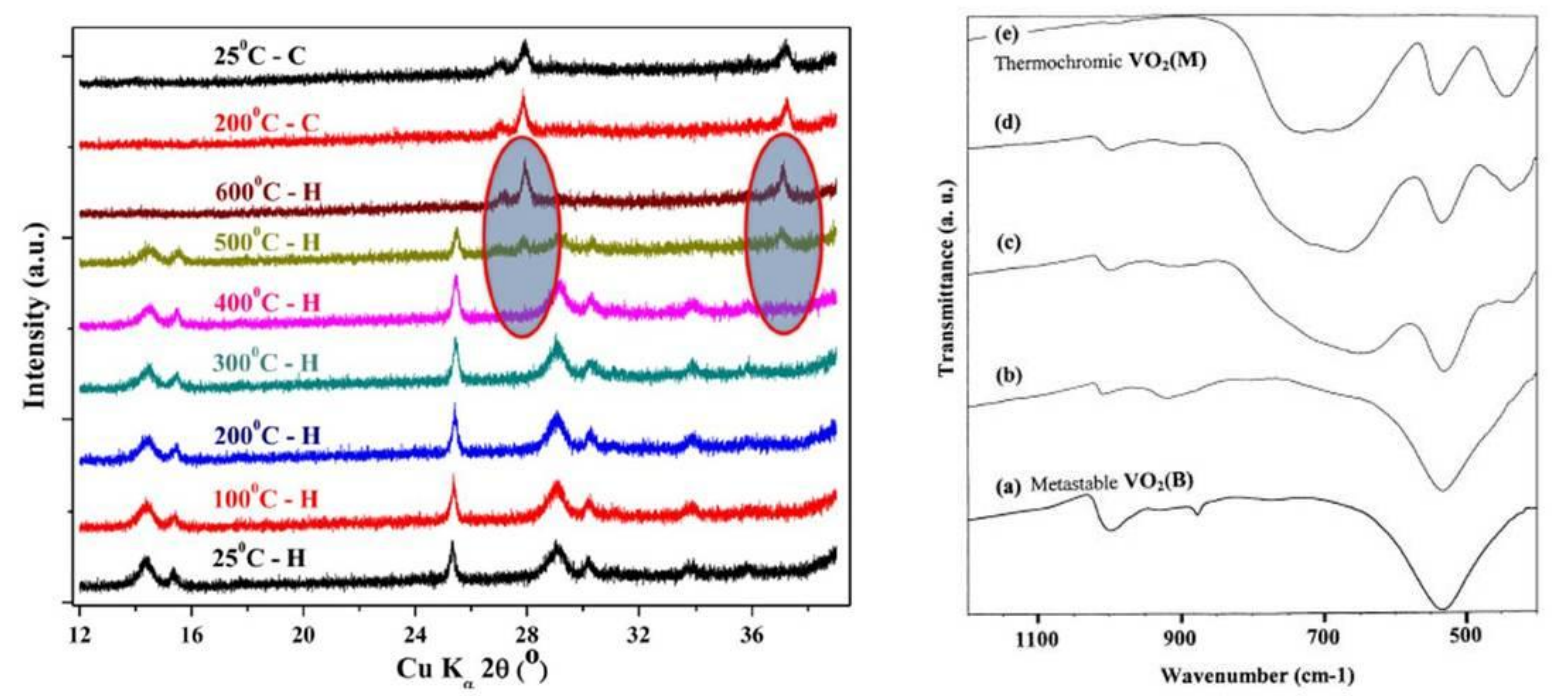
Figure 9. Left : In situ-XRPD from $25^{\circ} \mathrm{C}$ to $600^{\circ} \mathrm{C}$ (Heating cycle) and $600^{\circ} \mathrm{C}$ to $25^{\circ} \mathrm{C}$ (cooling cycle) and right FTIR spectra with temperature of $\mathrm{VO}_{2}(\mathrm{~B})$ calcined at (a) $380^{\circ} \mathrm{C}$ for $5 \mathrm{~min}$, (b) $490^{\circ} \mathrm{C}$ for $5 \mathrm{~min}$, (c) $540^{\circ} \mathrm{C}$ for $5 \mathrm{~min}$, (d) $600^{\circ} \mathrm{C}$ for $5 \mathrm{~min}$ and $(\mathrm{e}) 600^{\circ} \mathrm{C}$ for $30 \mathrm{~min}$. Adapted with permission from ref. ${ }^{[142][146]} 2012,1998$, American Chemical Society, Elsevier .

Li et al. ${ }^{[110]}$ reported the conversion of $\mathrm{VO}_{2}(\mathrm{~A})$ nanofibers prepared by hydrothermally assisted reduction of $\mathrm{NH}_{4} \mathrm{VO}_{3}$ in an acidic solution containing 1, 3- propyleneglycol into $\mathrm{VO}_{2}(\mathrm{M})$. $\mathrm{SiO}_{2}$ coating maintained the shape of the fibers during the annealing step limiting the strain and distortion during the structure conversion into $\mathrm{VO}_{2}(\mathrm{M})$. Amorphous $\mathrm{VO}_{2} @ \mathrm{SiO}_{2}$ nanorods were also prepared using an elegant strategy based on microemulsion. ${ }^{[147]} \mathrm{A}$ short-time annealing at $800^{\circ} \mathrm{C}$ in an inert atmosphere led to well-crystallized $\mathrm{VO}_{2}(\mathrm{M}) @ \mathrm{SiO}_{2}$ core-shell nanorods with lengths of about $200 \mathrm{~nm}$. Interestingly the $\mathrm{SiO}_{2}$ shell avoided sintering of $\mathrm{VO}_{2}$ particles during the thermal treatment.

Interestingly, a $\mathrm{VO}_{2}(\mathrm{D})$ metastable precursor was converted to $\mathrm{VO}_{2}(\mathrm{M})$ in maintaining the precursor particle size through calcination at low temperature (i.e., $\left.250^{\circ} \mathrm{C}\right){ }^{[148]}$ due to the high structural resemblance between the two polymorphs. Utilizing $\mathrm{VO}_{2}(\mathrm{D})$ nanoparticles thus revealed to be an efficient way to produce $\mathrm{VO}_{2}(\mathrm{M})$ nanoparticles by annealing compared to the $\mathrm{VO}_{2}(\mathrm{~B})$ and $\mathrm{VO}_{2}(\mathrm{~A})$ polymorphs. ${ }^{[104][148][149][150]}$

An ultrafast transformation from $\mathrm{VO}_{2}(\mathrm{P})$ to $\mathrm{VO}_{2}(\mathrm{M})$ in air was also reported by Sun et al. ${ }^{[151]} \mathrm{VO}_{2}(\mathrm{P})$ nanocrystals $(10-$ $30 \mathrm{~nm}$ ) obtained by solvothermal method using $\mathrm{VO}\left(\mathrm{OC}_{3} \mathrm{H}_{7}\right)$ and oleylamine were easily transformed in $\mathrm{VO}_{2}(\mathrm{M})$ thanks to their structural resemblance. Extended X-ray absorption fine structure spectroscopy (XAFS) measurements conjointly wit XRD, XPS and TEM (Figure 10) confirmed that the product obtained after annealing at $400^{\circ} \mathrm{C}$ was composed of high-quality $\mathrm{VO}_{2}(\mathrm{M})$ nanocrystals, which have maintained the same morphology and particle size upon annealing. These single domain nanocrystals allowed getting better insight into the size dependent MIT behavior thanks to in situ variable temperature IR spectroscopy experiments. Conversion of $\mathrm{VO}_{2}(\mathrm{P})$ nanocrystal prepared by hydrothermal synthesis in the presence of the surfactant: bis(2-ethylhexyl) sulfosuccinate sodium salt (AOT), could be easily performed by mild annealing treatment producing $\mathrm{VO}_{2}(\mathrm{M})$ nanoparticles with diameters in the range of 59 to $89 \mathrm{~nm}$ with no size and morphological changes. ${ }^{[152]}$ 

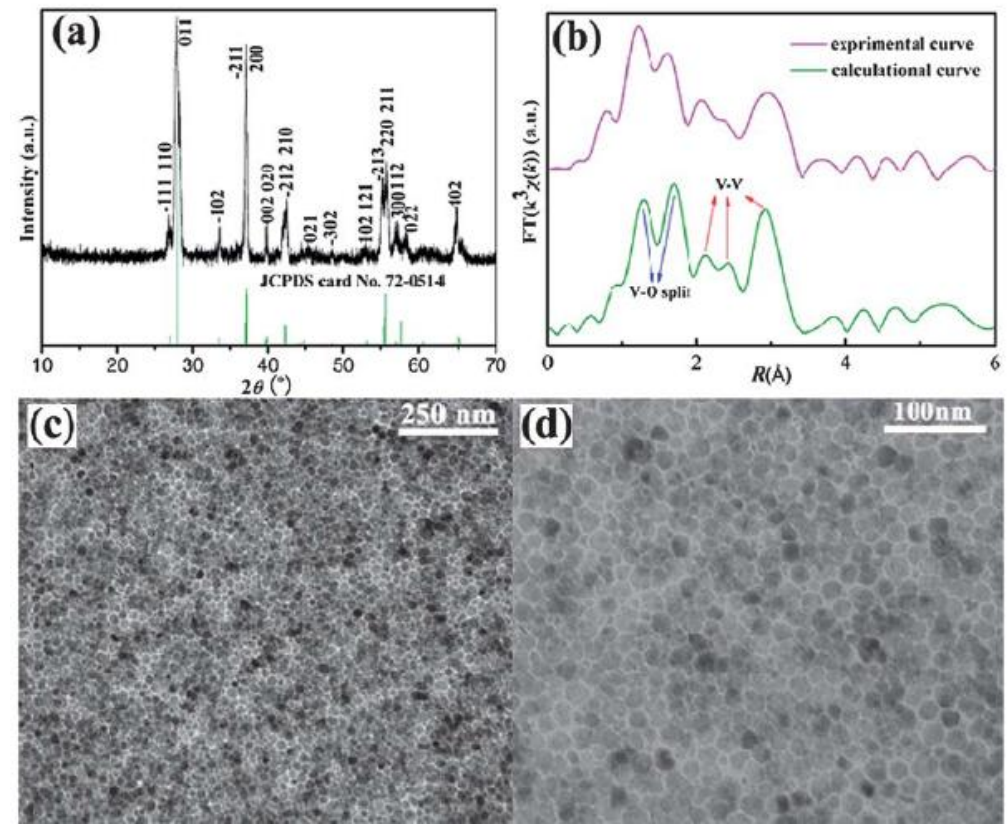

Figure 10. a) XRD pattern, b) vanadium K-edge radial distribution functions, and c) and d) TEM images at low and high magnification of $\mathrm{VO}_{2}(\mathrm{M})$ nanocrystals. Adapted with permission from ref. ${ }^{[151]}$ Copyright 2015, Nature publishing group.

Table 2. Experimental conditions reported to convert vanadium oxide phases into $\mathrm{VO}_{2}(\mathrm{M})$ by thermal treatment or annealing.

\begin{tabular}{|c|c|c|c|c|c|}
\hline Ref. & Vanadium precursor & $\mathrm{T}\left({ }^{\circ} \mathrm{C}\right)$ & Time (h) & Atmosphere & Size, Morphology \\
\hline [142] & $\mathrm{VO}_{2}(\mathrm{~B})$ & 550 & 1 & Vacuum & Platelets \\
\hline [145] & $\mathrm{VO}_{2}(\mathrm{~B})$ & $350-550$ & 1 & $\mathrm{~N}_{2}$ & Nanorods (several hundreds x 40-90 \\
\hline [110] & $\mathrm{VO}_{2}(\mathrm{~A}) @ \mathrm{SiO}_{2}$ & 700 & 1 & $\mathrm{~N}_{2}$ & Nanofibers \\
\hline [153] & $\mathrm{VO}_{2}(\mathrm{D})$ & 165 & - & $\mathrm{N}_{2}$ & Nanoparticles (20-30 nm) \\
\hline [148] & $\mathrm{VO}_{2}(\mathrm{D})$ & $300-450$ & 1 & Vacuum & Nanoparticles (74-109 nm) \\
\hline [149] & $\mathrm{VO}_{2}(\mathrm{D})$ & $250-550$ & 3 & Vacuum & Nanoaggregates/Cucumber-like \\
\hline [150] & $\mathrm{VO}_{2}(\mathrm{D})$ & $300-450$ & 1 & Vacuum & Star shaped particles \\
\hline [154] & $\mathrm{VO}_{2}(\mathrm{D})$ & 320 & 2 & $\mathrm{~N}_{2}$ & Hierarchical structures $(1-2 \mu \mathrm{m})$ \\
\hline [151] & Paramontroseite $\mathrm{VO}_{2}$ & 400 & 0.01 & Air & Nanocrystals (10-30 nm) \\
\hline [155] & Paramontroseite $\mathrm{VO}_{2}$ & 400 & 0.0167 & $\mathrm{~N}_{2}$ & - \\
\hline [152] & Paramontroseite $\mathrm{VO}_{2}$ & 350 & 1 & Vacuum & Nanoparticles (59-89 nm) \\
\hline [156] & Nsutite-type $\mathrm{VO}_{2}$ & 350 & 48 & $\mathrm{Ar}$ & $\begin{array}{l}\text { Hollow spheres }(300-400 \mathrm{~nm}) \\
\text { Shell thickness }(40-70 \mathrm{~nm})\end{array}$ \\
\hline [157] & $\mathrm{V}_{2} \mathrm{O}_{5}$. xPyridine & 150,300 , & 1 or 2 & Air, $\mathrm{H}_{2}$ or $\mathrm{N}_{2}$ & Spherical particles (200-600 nm) \\
\hline
\end{tabular}

Starting from amorphous $\mathrm{V}_{2} \mathrm{O}_{5}$ spherical particles obtained through vanadium isopropoxide hydrolysis, Lu et al. ${ }^{[157]}$ reported the formation of $\mathrm{VO}_{2}(\mathrm{M})$ spherical particles dispersible in solution through sequential annealing and reduction steps (Figure 11). After a reduction step in $\mathrm{H}_{2}$, an intermediate $\mathrm{V}_{2} \mathrm{O}_{3}$ phase was formed and subsequently converted in pure $\mathrm{VO}_{2}(\mathrm{M})$ during the last annealing step in $\mathrm{N}_{2}$ through partial re-oxidation by trace of $\mathrm{O}_{2}$ in nitrogen. The size of the particles could be easily tuned in the range of $200-600 \mathrm{~nm}$ by changing the hydrolysis conditions of thevanadium precursors. 
Other amorphous ill-defined vanadium based oxides $\left(\mathrm{VOx} . \mathrm{H}_{2} \mathrm{O}\right)$ allowed to prepare $\mathrm{VO}_{2}(\mathrm{M})$ by annealing. ${ }^{[158][159][160]}$ For instance, amorphous $\mathrm{VO}_{2}$ colloids were electrochemically prepared by anodic oxidation of metallic $\mathrm{V}^{[56]}$ producing by fast $(5 \mathrm{~s})$ annealing at $310^{\circ} \mathrm{C}$ spherical particles of $\mathrm{VO}_{2}(\mathrm{M})$ with a size of about $50 \mathrm{~nm}$.

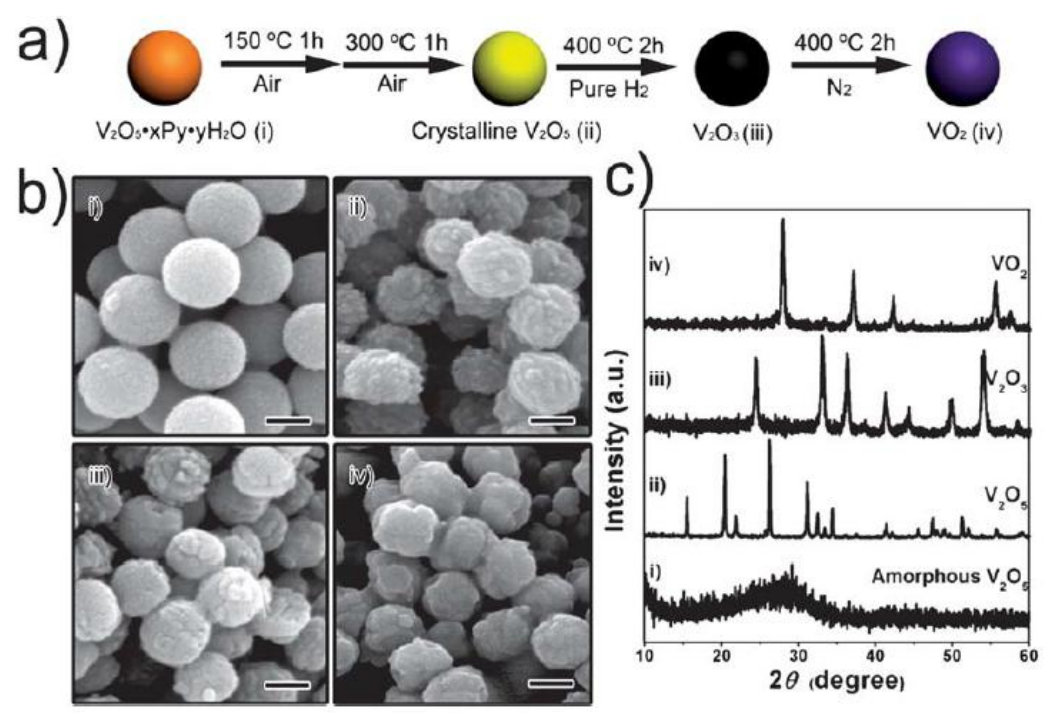

Figure 11. Synthetic scheme for the $\mathrm{VO}_{2}(\mathrm{M})$, b) SEM images of i) amorphous $\mathrm{V}_{2} \mathrm{O}_{5} \cdot \mathrm{xPy} \cdot \mathrm{yH}_{2} \mathrm{O}$, ii) crystalline $\mathrm{V}_{2} \mathrm{O}_{5}$, iii) $\mathrm{V}_{2} \mathrm{O}_{3}$ and iv) $\mathrm{VO}_{2}(\mathrm{M})$ particles. Adapted with permission from ref. ${ }^{[157]}$ Copyright 2011, The Royal Society of Chemistry.

As an alternative to vanadium oxides, vanadyl ethylene glycolate obtained from ammonium meta-vanadate $\left(\mathrm{NH}_{4} \mathrm{VO}_{3}\right)$ and ethylene glycol mixture appeared as a suitable precursor to produce highly crystalline and pure $\mathrm{VO}_{2}(\mathrm{M})$ particles by thermolysis. ${ }^{[140][161][162][163]}$ The importance of controlling the annealing treatment under controlled atmosphere and temperature was reported by Mjejri et al. ${ }^{[112]}$ Depending on the annealing conditions used, different valence states in vanadium oxides were obtained. $\mathrm{VO}_{2}(\mathrm{M})$ particles were formed upon annealing for $2 \mathrm{~h}$ at $500^{\circ} \mathrm{C}$ under vacuum while $\mathrm{V}_{2} \mathrm{O}_{3}$ and $\mathrm{V}_{2} \mathrm{O}_{5}$ were obtained under $\mathrm{Ar} / \mathrm{H}_{2}$ (95:5) and air, respectively.

Obviously, the structure of the solid vanadium precursors and the annealing conditions are of great importance to form $\mathrm{VO}_{2}(\mathrm{M})$; but the morphology of the solid precursors appeared to be another key parameter favoring vanadium precursor source conversion. Freeze drying before the annealing step reduced agglomeration of the particles and ensured an homogenous heating promoting the formation of pure $\mathrm{VO}_{2}(\mathrm{M})$ nanoparticles of $50 \mathrm{~nm} \cdot{ }^{[124]}$ Ran et al. ${ }^{[42]}$ also illustrated the freeze drying effect on the formation of pure $\mathrm{VO}_{2}(\mathrm{M})$ and on the morphology.

In summary, many synthetic strategies in solution involving various reactants were reported to prepare $\mathrm{VO}_{2}(\mathrm{M})$ nanoparticles most often involving hydrothermal treatment of vanadium precursors. Obviously, each synthetic parameter plays a key role on the stabilization of the expected $\mathrm{VO}_{2}(\mathrm{M})$ polymorph which imposes a strict control of the conditions to stabilize $\mathrm{VO}_{2}(\mathrm{M})$ colloidal suspensions.

\section{4. $\mathrm{VO}_{2}$-based composite materials}


As mentioned above, there are still big challenges associated to the formation of cost-effective $\mathrm{VO}_{2}$ nanoparticles. In turn, big challenges also remain in incorporating such nanoparticles into coatings on large surfaces. Scientific works provide elaboration routes that can be divided into two classes: fully inorganic materials and hybrid systems composed of $\mathrm{VO}_{2}$ particles embedded in a polymer matrix. Compared to $\mathrm{VO}_{2}$ /inorganic composites, examples of elaboration of composite materials made of $\mathrm{VO}_{2}$ particles incorporated into a polymer matrix are less numerous. According to Madida et al. ${ }^{[164]}$, the elaboration of stable and efficient composite films is challenging for several reasons. One first reason is that vanadium can adopt multiple oxidation states and is thus sensitive to oxygen. Indeed vanadium oxide can be progressively transformed into the more stable $\mathrm{V}_{2} \mathrm{O}_{5}$, which will inevitably affect the overall performances of the coating. ${ }^{[165][29]}$ Besides, $\mathrm{VO}_{2}$ particles are often on the micron scale in size and tend to aggregate after heat treatment. The coarse aggregates need therefore to be broken down. Indeed the presence of large particles can induce significant light scattering and affect the transparency of the coating with the generation of haze. Therefore, the polymer host has to be selected such as: i) to afford an efficient stabilization of the $\mathrm{VO}_{2}$ particles to prevent their agglomeration during processing, ii) to ensure high environmental stability, and iii) to guarantee a transparent host. In general the polymer is chosen to be as transparent as possible for radiations close to wavelengths of around $1 \mu \mathrm{m}$. The $\mathrm{VO}_{2}$, on the other hand, can be of various origins (commercial powders or homemade particles). However, as previously mentioned, the thermochromic properties of $\mathrm{VO}_{2}$ films strongly depend on the particle size and morphology. Producing high quality dispersions with small particles sizes, narrow size distribution and uniform morphology is therefore crucial to obtain highly performant composite films. Furthermore, to satisfy the current requirements in energy saving efficiency, notably in the architectural sector, and allow in particular the formation of $\mathrm{VO}_{2}$-based coatings on large surfaces, the deposition technique should be compatible with standard paint technology.

\subsection{Acrylic-based coatings}

The first reports on the elaboration of $\mathrm{VO}_{2}$-based polymer composites were released in 1994 by Alfred-Duplan, ${ }^{[166]}$ and Valmalette, ${ }^{[116]}$ respectively. Alfred-Duplan et al. ${ }^{[166]}$ reported the incorporation of $\mathrm{VO}_{2}$ particles into low-density polyethylene (LPDE) by melt blending and studied the impact of the thermochromic particles on the electrical properties of the composite material. Complex impedance analyses below and above the insulator-to-metal transition temperature revealed a pronounced influence of the amount of $\mathrm{VO}_{2}$ on conductivity. A percolation model was proposed to interpret the experimental results. Above the percolation threshold, the metal-insulator transition was effectively reflected in the impedance measurements. Actually, Valmalette and Gavarri were the very first ones to report on the incorporation of $\mathrm{VO}_{2}$ particles into a polymer matrix for thermochromic applications. ${ }^{[116]}$ To reduce the grain size, the $\mathrm{VO}_{2}$ powder was mechanically grinded using wet ball milling in a mixture of isobutyl methacrylate and a standard volatile solvent with the help of a dispersing agent, and polymerized. However, the nature of the compatibilizing agent was not indicated in this article nor were the polymerization conditions. Instead, the article focused on the modeling of the optical transmittance of the coating below and above the phase transition 
temperature as a function of the grain size and spatial distribution for increasing volume fractions of the $\mathrm{VO}_{2}$ pigment (typically in the range 0.1-5\%). It was shown that both the pigment distribution and its mean size played a critical role in the optical properties. Thus it is possible to determine the chemical preparation conditions for manufacturing and optimizing specific pigments for coatings presenting well-defined thermochromic behavior. It is only several years later that the effective performance of a thermochromic coating obtained by embedding $\mathrm{W}$ doped $\mathrm{VO}_{2}$ particles in an acrylic matrix, was reported by Shi et al. ${ }^{[75]}$ The particles were prepared by solution precipitation using $\mathrm{VOSO}_{4}$ as precursor in the presence of a stoichiometric volume of sodium tungstate. The resulting $\mathrm{VO}_{2}$ particles, whose $\mathrm{T}_{\mathrm{c}}$ varied from $66^{\circ} \mathrm{C}$ to $-4.1^{\circ} \mathrm{C}$ upon increasing the $\mathrm{W}$ atomic at\% from 0 to $2.83 \%$, were next suspended into xylene by grinding in a planetary ball mill, and the resulting dispersion was mixed with the acrylic resin (a styrene-acrylate copolymer with a $\mathrm{T}_{\mathrm{g}}$ of around $54^{\circ} \mathrm{C}$ ) under vigorous stirring. The grinding process not only reduced the particle size, but also decreased the crystal size as attested by XRD. The obtained films displayed good thermochromic properties with a $\Delta T_{\text {sol }}$ of $23 \%$ at $2500 \mathrm{~nm}$ and a maximum visible transmittance of $60 \%$ (see Table 3 ). A similar approach was reported by Xiao et al. ${ }^{[167][168]}$ using tungsten-doped and undoped particles leading to composite films with similar performances. The un-doped films showed an IR transmission modulation of about $37.3 \%$ at $2000 \mathrm{~nm}$ (which is comparable with CVD films) but a low luminous transmittance ( $T_{\text {lum }}=31.3 \%$ ) due to the presence of the $\mathrm{VO}_{2}$ particles that induced significant scattering and the formation of haze. Tungsten doping decreased both $T_{\text {lum }}$ and $\Delta T_{\text {sol }}$ (at $2000 \mathrm{~nm}$ ) while the polymer matrix had no influence on the phase transition temperature of the $\mathrm{VO}_{2}$ particles.

Although the properties reported in these preliminary papers were promising, the performances were not optimal and could be further improved if the grain size could be reduced. Indeed, according to Li et al., ${ }^{[23]}$ reducing the size of the $\mathrm{VO}_{2}$ particles should lead to a lower transition temperature and to a wider hysteresis loop during the semiconductor-to-metal transition. Following this direction, Lu et al. ${ }^{[157]}$ reported the synthesis of colloidal $\mathrm{VO}_{2}$ particles and their incorporation into a thin plastic film. The particle size could be controlled from several tens to a few hundreds of nanometers, which had a significant influence on the optical properties of $\mathrm{VO}_{2}$ and enabled the formation of stable suspensions. The trick to obtain such small particles is to use uniform $\mathrm{V}_{2} \mathrm{O}_{5}$ colloidal particles as precursors followed by sequential annealing and reduction steps. $\mathrm{VO}_{2}(\mathrm{M})$ with high purity and different particles sizes was obtained by controlling the size of the initial $\mathrm{V}_{2} \mathrm{O}_{5}$ particles. The particles were next introduced in poly(ethylene glycol) diacrylate (PEGDA, $M_{\mathrm{w}}=700 \mathrm{~g} \mathrm{~mol}^{-1}$ ) at the concentration of $10 \mathrm{~g} \mathrm{~L}^{-1}$, and the resulting mixture was deposited between two glass slides as a thin film with a thickness of several hundreds micrometers. The film was finally polymerized by UV-irradiation using dimethoxy-2-phenylacetophenone as photo-initiator (Figure 12a). To test the performance of the composite coating, the glass substrate was placed on top of an adiabatic chamber and irradiated under an IR lamp (Figure 12b). The thermochromic coating enabled to significantly delay the temperature increase of the chamber compared to a reference film containing $\mathrm{V}_{2} \mathrm{O}_{3}$ particles: the temperature rose to only $45^{\circ} \mathrm{C}$ after $15 \mathrm{~min}$ compared to $75^{\circ} \mathrm{C}$ for the $\mathrm{V}_{2} \mathrm{O}_{3}$ film (Figure $12 \mathrm{~d}$ ). 
a
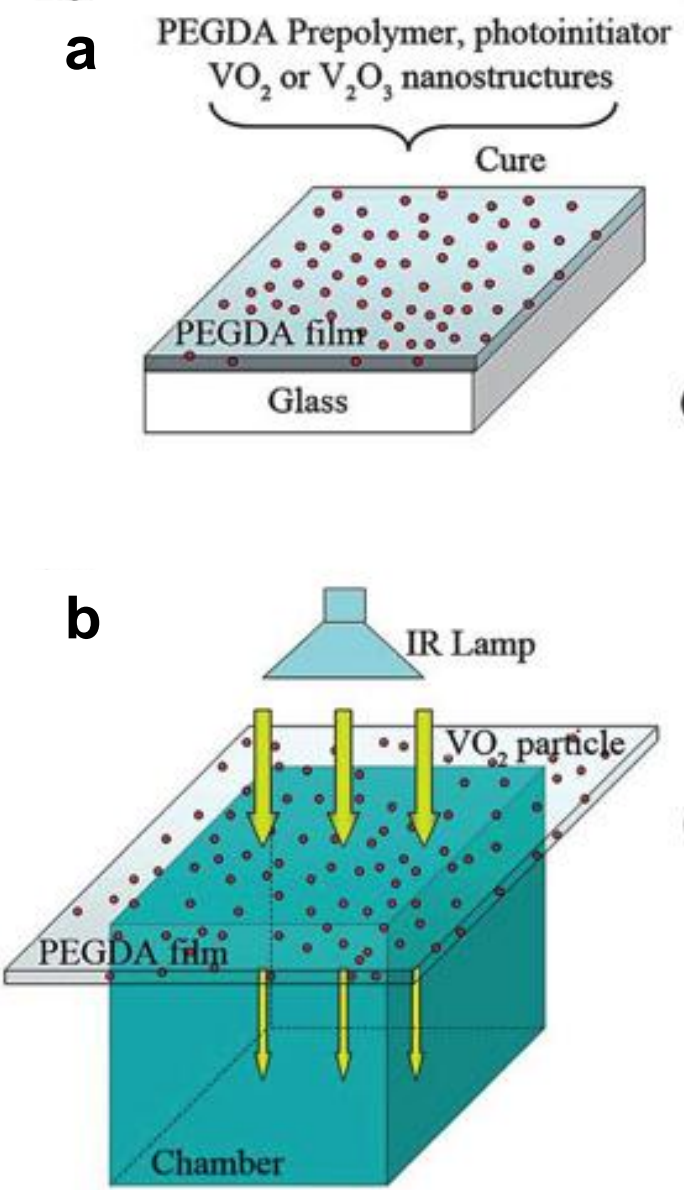

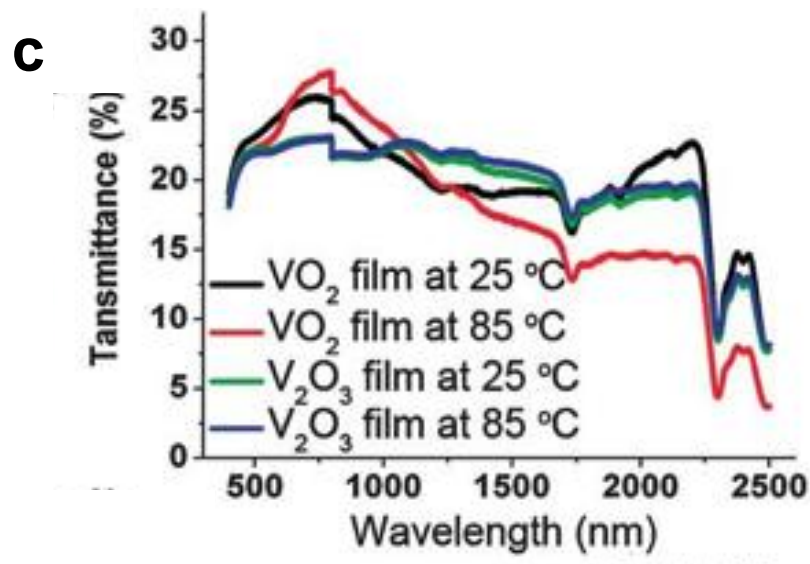

d

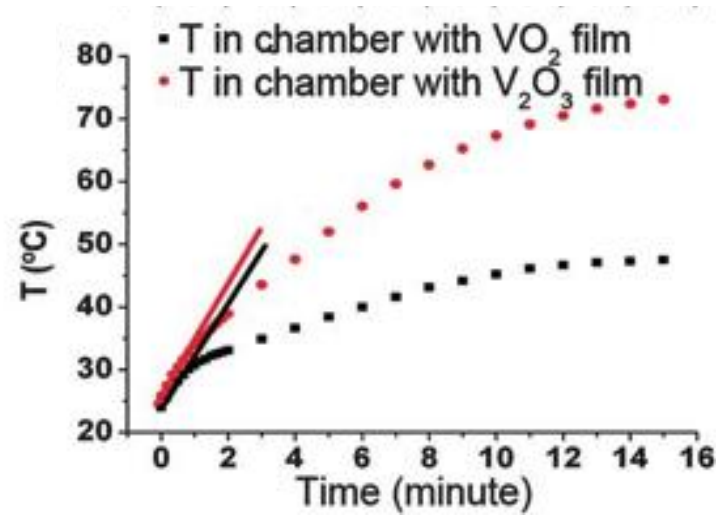

Figure 12. Illustration of the process used to form: a) a polymer film containing $\mathrm{VO}_{2}(\mathrm{M})$ particles by

photopolymerization and b) a prototype device to demonstrate the potential of the composite film to regulate the temperature of an adiabatic chamber. c) Transmission of the composite films at different temperatures compared to the same film containing $\mathrm{V}_{2} \mathrm{O}_{3}$ particles and d) temperature inside the chamber for increasing irradiation times. Adapted with permission from ref. ${ }^{[157]}$ Copyright 2011, The Royal Society of Chemistry.

Around the same time, $\mathrm{He}$ and co-workers ${ }^{[169]}$ reported the thermochromic properties of $\mathrm{VO}_{2}$-coated mica sheets embedded in a transparent UV-curing acrylic resin. The $\mathrm{VO}_{2} /$ mica pigment was dispersed in the resin and the mixture was spread on a glass substrate to afford a composite film after irradiation with a mercury lamp. The material displayed 35\% change in IR transmittance at $2200 \mathrm{~nm}$ and a transmittance of around $50 \%$ in the visible range. As mentioned above, to minimize light scattering and guarantee a high transparency, it is essential to decrease the size of the inorganic pigment and ensure an adequate dispersion in the polymeric host matrix. Furthermore, the high dielectric constant thermochromic particles need to be refractive index matched with the matrix. These challenges have been addressed by Fleer et al. ${ }^{[138]}$ in a recent paper reporting an entirely aqueous processing approach to the elaboration of nanocomposite films with embedded $\mathrm{VO}_{2}$ nanocrystals. The as prepared $\mathrm{VO}_{2}$ particles were first coated with a silica shell to reduce their degree of agglomeration and facilitate their dispersion in water. It was shown that $\mathrm{SiO}_{2}$ deposition did not affect the MIT temperature. The $\mathrm{VO}_{2} @ \mathrm{SiO}_{2}$ pigments were further functionalized with heptadecafluoro-1,1,2,2-tetrahydrodecyl - trimethoxysilane, and dispersed in water 
with the help of perfluoro-octane sulfonate (PFOS) (Figure 13). The fluorinated silane provided the pigments with effective protection against oxidation when compared to pure $\mathrm{VO}_{2}$ or $\mathrm{VO}_{2} @ \mathrm{SiO}_{2}$. The pigments were next mixed with a commercial aqueous solution of methacrylic acid/ethyl acrylate copolymer under basic conditions, and deposited on a glass substrate by casting. A comparison between pigments of varying size distributions showed that the smallest particles displayed the highest magnitude of NIR modulation and the lowest onset wavelength $(<800 \mathrm{~nm})$ of NIR suppression, indicating an effective reflectance of the considerable solar spectra irradiance in this low wavelength region (in other words, the region of maximum NIR suppression was shifted nearer to the highest solar flux part of the spectrum). The NIR modulation, the visible transmittance and the onset of NIR suppression also depend on the amount of pigment and on their state of dispersion in the matrix. The higher the amount of pigment, the poorer was their dispersion in the matrix, and the lower were consequently the visible transmittance and the NIR modulation efficiency, while the onset wavelength was shifted to higher wavenumbers. The fluorinated coreshell particles exhibited good dispersion properties in the matrix, and led to an optimal combination of performances with a high visible light transmittance of around 62\%, a high extent of NIR modulation of $30 \%$ and an early onset of NIR suppression of $758 \mathrm{~nm}$ (Table 3).

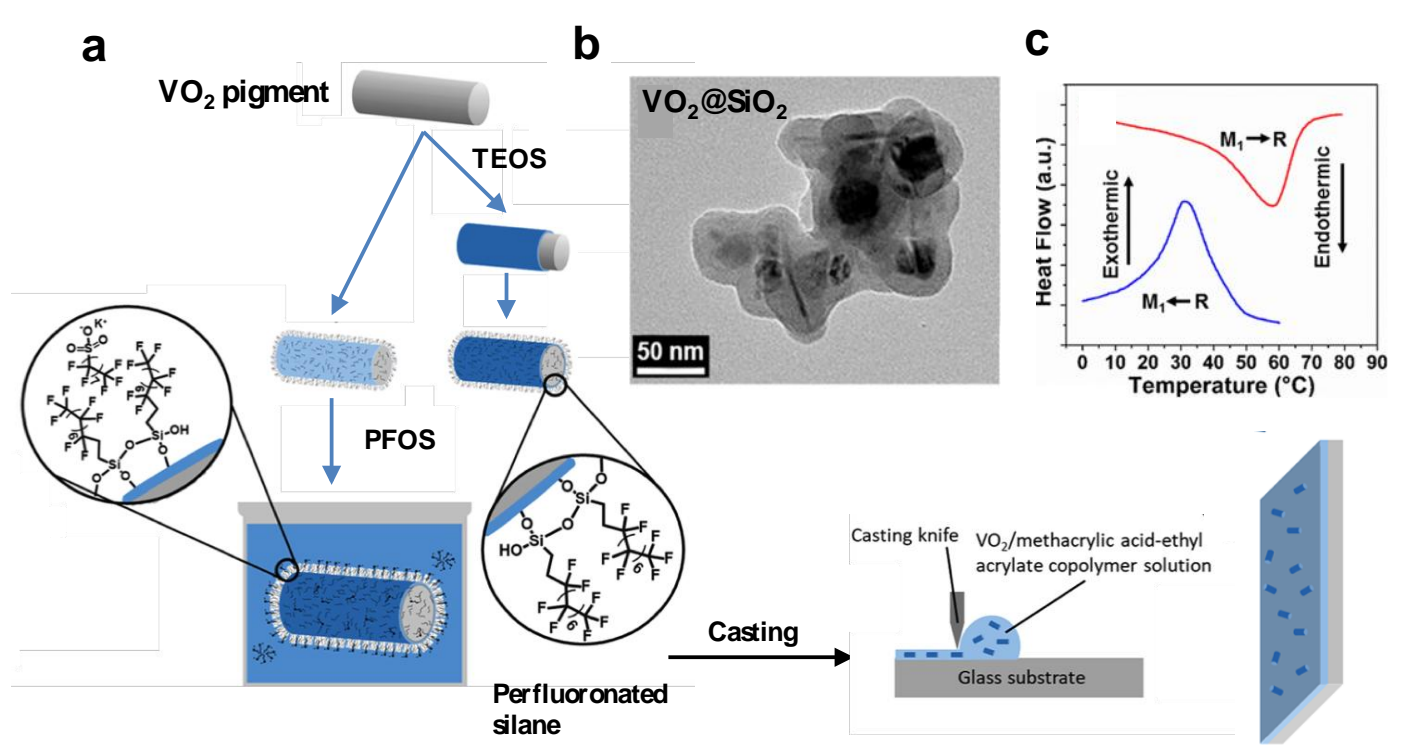

Figure 13: (a) Scheme illustrating the procedure used to prepare an acrylic thermochromic coating through an allaqueous route. (b) TEM image of core-shell $\mathrm{VO}_{2} @ \mathrm{SiO}_{2}$ nanocrystals and c) DSC traces showing an endothermic pic at $58^{\circ} \mathrm{C}$ upon heating and an exothermic pic at $31^{\circ} \mathrm{C}$ upon cooling, characteristics of the MIT transition. Adapted with permission from ref. ${ }^{[138]}$ Copyright 2017, American Chemical Society.

More recently, Liang et al. ${ }^{[170]}$ reported the formation of composite film materials with optical modulation abilities in both the visible and NIR ranges (so-called dual-band optical modulation) using an all-solution approach. The films were obtained by UV-curing of a suspension containing a mixture of acrylate monomers, a liquid crystal with a positive dielectric constant ( $\mathrm{P}$-LCS), $\mathrm{W}$-doped $\mathrm{VO}_{2}$ particles and polystyrene latex particles (to adjust the film thickness). Applying a voltage led to composite films with oriented LC microdomains that were subsequently removed by soaking with cyclohexane, and replaced by liquid crystals with a negative dielectric constant (N-LCs). The 
resulting liquid-crystalline polymer network showed a dual-band modulating ability. Indeed, application of an external voltage aligned the LC domains, and actively modulated the visible light transmittance of the film that switched between a fully transparent (for homeotropically aligned LCs) to a strongly scattering state (for disordered LCs) due to refractive index mismatch between the N-LCs domains and the polymer matrix. The phenomenon was fully reversible. Interestingly, the solar modulation efficiency and the luminous transmittance of the coating were strongly dependent on the applied voltage and increased from $7.5 \%$ (respectively $11.6 \%$ ) to $34.6 \%$ (respectively $57.8 \%$ ) with increasing the voltage from 0 to $34 \mathrm{~V}$, which is comparable to the optical performances of $\mathrm{VO}_{2}$-based hydrogels previously reported in the literature ${ }^{[171]}$ that also exhibit a dual-band modulation ability (vide infra).

\subsection{Polyurethane (PU)-based coatings}

Another family of polymers that is particularly relevant for coating applications is polyurethanes (PUs). PUs-based formulations yield coatings with excellent chemical and solvent resistance and high durability. A few examples are given below. One first illustration is the work of Gao et al. ${ }^{[92]}$ who successfully demonstrated the formation of a flexible PU film incorporating $\mathrm{VO}_{2} @ \mathrm{SiO}_{2}$ thermochromic nanoparticles. The $\mathrm{VO}_{2}$ particles were synthesized by the hydrothermal method and coated with a silica shell using polyvinyl pyrrolidone (PVP K30) as compatibilizing agent. The shell played a crucial role in the durability properties of the $\mathrm{VO}_{2}$ particles, providing an effective protection against oxidation and corrosion in acidic media. The core-shell particles were further functionalized with a methacrylate silane to favor their dispersion in the PU resin, mixed with a waterborne high molecular weight PU dispersion stabilized by sulfonate groups (Dispercoll U54, Bayer) and cast on a polyethylene terephthalate (PET) substrate (Figure 14a). The film containing the highest $\mathrm{VO}_{2}$ content exhibited a brown color (Figure 14b) but displayed nevertheless an acceptable luminous transmittance $\left(T_{\text {lum }}\right)$ of $29 \%$. Besides, the films showed a marked change in IR transmission across the MIT (up to $38 \%$ at $2000 \mathrm{~nm}$ ) and UV-shielding properties (almost no transmittance below $500 \mathrm{~nm}$ ) (Figure 14c). Their remarkably high solar modulation efficiency $\Delta T_{\text {sol }}$ achieved values up to $13.6 \%$ - significantly higher than the modulation ability of pristine $\mathrm{VO}_{2}$ films or multilayer films so far reported in the academic literature - make these flexible PU composite foils promising candidates for applications in construction and automotive glasses. 
<smiles>CC1CCCCC1COCCO</smiles>

$\mathrm{VO}_{2} @ \mathrm{SiO}_{2}$

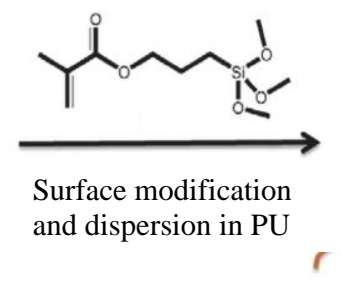

b

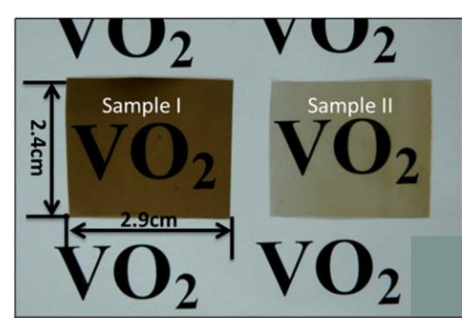

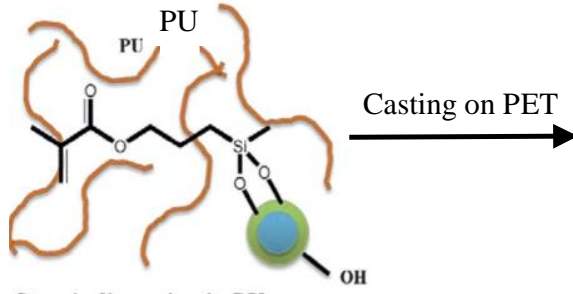

$\mathrm{VO}_{2} @ \mathrm{SiO}_{2} / \mathrm{PU}$ composite coating

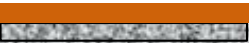

PET substrate

d

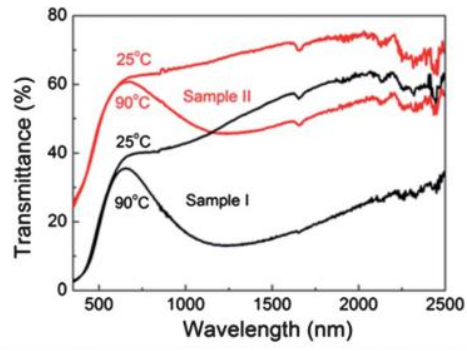

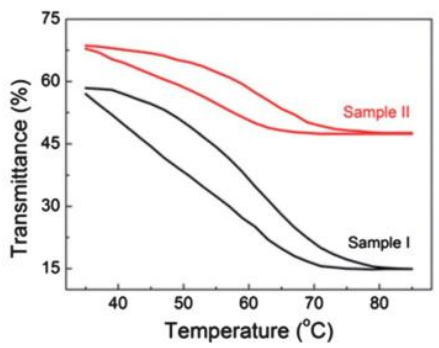

Figure 14. a) Scheme illustrating the process of formation of flexible PU composite films incorporating $\mathrm{VO}_{2} @ \mathrm{SiO}_{2}$ core-shell particles, b) digital photographs of the films with high (sample I) and low (sample II) $\mathrm{VO}_{2}$ contents, c) transmission spectra of the sample films at $25^{\circ} \mathrm{C}$ and $90^{\circ} \mathrm{C}$ and d) thermal hysteresis of the sample films at a wavelength of $1500 \mathrm{~nm}$. Adapted with permission from ref. ${ }^{[92]}$ Copyright 2012, The Royal Society of Chemistry.

In subsequent papers from the same group, ${ }^{[26][172][173]}$ the thermochromic properties of the PU composite films were further improved by using a mixture of $\mathrm{VO}_{2}$ and antimony-doped tin oxide (ATO) nanoparticles, ${ }^{[172]} \mathrm{Ti}^{\mathrm{i}-\text { doped }} \mathrm{VO}_{2}{ }^{[173]}$ or highly crystalline $\mathrm{VO}_{2}$ particles, ${ }^{[26]}$ and confronted to simulations. The incorporation of ATO particles decreased the solar modulation efficiency but also decreased the IR transmittance at high temperature, which is beneficial for energy saving as it decreases the solar heat gain during summer and thus reduces the cooling energy demand, while the visible transmittance was not affected by the presence of the particles. ${ }^{[172]} \mathrm{Ti}$ doping (1 wt\%) led to a further enhancement of the thermochromic properties of the composite foils that exhibited a $T_{\text {lum }}$ of $53 \%$ and a $\Delta T_{\text {sol }}$ of $17.2 \%{ }^{[173]}$ The best results were obtained for highly crystalline $\mathrm{VO}_{2}$ particles, whose composite films exhibited a $T_{\text {lum }}$ of $45.6 \%$ and a $\Delta T_{\text {sol }}$ of $22.3 \%$ (Table 3). ${ }^{[26]}$

Figure 15 shows the microstructure and the optical performance of a $\mathrm{VO}_{2} / \mathrm{PU}$ composite coating containing 25-45 $\mathrm{nm}$ diameter $\mathrm{VO}_{2}$ particles synthesized by the hydrothermal method at $330^{\circ} \mathrm{C}$. 


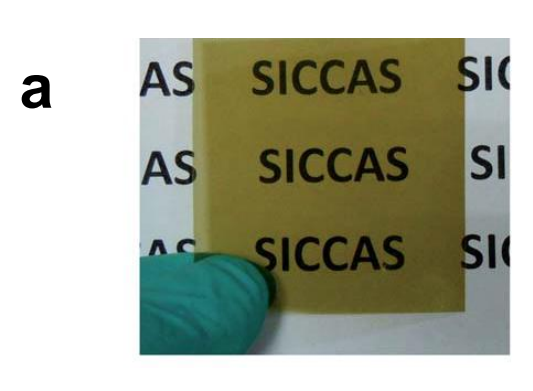

b

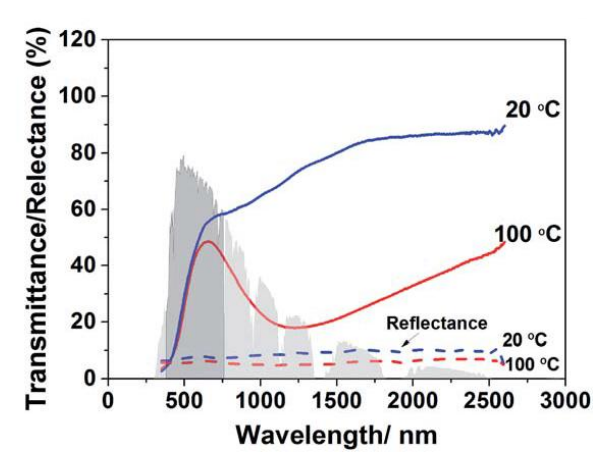

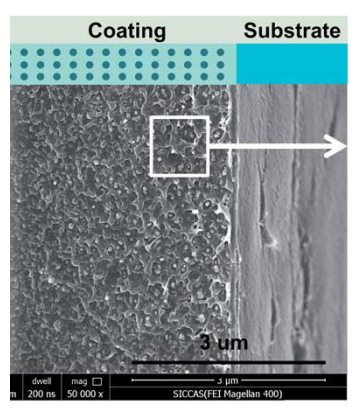

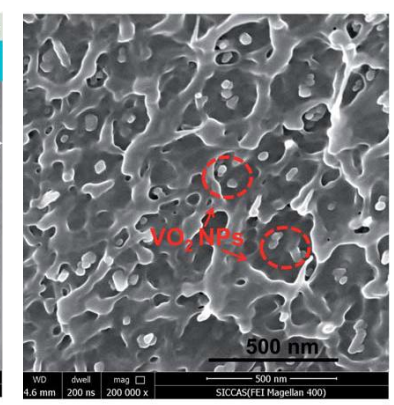

C

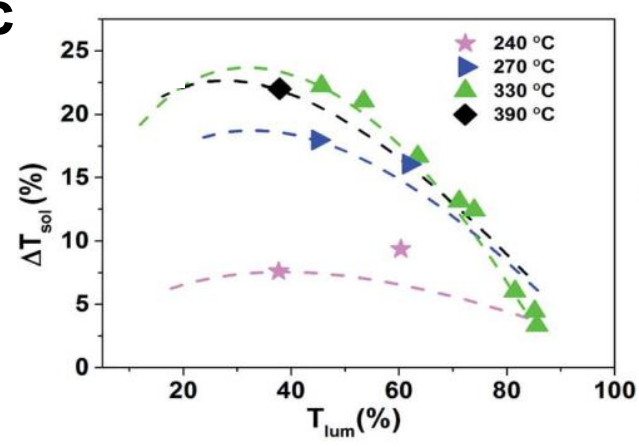

Figure 15. a) Photograph and cross-sectional SEM images (small and larger magnification) of a PU composite film containing highly crystalline $\mathrm{VO}_{2}$ particles prepared by the hydrothermal method at $330^{\circ} \mathrm{C}$ showing that the nanoparticles are well dispersed within the matrix, b) transmission spectra of the composite film below and above the transition temperature and c) comparison between experimental (symbols) and calculated (dot lines) solar modulation efficiencies $\left(\Delta T_{\text {sol }}\right)$ and luminous transmittance $\left(T_{\text {lum }}\right)$ of composite films with different thicknesses and containing $\mathrm{VO}_{2}$ particles heated at different temperatures. Adapted with permission from ref. ${ }^{[26]}$ Copyright 2014, The Royal Society of Chemistry.

This optimized temperature led to highly pure particles with a crystallinity close to that of bulk $\mathrm{VO}_{2}$. The particles were uniformly distributed within the film and had a significant influence on the thermochromic behavior of the coating, which displayed a huge transmittance difference below and above the transition temperature (Figure 15b). Calculations performed on composite films of varying thicknesses and containing $\mathrm{VO}_{2}$ particles heated at different temperature showed a very good agreement with the experimental results in particular for the $\mathrm{VO}_{2}$ particles synthesized at high temperature (Figure 15c). Under these optimized conditions, the composite coating was highly performant with a $\Delta T_{\text {sol }}$ of $22.3 \%$ and a $T_{\text {lum }}$ of $45.6 \%$. In another example along the same line, Mo-W-co-doped $\mathrm{VO}_{2}$ particles with a flower-like morphology, were synthesized by a microwave-assisted hydrothermal method, and incorporated into PU through in situ polymerization. ${ }^{[174]}$ The PU dispersion was prepared from isophorone diisocyanate, 2-bis(hydroxymethyl) propionic acid, poly( $\varepsilon$-caprolactone) diol, glycerol, and triethylamine by means of phase inversion through the acetone process in the presence of the nanosized co-doped $\mathrm{VO}_{2}$ particles. The resulting coatings showed a high visible transmittance and good optical properties in the IR range. 


\subsection{Other polymeric host materials}

Several other publications have reported the use of a variety of polymeric host materials to improve the processability and final properties of $\mathrm{VO}_{2}$-based coatings. [101][175][164][162][127][134][176][98][177] Examples of hosting polymeric materials include poly(lactic acid) $(\mathrm{PLA}),^{[101]}$ polyvinyl phenol, ${ }^{[175][164]}$ ethylene-vinyl acetate (EVA) copolymers, ${ }^{[176]}$ polyvinyl butyral (PVB), ${ }^{[98]}$ and PVP. ${ }^{[177] 47}$ For instance, Suzuki et al. ${ }^{[101] 19}$ reported the synthesis of $\mathrm{VO}_{2}$-coated $\mathrm{SiO}_{2}$ particles and their incorporation into PLA by solution mixing using $\mathrm{N}, \mathrm{N}$-dimethyl formamide as solvent. Madiba et al. ${ }^{[175][164]}$ reported the elaboration of large surface area and chemically stable thermochromic $\mathrm{VO}_{2}$ /polyvinyl phenol composite films by spin and dip coating techniques. Coarse $\mathrm{VO}_{2}$ particles (of commercial grade) were dispersed in ethanol containing the polymer and the resulting dispersion was cast on freshly cleaved sodium chloride or glass substrates. The solutions were subjected to an intensive ultrasonic treatment to reduce the grain size and improve homogeneity. Removal of the solvent led to $850 \mathrm{~nm}$ thick $\mathrm{VO}_{2}$-based composite films with a granular surface. However, for too high $\mathrm{VO}_{2}$ contents, poor dispersion of the submicronic crystallites within the matrix compromised the thermochromic performance of the coating. Optimal performances were obtained for a $\mathrm{VO}_{2}$-to-polymer mass ratio of 0.8. A similar approach was recently undertaken by $\mathrm{Wu}$ et al. ${ }^{[177]}$ using porous $\mathrm{VO}_{2}$ particles dispersed in a PVP matrix. Indeed, optical calculations predict that the incorporation of air voids should enhance the thermochromic properties of $\mathrm{VO}_{2}$ films. ${ }^{[175]}$ The $\mathrm{VO}_{2}$ particles were obtained by the hydrothermal method using cotton as a template. The authors studied the effect of the hydrothermal temperature (from $120^{\circ} \mathrm{C}$ to $180^{\circ} \mathrm{C}$ ) on the properties of the $\mathrm{VO}_{2}$ particles, and showed that the crystallinity and the particle size increased with increasing temperature while the mean pore size first increased and then decreased. The nanoporous $\mathrm{VO}_{2}$ crystallites were uniformly distributed within the film as attested by energy-dispersive X-ray spectroscopy (EDS) mapping of $\mathrm{O}$ and $\mathrm{V}$ elements (Figure 16, left). Furthermore, the composite film containing the $\mathrm{VO}_{2}$ particles heated at $180^{\circ} \mathrm{C}$ exhibited excellent optical properties with a solar modulation ability $\left(\Delta T_{\text {sol }}\right)$ of $12.4 \%$ while retaining a high visible transmission $\left(T_{\text {lum }}\right)$ of $56 \%$ (Figure 16 , right).
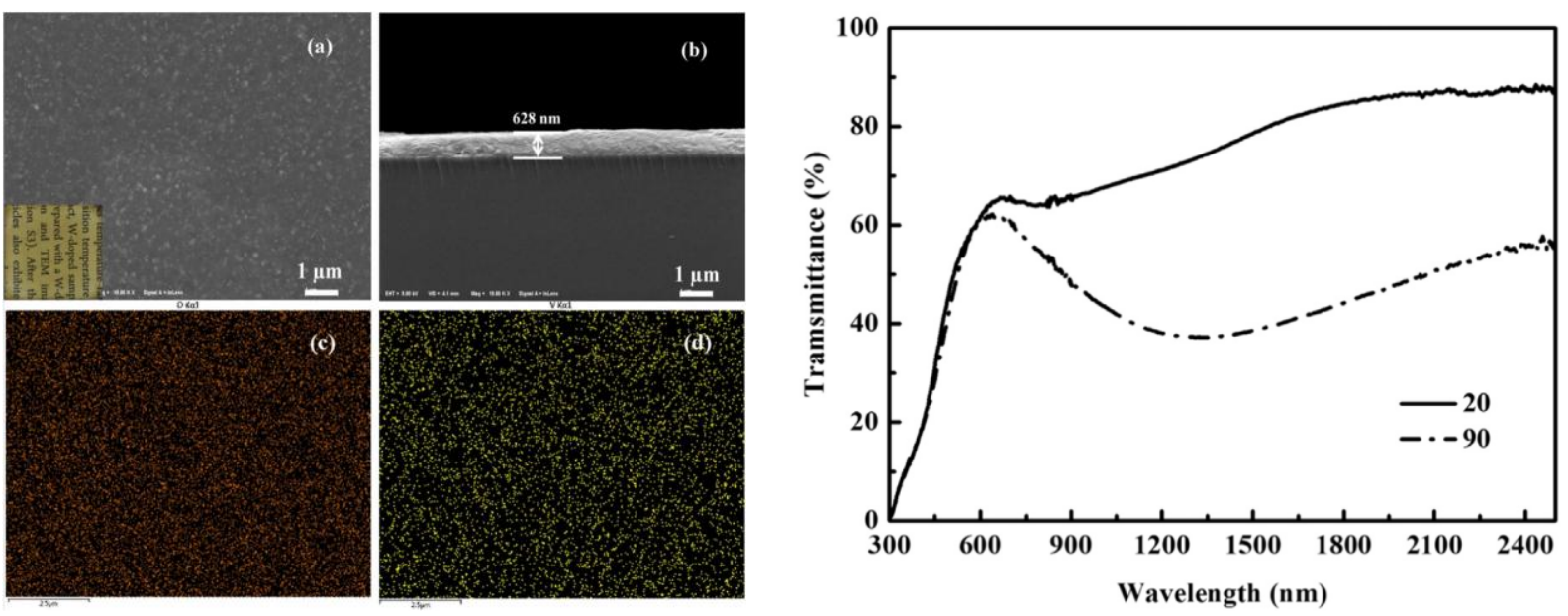
Figure 16. Left : a, b) SEM images of the surface and the cross-section of the $\mathrm{VO}_{2} / \mathrm{PVP}$ composite film containing nanoporous $\mathrm{VO}_{2}$ particles heated at $180^{\circ} \mathrm{C}$, and $\mathrm{c}, \mathrm{d}$ ) EDS mapping of $\mathrm{O}$ and $\mathrm{V}$ elements showing uniform distribution of the $\mathrm{VO}_{2}$ crystallites within the film. Right : transmission spectra of the film below and above the transition temperature. Reproduced with permission from ref. ${ }^{[177]}$ Copyright 2017, Elsevier.

Using a polyelectrolyte as the matrix, Miao et al. ${ }^{[127]}$ also reported the formation of composite films by the spincoating technique. The $\mathrm{VO}_{2}$ particles were dispersed in butyl acetate containing an appropriate amount of polyelectrolyte, followed by grinding in a planetary ball mill. The polyelectrolyte enabled to effectively prevent the particles from re-aggregating during the dispersion process, and particles sizes as small as $40 \mathrm{~nm}$ in diameter were obtained after 12 hours, although the crystallinity also decreased with increasing grinding time in agreement with previous literature. ${ }^{[75]}$ The films prepared under these optimized milling conditions displayed a high luminous transmittance ( $T_{\text {lum }}=38.5 \%$ ) and depressed haze as a consequence of the small particle size. The concomitant loss of crystallinity led however to a lower transmittance difference at $2000 \mathrm{~nm}$ below and above the phase transition compared to the film materials obtained after grinding for shorter times. The presence of defects also resulted in a shift of the transition temperature towards a higher temperature on heating and a lower temperature on cooling (i.e., the hysteresis loops broadened). The 12 hours grinding composite film exhibited nonetheless the highest solar modulation efficiency of the series $\left(\Delta T_{\text {sol }}=16.9 \%\right)$, illustrating the tremendous influence of the $\mathrm{VO}_{2}$ particle size on the optical properties of the thermochromic coatings. The importance of controlling the size and state of dispersion of the $\mathrm{VO}_{2}$ particles was recently illustrated by Srirodpai et al. ${ }^{[176]}$ who investigated the effect of processing conditions on the thermochromic properties of $\mathrm{VO}_{2} / \mathrm{EVA}$ laminate films. As shown in Figure 17, the film obtained by solution mixing displayed a greater visible transmittance as a consequence of a more uniform distribution of the $\mathrm{VO}_{2}$ pigment. A demo system was further developed by exposing the $\mathrm{VO}_{2} /$ EVA laminate film (previously coated on a window) to an IR lamp, and measuring the temperature behind the window as a function of irradiation time. The temperature was lowered by around $10^{\circ} \mathrm{C}$ when compared to a reference film that did not contain $\mathrm{VO}_{2}$ particles.
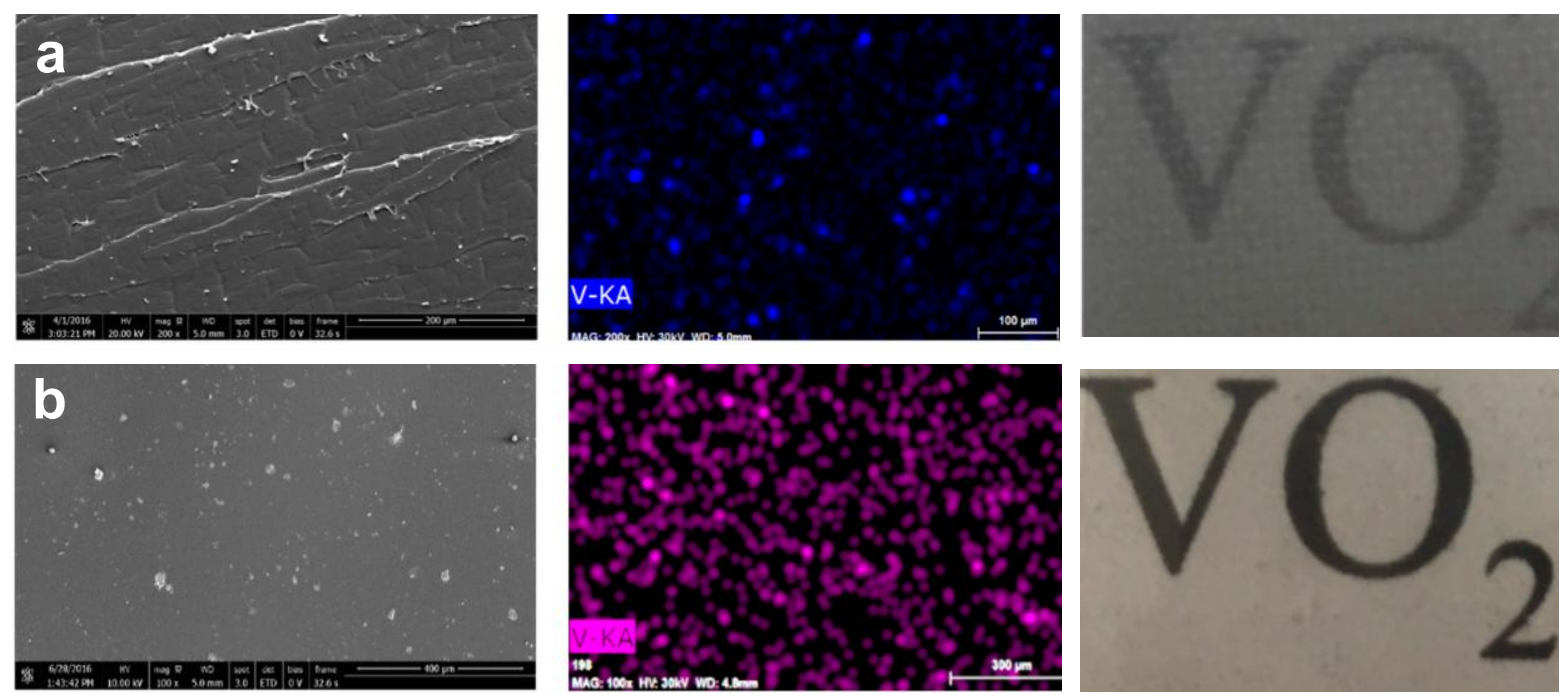
Figure 17. Influence of processing conditions: melt blending (a) versus solution mixing (b) on the microstructure and transparency of $\mathrm{VO}_{2}$ /EVA composite films. From left to right: SEM images, $\mathrm{X}$-ray dot mapping and photographs of self-standing films. Reproduced with permission from ref. ${ }^{[176]}$ Copyright 2017, MDPI.

\subsection{Electrospun $\mathrm{VO}_{2}$ / polymer composite fibers}

In an attempt to produce porous discontinuous films, the incorporation of inorganic materials into electrospun fibers has retained considerable attention in the recent literature. The resulting materials can find applications in a variety of domains as for instance filtration, tissue engineering and coatings. Some examples of composite fibers incorporating $\mathrm{VO}_{2}$ particles are given below. ${ }^{[178][179][180][181]}$ The first article along this line was reported by Li et al. ${ }^{[178]}$ only a few years ago. Thermochromic $\mathrm{VO}_{2}$ nanoparticles prepared by the hydrothermal method (pure $\mathrm{VO}_{2}$ or $\mathrm{W}$ doped $\mathrm{VO}_{2}$ ), were ultrasonically dispersed in an ethanol solution containing PVP, and further processed into 500 $800 \mathrm{~nm}$ diameter fibers by electrospinning (Figure 18a). Contrary to pure $\mathrm{VO}_{2}$, the fiber mat revealed a decreased reflectance (and greater transmittance) when heated above the phase transition temperature. The larger the fiber diameter, the lower was the diffuse reflectance of the fiber mat both under and above the transition temperature (Figure 18b). This was interpreted by the authors as being the result of multiple inner and inter-fiber scatterings as depicted in Figure 18c. The process was next extended to $\mathrm{VO}_{2}$ nanorods, ${ }^{[179]}$ leading to similar observations.
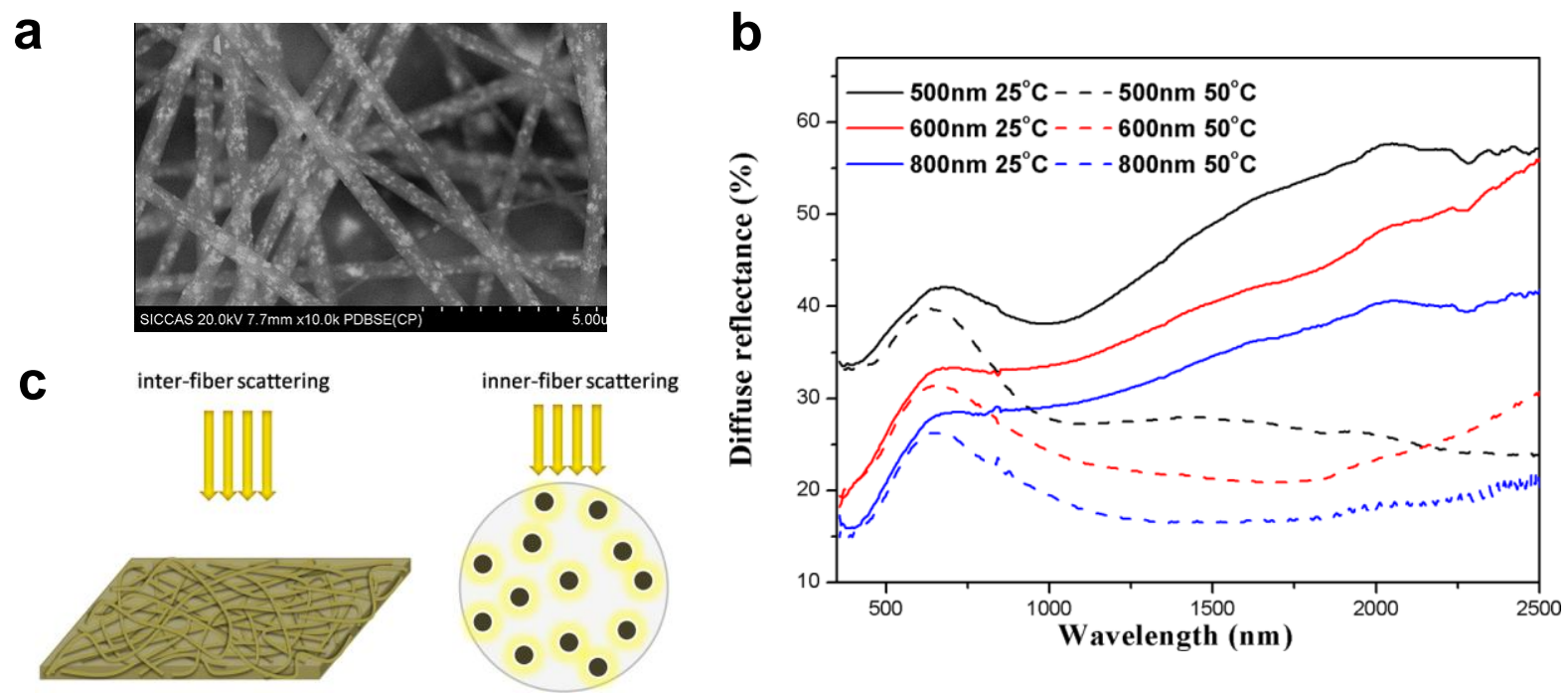

Figure 18. a) SEM image of the electrospun $\mathrm{VO}_{2} / \mathrm{PVP}$ composite fibers with a diameter of $500 \mathrm{~nm}$, b) diffuse reflection spectra of composite fiber mats containing $\mathrm{W}$-doped $\mathrm{VO}_{2}$ particles for different fiber diameters and $\mathrm{c}$ ) illustration of the multiple scattering-absorbing mechanism of the fiber mats at the origin of the peculiar optical behavior of the mat. Reproduced with permission from ref. ${ }^{[178]}$ Copyright 2013, American Chemical Society.

More recently, Lu et al. ${ }^{[180]}$ described the incorporation of $\mathrm{VO}_{2}$ into poly(methyl methacrylate) fibers still using the electrospinning approach, with the aim of affording thermochromic coatings with enhanced antioxidation properties and higher hydrophobicity. The thermochromic performances of the composite fiber mats coating were however 
poor with a luminous transmittance of only $21 \%$ and a $\Delta T_{\text {sol }}$ lower than $7 \%$. The same authors also published the fabrication of thermochromic films with superhydrophobic properties using a similar approach that combines electrospinning and hot pressing. ${ }^{[171]}$ However again, the properties of the resulting films were quite disappointing.

\subsection{Hydrogel-based coatings}

As mentioned above, to reinforce the solar transmittance modulation, $\mathrm{VO}_{2}$ particles can be combined with thermotropic materials (i.e., materials that exhibit a temperature-dependent change of the light scattering properties) leading to the so-called dual-band optical modulation. A typical example of thermotropic materials is hydrogels. Hydrogels are three-dimensional crosslinked polymer networks capable of swelling and de-swelling reversibly in water under different conditions ( $\mathrm{pH}$, temperature or light), which modifies their optical characteristics. Thermotropic effects are caused in this case by a phase separation process above the lower critical solution temperature (LCST) resulting in the formation of scattering domains. Poly(N-isopropylacrylamide) (PNIPAM), one of the most investigated thermoresponsive hydrogel polymers, undergoes an hydrophilic-to-hydrophobic transition at around $32^{\circ} \mathrm{C}$ which makes it an ideal candidate for thermochromic applications. The crosslinked polymer swells extensively in water at room temperature and exhibits a pronounced collapse on heating which is accompanied by a change of the optical transparency of the coating. Although the thermotropic behavior of polymer gels has been studied for many years, their application in smart windows was hampered by their strong volume reduction and their lack of transparency above the phase transition. ${ }^{[182]}$ However, by designing a suitable glass panel set-up, Zhou et al. ${ }^{[183]}$ showed that a PNIPAM hydrogel film sandwiched between two glass sides, could be a potential candidate for smart windows applications. After carefully adjusting the film thickness to $52 \mu \mathrm{m}$, the PNIPAM hydrogel displayed a high $T_{\text {lum }}$ of $87.9 \%$ at room temperature and an acceptable opacity at higher temperature $\left(T_{\operatorname{lum}\left(40^{\circ} \mathrm{C}\right)}=59.9 \%\right)$. Overall, the hydrogel coating enabled to achieve a solar modulation efficiency $\left.\left(\Delta T_{\text {sol(20-40 }} \mathrm{C}\right)=20.4 \%\right)$ comparable to that of the most efficient $\mathrm{VO}_{2}$ thermochromic coatings. The PNIPAM hydrogels were further combined with $\mathrm{VO}_{2}$ particles to make a hybrid thermochromic material. ${ }^{[171]}$ The $\mathrm{VO}_{2}$ /hydrogel hybrid was synthesized by in situ polymerization starting from an homogeneous dispersion of $\mathrm{VO}_{2}$ particles into an aqueous solution containing the monomer (NIPAM), polyvinyl alcohol and $N, N^{\prime}$-methylene bis acrylamide) used as crosslinker. Dipropylene glycol methyl ether (DMP) and Disperbyk 180 were used to assist pigment dispersion in water. The approach allowed increasing the $\Delta T_{\text {sol }}$ to up to $35 \%$ while maintaining a high $T_{\text {lum }}$ of around $82 \%$. Thermochromic materials based on hydroxypropyl cellulose (HPC) have also been reported. ${ }^{[184]}$ Compared to PNIPAM, HPC presents the advantage of being less toxic while its LCST can be tuned from 42 to $30^{\circ} \mathrm{C}$ by the addition of sodium chloride $(\mathrm{NaCl})$. Thermochromic coatings with optimum performances were obtained for $0.5 \mathrm{wt} \%$ of $\mathrm{NaCl}$ and a film thickness of 350 $\mu \mathrm{m}$. The hydrogel was totally transparent at room temperature $\left(T_{\text {lum }}=86.1 \%\right)$ and translucent at $45^{\circ} \mathrm{C}\left(T_{\text {lum }}\left(45^{\circ} \mathrm{C}\right)=\right.$ $48.7 \%)$, which led overall to an optimized $\Delta T_{\text {sol }}\left(20-45^{\circ} \mathrm{C}\right)$ of $25.7 \%$. The incorporation of tungsten-doped $\mathrm{VO}_{2}$ particles into the HPC microgel led to a further enhancement of the thermochromic properties with a high $T_{\text {lum }}$ of $80 \%$ at room temperature and an acceptable $T_{\text {lum }}$ of $33 \%$ at $60^{\circ} \mathrm{C}^{[67]}$ The luminous contrast of the hydrogel combined 
with the IR transmittance contrast of $\mathrm{VO}_{2}$ gave a high $\Delta T_{\text {sol }}$ of $36 \%$ which is the highest ever reported among $\mathrm{VO}_{2^{-}}$ based thermochromic composite coatings (Table 3 ). 
Table 3. Summary of the $\mathrm{VO}_{2}$-based composite thermochromic coatings reported in the literature: nature of the polymer matrix and of the precursors used to synthesize the $\mathrm{VO}_{2}$ particles, transition temperature of $\mathrm{VO}_{2}$ and optical performances of the coatings.

\begin{tabular}{|c|c|c|c|c|c|c|c|c|}
\hline \multirow[t]{2}{*}{ Ref. } & \multirow[t]{2}{*}{ Polymer matrix } & \multirow{2}{*}{$\begin{array}{l}\mathrm{VO}_{2} \\
\text { Precursors }\end{array}$} & \multirow[b]{2}{*}{ Type } & \multirow[t]{2}{*}{$\mathrm{T}_{\mathrm{c}}\left({ }^{\circ} \mathrm{C}\right)$} & \multicolumn{2}{|c|}{$\Delta T_{\text {sol }}(\%)$ at $\lambda(\mathrm{nm})$} & \multirow[t]{2}{*}{$T_{\text {lum }}(\%)$} & \multirow[t]{2}{*}{$\Delta T_{\text {sol }}(\%)$} \\
\hline & & & & & $2000 \mathrm{~nm}$ & $2500 \mathrm{~nm}$ & & \\
\hline$[98]$ & PVB/ethanol & $\mathrm{V}_{2} \mathrm{O}_{5} / \mathrm{OA}$ & $\mathrm{VO}_{2} @ \mathrm{ZnO}$ & 63.6 & / & / & 51 & 19.1 \\
\hline [101] & PLA/solvent & $\mathrm{VO}(\mathrm{OiPr})_{3}$ & $\mathrm{SiO}_{2} @ \mathrm{VO}_{2}$ & / & / & 10 & / & / \\
\hline [164][175] & Poly vinyl phenol /EtOH & / & $\mathrm{VO}_{2}$ powder (commercial) & 67.8 & 25 & 24 & / & / \\
\hline [127] & $\begin{array}{l}\text { Polyelectrolyte/butyl } \\
\text { acetate }\end{array}$ & $\mathrm{NH}_{4} \mathrm{VO}_{3} / \mathrm{OA}$ & $\mathrm{VO}_{2}$ nanobelts & 64 to 68.5 & 48.7 & 43 & 38.5 & 16.9 \\
\hline [177] & PVP/ethanol & $\mathrm{V}_{2} \mathrm{O}_{5} / \mathrm{OA} /$ cotton & Mesoporous $\mathrm{VO}_{2}$ nanocrystals & / & 40 & 25 & 56.0 & 12.9 \\
\hline [75] & Acrylic/solvent & $\mathrm{VOSO}_{4}, \mathrm{xH}_{2} \mathrm{O}$ & W-doped and undoped $\mathrm{VO}_{2}$ & -4 to 66 & / & 23 & / & / \\
\hline$[167]$ & Acrylic & $\mathrm{V}_{2} \mathrm{O}_{5} / \mathrm{OA}$ & W-doped and undoped $\mathrm{VO}_{2}$ & 58 to 68 & 31.5 & / & / & / \\
\hline [168] & Acrylic & $\mathrm{VOSO}_{4}, \mathrm{xH}_{2} \mathrm{O}$ & W-doped and undoped $\mathrm{VO}_{2}$ & 47 & 37.3 & / & 26 & 3.4 \\
\hline [157] & $\begin{array}{l}\text { Acrylic/photo } \\
\text { polymerization }\end{array}$ & $\mathrm{VO}(\mathrm{OiPr})_{3}$ & Colloidal $\mathrm{VO}_{2}$ & 65 to 78 & 5 & / & / & / \\
\hline [169] & $\begin{array}{l}\text { Acrylic/photo } \\
\text { polymerization }\end{array}$ & $\mathrm{V}_{2} \mathrm{O}_{5}$ & $\mathrm{VO}_{2}$ on mica & 71 & $35_{\lambda=2200}$ & / & / & / \\
\hline$[138]$ & Acrylic/waterborne & $\mathrm{NH}_{4} \mathrm{VO}_{3}(\mathrm{aq})$ & $\mathrm{VO}_{2} @ \mathrm{SiO}_{2}$ nanoparticles & / & / & / & / & / \\
\hline [170] & $\begin{array}{l}\text { Acrylic }+ \text { LCs/photo } \\
\text { polymerization }\end{array}$ & $\mathrm{V}_{2} \mathrm{O}_{5} / \mathrm{N}_{2} \mathrm{H}_{4}, \mathrm{HCl}$ & $\mathrm{W}$-doped $\mathrm{VO}_{2}$ nanocrystals & 43.2 & 22.5 & 15 & 57.8 & 34.6 \\
\hline [92] & PU/waterborne & $\mathrm{V}_{2} \mathrm{O}_{5} / \mathrm{OA}$ & $\mathrm{VO}_{2} @ \mathrm{SiO}_{2}$ & 51.5 & 38 & 26.5 & 29 & 13.6 \\
\hline [172] & PU/waterborne & $\mathrm{V}_{2} \mathrm{O}_{5} / \mathrm{OA}$ & $\mathrm{VO}_{2}-\mathrm{Sb}: \mathrm{SnO}_{2}$ & / & 17 & / & 53 & 11.7 \\
\hline [173] & PU/waterborne & $\mathrm{V}_{2} \mathrm{O}_{5} / \mathrm{OA}$ & Ti-doped $\mathrm{VO}_{2}$ & 66.8 & 30 & 20 & 53 & 17.2 \\
\hline [174] & PU/waterborne & $\mathrm{V}_{2} \mathrm{O}_{5} / \mathrm{OA}$ & Mo-W-doped $\mathrm{VO}_{2}$ & 17.6 to 38.5 & $23-72$ & $25-76$ & / & / \\
\hline [26] & PU/waterborne & $\mathrm{V}_{2} \mathrm{O}_{5} / \mathrm{N}_{2} \mathrm{H}_{4}, \mathrm{HCl}$ & Highly crystalline $\mathrm{VO}_{2}+\mathrm{W}$ & 21 to 68 & 55 & 41 & 45.6 & 22.3 \\
\hline [178] & PVP/electrospinning & $\mathrm{V}_{2} \mathrm{O}_{5} / \mathrm{H}_{2} \mathrm{O}_{2}$ & W-doped $\mathrm{VO}_{2}$ nanoparticles & 40 to 68 & / & / & / & / \\
\hline [179] & PVP/electrospinning & $\mathrm{V}_{2} \mathrm{O}_{5} / \mathrm{OA}$ & $\mathrm{VO}_{2}$ nanorods & 60.5 & 17.5 & 15 & / & / \\
\hline [180] & PMMA/electrospinning & $\mathrm{NH}_{4} \mathrm{VO}_{3} / \mathrm{EG}$ & $\mathrm{VO}_{2}$ nanoparticles & / & / & / & 21 & 6.8 \\
\hline [181] & PMMA/electrospinning & $\mathrm{VOSO}_{4}, \mathrm{xH}_{2} \mathrm{O}$ & $\mathrm{VO}_{2}$ nanoparticles & / & 22 & 18 & / & 7.4 \\
\hline [183] & PNIPAM/hydrogel & / & No $\mathrm{VO}_{2}$ & / & / & / & 87.9 & 20.4 \\
\hline [171] & PNIPAM/hydrogel & / & $\mathrm{VO}_{2}$ powder (commercial) & 68 & / & / & 82.1 & 34.7 \\
\hline [184] & HPC/hydrogel & / & No $\mathrm{VO}_{2}$ & / & / & / & 86.1 & 25.7 \\
\hline [67] & HPC/hydrogel & / & W-doped $\mathrm{VO}_{2}$ (commercial) & 50 & / & / & 80 & 36 \\
\hline
\end{tabular}




\section{Conclusions}

Large-scale production of $\mathrm{VO}_{2}$ smart coatings is necessary to turn this technology from the laboratory into the industrial and commercial applications. For instance, for uses in buildings envelopes, the final properties to be achieved are high solar transmittance modulation $\left(\Delta T_{\text {sol }}\right)$ to reach high passive adaptive thermal comfort in buildings with a control of the transition characteristics such as a narrow hysteresis width and a low transition temperature, $T_{c}$. If transparent applications are aimed, such as smart windows, an additional high luminous transmittance should be achieved. For practical applications, $\mathrm{VO}_{2}$ smart coatings should have $50 \%$ luminous transmittance and $15 \%$ solar transmittance modulation ability for sufficient energy-saving effect. We have reviewed in this paper complementary building blocks that enable to envision the use of $\mathrm{VO}_{2}$ nanoparticles as fillers in efficient thermochromic polymer- $\mathrm{VO}_{2}$ nanocomposites. It was shown that the nanoparticle approach enables to improve the optical characteristics of the coatings ( $T_{\text {lum }}$ and $\Delta T_{\text {sol }}$ ). However, nanoparticles exhibit a wider hysteresis, which can be in turn reduced by elemental or interfacial doping of the $\mathrm{VO}_{2}$. In addition, doping lowers down the transition temperature closer to room temperature, which is more adequate for human comfort thermal applications and also impacts the morphology and phase of the nanoparticles.

It appeared that direct synthetic protocols in solution are particularly attractive being simpler, with lower costs and allowing direct functionalization compared to methods involving solid-state transformation and annealing process. However, only a few of one-step strategies in solution have been reported to successfully prepare $\mathrm{VO}_{2}(\mathrm{R})$ nanomaterials. Clearly the stabilization of the $\mathrm{VO}_{2}(\mathrm{M})$ phase directly from molecular precursors or solid phases in solution is challenging and is strongly affected by many parameters especially the presence of doping element. It was found that post-thermal treatment of a precursor phase, typically other vanadium dioxide polymorphs and vanadyl complexes is also a widely used approach to obtain $\mathrm{VO}_{2}(\mathrm{M})$ nanoparticles. The fact that vanadium can adopt multiple oxidation states makes it very sensitive to oxygen, thus elaboration of composite materials made of $\mathrm{VO}_{2}$ particles incorporated into a polymer matrix is still a challenge. However, various polymer matrices have been explored such as acrylics, polyurethanes and hydrogels. However, doped-nanoparticles or composite-nanoparticles embedded in polymer matrices can combine improved optical properties (narrow hysteresis, high luminous transmittance and high solar modulation), convenient process deposition according to polymer coatings technologies and low transition temperature. By combining the properties of $\mathrm{VO}_{2}$ nanoparticles as fillers within the polymer matrix, one will take advantage of the long-run experience in coatings technology to tackle industrial scaleup steps such as coatings formulation for shelf-life and environmental outdoor stability. Future work can be carried out by combining other functional materials such as protective, antireflection and self-cleaning within the same coating or within the same nanoparticles (for instance into core-shell nanostructures). If so, approaches to $\mathrm{VO}_{2}$ surface functionalization and compatibilisation to favor tuning of nanostructures and improve dispersion into the polymer matrix might be next challenges to tackle. 


\section{References}

[1] S. Wang, M. Liu, L. Kong, Y. Long, X. Jiang, A. Yu, Prog. Mater. Sci. 2016, 81, 1.

[2] F.J. Morin, Phys. Rev. Lett. 1959, 3, 34.

[3] B.-J. Kim, Y.W. Lee, S. Choi, J.-W. Lim, S.J. Yun, H.-T. Kim, T.-J. Shin, H.-S. Yun, Phys. Rev. B 2008, 77, 235401.

[4] G. Xu, C.-M. Huang, M. Tazawa, P. Jin, D.-M. Chen, L. Miao, Appl. Phys. Lett. 2008, 93, 061911.

[5] G. Golan, A. Axelevitch, B. Sigalov, B. Gorenstein, Microelectronics J. 2003, 34, 255.

[6] F. Guinneton, L. Sauques, J.. Valmalette, F. Cros, J.. Gavarri, J. Phys. Chem. Solids 2001, 62, 1229.

[7] S.Y. Li, G.A. Niklasson, C.G. Granqvist, J. Appl. Phys. 2010, 108, 1.

[8] D. Mercs, A. Didelot, F. Capon, J.-F. Pierson, B. Hafner, A. Pazidis, S. Föste, R. Reineke-Koch, 2016.

[9] C.G. Granqvist, Adv. Mater. 2003, 15, 1789.

[10] C.G. Granqvist, Thin Solid Films 1990, 193-194, 730.

[11] J. Zhou, Y. Gao, Z. Zhang, H. Luo, C. Cao, Z. Chen, L. Dai, X. Liu, Sci. Rep. 2013, 3, 3029.

[12] F. Malara, A. Cannavale, S. Carallo, G. Gigli, ACS Appl. Mater. Interfaces 2014, 6, 9290.

[13] S.Y. Li, G.A. Niklasson, C.G. Granqvist, Thin Solid Films 2012, 520, 3823.

[14] T.D. Manning, I.P. Parkin, R.J.H. Clark, D. Sheel, M.E. Pemble, D. Vernadou, J. Mater. Chem. 2002, 12, 2936.

[15] A. Gonçalves, J. Resende, A.C.C. Marques, J.V. V. Pinto, D. Nunes, A. Marie, R. Goncalves, L. Pereira, R. Martins, E. Fortunato, Sol. Energy Mater. Sol. Cells 2016, 150, 1.

[16] C. Granqvist, G. Niklasson, Buildings 2016, 7, 3.

[17] M. Saeli, C. Piccirillo, I.P. Parkin, R. Binions, I. Ridley, Energy Build. 2010, 42, 1666.

[18] Y. Ke, X. Wen, D. Zhao, R. Che, Q. Xiong, Y. Long, ACS Nano 2017, 11, 7542.

[19] H. Ji, D. Liu, H. Cheng, C. Zhang, L. Yang, Sol. Energy Mater. Sol. Cells 2018, 175, 96.

[20] A. Hendaoui, N. Émond, S. Dorval, M. Chaker, E. Haddad, Curr. Appl. Phys. 2013, 13, 875.

[21] M. Benkahoul, M. Chaker, J. Margot, E. Haddad, R. Kruzelecky, B. Wong, W. Jamroz, P. Poinas, Sol. Energy Mater. Sol. Cells 2011, 95, 3504.

[22] S. Chen, H. Ma, X. Yi, T. Xiong, H. Wang, C. Ke, Sensors Actuators A Phys. 2004, 115, 28.

[23] S.Y. Li, G.A. Niklasson, C.G. Granqvist, J. Appl. Phys. 2011, 109, 113515.

[24] S.Y. Li, G.A. Niklasson, C.G. Granqvist, Appl. Phys. Lett. 2011, 99, 131907.

[25] K. Laaksonen, S.Y. Li, S.R. Puisto, N.K.J. Rostedt, T. Ala-Nissila, C.G. Granqvist, R.M. Nieminen, G.A. Niklasson, Sol. Energy Mater. Sol. Cells 2014, 130, 132.

[26] Z. Chen, Y. Gao, L. Kang, C. Cao, S. Chen, H. Luo, J. Mater. Chem. A 2014, 2, 2718.

[27] S.-Y. Li, G.A. Niklasson, C.G. Granqvist, J. Appl. Phys. 2014, 115, 53513.

[28] Y. Naoi, J. Amano, J. Appl. Phys. 2016, 120, 235301.

[29] M. Li, S. Magdassi, Y. Gao, Y. Long, Small 2017, 13, n/a.

[30] M.E.A. Warwick, R. Binions, J. Mater. Chem. A 2014, 2, 3275.

[31] S. Wang, M. Liu, L. Kong, Y. Long, X. Jiang, A. Yu, Prog. Mater. Sci. 2016, 81, 1.

[32] Y. Gao, H. Luo, Z. Zhang, L. Kang, Z. Chen, J. Du, M. Kanehira, C. Cao, Nano Energy 2012, 1, 221. 
[33] J. Montero, Y.-X. Ji, S.-Y. Li, G.A. Niklasson, C.G. Granqvist, J. Vac. Sci. Technol. B, Nanotechnol. Microelectron. Mater. Process. Meas. Phenom. 2015, 33, 031805.

[34] H. Zhang, Z. Wu, X. Wu, W. Yang, Y. Jiang, Vacuum 2014, 104, 47.

[35] X. Cao, N. Wang, J.Y. Law, S.C.J. Loo, S. Magdassi, Y. Long, Langmuir 2014, 30, 1710.

[36] W. Ning, H. Yizhong, S. Magdassi, D. Mandler, L. Hai, L. Yi, RSC Adv. 2013, 3, 7124.

[37] S. Ding, Z. Liu, D. Li, W. Zhao, Y. Wang, D. Wan, F. Huang, ACS Appl. Mater. Interfaces 2013, 5, 1630.

[38] Y. Xu, W. Huang, Q. Shi, Y. Zhang, J. Wu, L. Song, J. Mater. Sci. Mater. Electron. 2013, 24, 3823.

[39] Y. Xu, W. Huang, Q. Shi, Y. Zhang, J. Wu, L. Song, Mater. Res. Bull. 2013, 48, 4146.

[40] N. Wang, Y.K. Peh, S. Magdassi, Y. Long, J. Colloid Interface Sci. 2018, 512, 529.

[41] X. Li, S. Chen, S. Wang, J. Lai, C. Chen, X. Yi, in (Ed: A.R. Wilson), 2004, 256.

[42] K. Ran, W. Huang, Q. Shi, L. Tang, B. Peng, S. Liang, H. Zhu, Z. Mao, J. Alloys Compd. 2017, 728, 1076.

[43] V.G. Golubev, D.A. Kurdyukov, A.B. Pevtsov, A. V Sel'kin, E.B. Shadrin, A. V II'inskii, R. Boeyink, Semiconductors 2002, 36, 1043.

[44] A. V Scherbakov, A. V Akimov, V.G. Golubev, A.A. Kaplyanskii, D.A. Kurdyukov, A.A. Meluchev, A.B. Pevtsov, Phys. E Low-Dimensional Syst. Nanostructures 2003, 17, 429.

[45] D.A. Mazurenko, R. Kerst, J.I. Dijkhuis, A. V Akimov, V.G. Golubev, A.A. Kaplyanskii, D.A. Kurdyukov, A.B. Pevtsov, Appl. Phys. Lett. 2005, 86, 41114.

[46] J.-H.H. Son, J. Wei, D. Cobden, G. Cao, Y. Xia, Chem. Mater. 2010, 22, 3043.

[47] M. Zhou, J. Bao, M. Tao, R. Zhu, Y. Lin, X. Zhang, Y. Xie, Chem. Commun. 2013, 49, 6021.

[48] Z. Cao, Y. Lu, X. Xiao, Y. Zhan, H. Cheng, G. Xu, Mater. Lett. 2017, 209, 609.

[49] J.L. Martinez Hurtado, C. Kraeh, A. Popescu, H. Hedler, J.J. Finley, J.L.M. Hurtado, C. Kraeh, A. Popescu, H. Hedler, J.J. Finley, J.L. Martinez Hurtado, C. Kraeh, A. Popescu, H. Hedler, J.J. Finley, RSC Adv. 2015, 5, 59506.

[50] Q. Lu, C. Liu, N. Wang, S. Magdassi, D. Mandler, Y. Long, J. Mater. Chem. C 2016, 4, 8385.

[51] H. Bai, M.B. Cortie, A.I. Maaroof, A. Dowd, C. Kealley, G.B. Smith, Nanotechnology 2009, 20, 085607.

[52] O.P. Mikheeva, A.I. Sidorov, Tech. Phys. 2003, 48, 602.

[53] M. Maaza, O. Nemraoui, C. Sella, A.C. Beye, Gold Bull. 2005, 38, 100.

[54] R. Lopez, T.E. Haynes, L.A. Boatner, L.C. Feldman, R.F. Haglund, Opt. Lett. 2002, 27, 1327.

[55] M.B. Cortie, A. Dowd, N. Harris, M.J. Ford, Phys. Rev. B 2007, 75, 113405.

[56] F. Béteille, R. Morineau, J. Livage, M. Nagano, Mater. Res. Bull. 1997, 32, 1109.

[57] T.E. Phillips, R.A. Murphy, T.O. Poehler, Mater. Res. Bull. 1987, 22, 1113.

[58] S. Hu, S.-Y. Li, R. Ahuja, C.G. Granqvist, K. Hermansson, Appl. Phys. Lett 2012, 101, 201902.

[59] X. Tan, T. Yao, R. Long, Z. Sun, Y. Feng, H. Cheng, X. Yuan, W. Zhang, Q. Liu, C. Wu, Y. Xie, S. Wei, n.d.

[60] R. Lopez, T.E. Haynes, L.A. Boatner, L.C. Feldman, R.F. Haglund, Phys. Rev. B 2002, 65, 224113.

[61] B. Chen, D. Yang, P.A. Charpentier, M. Zeman, Sol. Energy Mater. Sol. Cells 2009, 93, 1550.

[62] G. Xu, P. Jin, M. Tazawa, K. Yoshimura, Appl. Surf. Sci. 2005, 244, 449.

[63] R. Binions, G. Hyett, C. Piccirillo, I.P. Parkin, J. Mater. Chem. 2007, 17, 4652.

[64] R. Lopez, T.E. Haynes, L.A. Boatner, L.C. Feldman, R.F. Haglund, Phys. Rev. B 2002, 65, 224113. 
[65] J. Wan, Q. Ren, N. Wu, Y. Gao, J. Alloys Compd. 2016, 662, 621.

[66] L. Whittaker, T.-L. Wu, C.J. Patridge, G. Sambandamurthy, S. Banerjee, J. Mater. Chem. 2011, 21, 5580.

[67] Y.-S. Yang, Y. Zhou, F.B.Y. Chiang, Y. Long, RSC Adv. 2017, 7, 7758.

[68] T.J. Hanlon, J.A. Coath, M.A. Richardson, Thin Solid Films 2003, 436, 269.

[69] J. Li, D. Dan, N. Yuan, T. Xie, in (Eds: J. Pan, J.C. Wyant, H. Wang), International Society For Optics And Photonics2007, 672310.

[70] H. Futaki, M. Aoki, Jpn. J. Appl. Phys. 1969, 8, 1008.

[71] Y. Gao, C. Cao, L. Dai, H. Luo, M. Kanehira, Y. Ding, Z.L. Wang, Z. Lin, Energy Environ. Sci. 2012, 5, 8708.

[72] Y. Cui, C. Cao, Z. Chen, H. Luo, Y. Gao, Comput. Mater. Sci. 2017, 130, 103.

[73] T.D. Manning, I.P. Parkin, M.E. Pemble, D. Sheel, D. Vernardou, † Troy D. Manning, * + Ivan P. Parkin, $\neq$ Martyn E. Pemble, ¥ and David Sheel, D. Vernardou $\ddagger$, Chem. Mater. 2004, 16, 744.

[74] Y. Zhang, X. Zhang, Y. Huang, C. Huang, F. Niu, C. Meng, X. Tan, Solid State Commun. 2014, 180, 24.

[75] J. Shi, S. Zhou, B. You, L. Wu, Sol. Energy Mater. Sol. Cells 2007, 91, 1856.

[76] L. Chen, C. Huang, G. Xu, L. Miao, J. Shi, J. Zhou, X. Xiao, J. Nanomater. 2012, 2012, 8.

[77] R. Binions, C. Piccirillo, I.P. Parkin, Surf. Coatings Technol. 2007, 201, 9369.

[78] C. Piccirillo, R. Binions, I.P. Parkin, Thin Solid Films 2008, 516, 1992.

[79] N.R. Mlyuka, G.A. Niklasson, C.G. Granqvist, Appl. Phys. Lett. 2009, 95, 2.

[80] J. Zhou, Y. Gao, X. Liu, Z. Chen, L. Dai, C. Cao, H. Luo, M. Kanahira, C. Sun, L. Yan, Phys. Chem. Chem. Phys. 2013, 15, 7505.

[81] W. Bruckner, U. Gerlach, W. Moldenhauer, H.-P. Bruckner, B. Thuss, H. Oppermann, E. Wolf, I. Storbeck, J. Phys. 1976, 37, C4.

[82] M.-H. Lee, M.-G. Kim, H.-K. Song, Thin Solid Films 1996, 290-291, 30.

[83] H. Kakiuchida, P. Jin, M. Tazawa, Thin Solid Films 2008, 516, 4563.

[84] I. Takahashi, M. Hibino, T. Kudo, Jpn. J. Appl. Phys. 2001, 40, 1391.

[85] G. Zhao, G. Han, M. Takahashi, T. Yoko, Thin Solid Films 2002, 410, 14.

[86] J. Du, Y. Gao, H. Luo, L. Kang, Z. Zhang, Sol. Energy Mater. Sol. Cells 2011, 95, 469.

[87] C. Cao, Y. Gao, H. Luo, J. Phys. Chem. C 2008, 112, 18810.

[88] K.C. Kam, A.K. Cheetham, Mater. Res. Bull. 2006, 41, 1015.

[89] E. Strelcov, Y. Lilach, A. Kolmakov, Nano Lett. 2009, 9, 2322.

[90] J.M. Baik, M.H. Kim, C. Larson, A.M. Wodtke, M. Moskovits, J. Phys. Chem. C 2008, 112, 13328.

[91] J.Y. Chou, J.L. Lensch-Falk, E.R. Hemesath, L.J. Lauhon, J. Appl. Phys. 2009, 105, 034310.

[92] Y. Gao, S. Wang, H. Luo, L. Dai, C. Cao, Y. Liu, Z. Chen, M. Kanehira, Energy Environ. Sci. 2012, 5, 6104.

[93] R. Li, S. Ji, Y. Li, Y. Gao, H. Luo, P. Jin, Synthesis and Characterization of Plate-like VO2(M)@SiO2 Nanoparticles and Their Application to Smart Window, 2013.

[94] Y. Zhou, S. Ji, Y. Li, Y. Gao, H. Luo, P. Jin, J. Mater. Chem. C 2014, 2, 3812.

[95] J. Zhu, Y. Zhou, B. Wang, J. Zheng, S. Ji, H. Yao, H. Luo, P. Jin, ACS Appl. Mater. Interfaces 2015, 7, 27796.

[96] M. Wang, J. Tian, H. Zhang, X. Shi, Z. Chen, Y. Wang, A. Ji, Y. Gao, RSC Adv. 2016, 6, 108286. 
[97] H.-K. Chen, H.-C. Hung, T.C.K. Yang, S.-F. Wang, J. Non. Cryst. Solids 2004, 347, 138.

[98] Y. Chen, X. Zeng, J. Zhu, R. Li, H. Yao, X. Cao, S. Ji, P. Jin, ACS Appl. Mater. Interfaces 2017, 9, 27784.

[99] K. Tong, R. Li, J. Zhu, H. Yao, H. Zhou, X. Zeng, S. Ji, P. Jin, Ceram. Int. 2017, 43, 4055.

[100] Y. Li, S. Ji, Y. Gao, H. Luo, M. Kanehira, Sci. Rep. 2013, 3, 1370.

[101] H. Suzuki, K. Yamaguchi, H. Miyazaki, Compos. Sci. Technol. 2007, 67, 3487.

[102] H. Miyazaki, N. Kusumoto, S. Sasaki, N. Sakamoto, N. Wakiya, H. Suzuki, J. Ceram. Soc. Japan 2009, 117, 970.

[103] U. Qureshi, T.D. Manning, C. Blackman, I.P. Parkin, Polyhedron 2006, 25, 334.

[104] J. Du, Y. Gao, H. Luo, Z. Zhang, L. Kang, Z. Chen, Sol. Energy Mater. Sol. Cells 2011, 95, 1604.

[105] G. Xu, C.-M. Huang, P. Jin, M. Tazawa, D.-M. Chen, J. Appl. Phys. 2008, 104, 53101.

[106] M. Saeli, C. Piccirillo, I.P. Parkin, I. Ridley, R. Binions, Sol. Energy Mater. Sol. Cells 2010, 94, 141.

[107] J.B. Kana Kana, J.M. Ndjaka, B.D. Ngom, N. Manyala, O. Nemraoui, A.Y. Fasasi, R. Nemutudi, A. Gibaud, D. Knoesen, M. Maaza, Thin Solid Films 2010, 518, 1641.

[108] R. Binions, C. Piccirillo, R.G. Palgrave, I.P. Parkin, Chem. Vap. Depos. 2008, 14, 33.

[109] L. Kang, Y. Gao, Z. Chen, J. Du, Z. Zhang, H. Luo, Sol. Energy Mater. Sol. Cells 2010, 94, 2078.

[110] S. Li, Y. Li, M. Jiang, S. Ji, H. Luo, Y. Gao, P. Jin, ACS Appl. Mater. Interfaces 2013, 5, 6453.

[111] M.M. Seyfouri, R. Binions, Sol. Energy Mater. Sol. Cells 2017, 159, 52.

[112] M.E.A.A. Warwick, R. Binions, J. Solid State Chem. 2014, 214, 53.

[113] M. Kamalisarvestani, R. Saidur, S. Mekhilef, F.S. Javadi, Renew. Sustain. Energy Rev. 2013, 26, 353.

[114] R. Lopez, L.C. Feldman, R.F. Haglund, Phys. Rev. Lett. 2004, 93, 177403.

[115] C. Liu, X. Cao, A. Kamyshny, J.Y. Law, S. Magdassi, Y. Long, J. Colloid Interface Sci. 2014, 427, 49.

[116] J.C. Valmalette, J.R. Gavarri, Sol. Energy Mater. Sol. Cells 1994, 33, 135.

[117] C. Wu, F. Feng, Y. Xie, Chem. Soc. Rev. 2013, 42, 5157.

[118] H. Yin, K. Yu, Z. Zhang, Z. Zhu, Appl. Surf. Sci. 2011, 257, 8840.

[119] L. Whittaker, C. Jaye, Z. Fu, D.A. Fischer, S. Banerjee, J. Am. Chem. Soc. 2009, 131, 8884.

[120] C. Wu, X. Zhang, J. Dai, J. Yang, Z. Wu, S. Wei, Y. Xie, J. Mater. Chem. 2011, 21, 4509.

[121] S. Ji, Y. Zhao, F. Zhang, P. Jin, J. Cryst. Growth 2010, 312, 282.

[122] D. Alie, L. Gedvilas, Z. Wang, R. Tenent, C. Engtrakul, Y. Yan, S.E. Shaheen, A.C. Dillon, C. Ban, J. Solid State Chem. 2014, 212, 237.

[123] J. Livage, Chem. Mater. 1991, 3, 578.

[124] X. Cao, M. Noe Thet, Y. Zhang, S. Chye Joachim Loo, ac Shlomo Magdassi, Q. Yan abe, Y. Long, RSC Adv. 2015, $00,1$.

[125] S. Ji, F. Zhang, P. Jin, Sol. Energy Mater. Sol. Cells 2011, 95, 3520.

[126] L. Dai, C. Cao, Y. Gao, H. Luo, Sol. Energy Mater. Sol. Cells 2011, 95, 712.

[127] L. Miao, R. Chen, J. Zhou, C. Liu, Y. Peng, J. Gao, L. Sun, S. Tanemura, RSC Adv. 2016, 6, 90813.

[128] R. Chen, L. Miao, C. Liu, J. Zhou, H. Cheng, T. Asaka, Y. Iwamoto, S. Tanemura, Sci. Rep. 2015, 5, 14087.

[129] S. Ji, F. Zhang, P. Jin, J. Solid State Chem. 2011, 184, 2285.

[130] B. Dong, N. Shen, C. Cao, Z. Chen, H. Luo, Y. Gao, RSC Adv. 2016, 6, 81559. 
[131] W. Li, S. Ji, Y. Li, A. Huang, H. Luo, P. Jin, RSC Adv. 2014, 4, 13026.

[132] T.-D. Nguyen, T.-O. Do, Langmuir 2009, 25, 5322.

[133] C. Wu, J. Dai, X. Zhang, J. Yang, F. Qi, C. Gao, Y. Xie, Angew. Chemie Int. Ed. 2010, 49, 134.

[134] Z. Cao, X. Xiao, X. Lu, Y. Zhan, H. Cheng, G. Xu, Sci. Rep. 2016, 6, 39154.

[135] C. Cao, Y. Gao, L. kang, H. Luo, CrystEngComm 2010, 12, 4048.

[136] H. Ji, D. Liu, H. Cheng, C. Zhang, J. Mater. Chem. C 2018, 6, 2424.

[137] H. Ji, D. Liu, H. Cheng, C. Zhang, L. Yang, Sol. Energy Mater. Sol. Cells 2018, 175, 96.

[138] N.A. Fleer, K.E. Pelcher, J. Zou, K. Nieto, L.D. Douglas, D.G. Sellers, S. Banerjee, ACS Appl. Mater. Interfaces 2017, 9, 38887.

[139] M.J. Powell, P. Marchand, C.J. Denis, J.C. Bear, J.A. Darr, I.P. Parkin, Nanoscale 2015, 7, 18686.

[140] I. Mjejri, A. Rougier, M. Gaudon, Inorg. Chem. 2017, 56, 1734.

[141] M. Liu, B. Su, Y. Tang, X. Jiang, A.C. Yu, Adv. Energy Mater. 2017, 7, 1700885.

[142] S.R. Popuri, M. Miclau, A. Artemenko, C. Labrugere, A. Villesuzanne, M. Pollet, Inorg. Chem. 2013, 52, 4780.

[143] S. Pavasupree, Y. Suzuki, S. Pivsa-Art, S. Yoshikawa, J. Solid State Chem. 2005, 178, 128.

[144] C. Leroux, G. Nihoul, G. Van Tendeloo, Phys. Rev. B 1998, 57, 5111.

[145] Y. Luo, M. Li, G. Li, Chinese J. Chem. Phys. 2014, 27, 471.

[146] J.-C. Valmalette, J.-R. Gavarri, Mater. Sci. Eng. B 1998, 54, 168.

[147] Y. Zhou, A. Huang, Y. Li, S. Ji, Y. Gao, P. Jin, Nanoscale 2013, 5, 9208.

[148] M. Li, X. Wu, L. Li, Y. Wang, D. Li, J. Pan, S. Li, L. Sun, G. Li, J. Mater. Chem. A 2014, 2, 4520.

[149] Z. Song, L. Zhang, F. Xia, N.A.S. Webster, J. Song, B. Liu, H. Luo, Y. Gao, Inorg. Chem. Front. 2016, 3, 1035.

[150] L. Zhong, M. Li, H. Wang, Y. Luo, J. Pan, G. Li, CrystEngComm 2015, 17, 5614.

[151] Y. Sun, S. Jiang, W. Bi, R. Long, X. Tan, C. Wu, S. Wei, Y. Xie, Nanoscale 2011, 3, 4394.

[152] L. Zhong, K. Li, Y. Luo, M. Li, H. Wang, G. Li, Cryst. Growth Des. 2017, 17, 5927.

[153] D. Teixeira, R. Quesada-Cabrera, M.J. Powell, G.K.L. Goh, G. Sankar, I.P. Parkin, R.G. Palgrave, New J. Chem. 2017, 41, 9216.

[154] L. Liu, F. Cao, T. Yao, Y. Xu, M. Zhou, B. Qu, B. Pan, C. Wu, S. Wei, Y. Xie, New J. Chem. 2012, 36, 619.

[155] C. Wu, F. Feng, J. Feng, J. Dai, J. Yang, Y. Xie, J. Phys. Chem. C 2011, 115, 791.

[156] J. Xie, C. Wu, S. Hu, J. Dai, N. Zhang, J. Feng, J. Yang, Y. Xie, Phys. Chem. Chem. Phys. 2012, 14, 4810.

[157] Z. Lu, C. Li, Y. Yin, J. Mater. Chem. 2011, 21, 14776.

[158] T. Paik, S.-H. Hong, E.A. Gaulding, H. Caglayan, T.R. Gordon, N. Engheta, C.R. Kagan, C.B. Murray, ACS Nano 2014, 8, 797.

[159] H. Wu, M. Li, L. Zhong, Y.Y. Luo, G.H. Li, Chem. - A Eur. J. 2016, 22, 17627.

[160] N. Shen, B. Dong, C. Cao, Z. Chen, H. Luo, Y. Gao, RSC Adv. 2015, 5, 108015.

[161] Y. Choi, D.M. Sim, Y.H. Hur, H.J. Han, Y.S. Jung, Sol. Energy Mater. Sol. Cells 2018, 176, 266.

[162] H. Zhang, X. Xiao, X. Lu, G. Chai, Y. Sun, Y. Zhan, G. Xu, J. Alloys Compd. 2015, 636, 106.

[163] J. Zou, Y. Peng, H. Lin, J. Mater. Chem. A 2013, 1, 4250.

[164] I.G. Madida, A. Simo, B. Sone, A. Maity, J.B. Kana Kana, A. Gibaud, G. Merad, F.T. Thema, M. Maaza, Sol. 
Energy 2014, 107, 758.

[165] S. Loquai, B. Baloukas, J.E. Klemberg-Sapieha, L. Martinu, Sol. Energy Mater. Sol. Cells 2017, 160, 217.

[166] C. Alfred-Duplan, J. Musso, J.-R.R. Gavarri, C. Cesari, J. Solid State Chem. 1994, 110, 6.

[167] X. Xiao, H. Cheng, G. Dong, Y. Yu, L. Chen, L. Miao, G. Xu, CrystEngComm 2013, 15, 1095.

[168] X. Xiao, H. Zhang, G. Chai, Y. Sun, T. Yang, H. Cheng, L. Chen, L. Miao, G. Xu, Mater. Res. Bull. 2014, 51, 6.

[169] P. He, W.-X. Huang, J.-Z. Yan, M.-Y. Zhi, J.-H. Cai, R.-R. Luo, Mater. Res. Bull. 2011, 46, 966.

[170] X. Liang, M. Chen, S. Guo, L. Zhang, F. Li, H. Yang, ACS Appl. Mater. Interfaces 2017, 9, 40810.

[171] Y. Zhou, Y. Cai, X. Hu, Y. Long, J. Mater. Chem. A 2015, 3, 1121.

[172] Y. Gao, S. Wang, L. Kang, Z. Chen, J. Du, X. Liu, H. Luo, M. Kanehira, Energy Environ. Sci. 2012, 5, 8234.

[173] S. Chen, L. Dai, J. Liu, Y. Gao, X. Liu, Z. Chen, J. Zhou, C. Cao, P. Han, H. Luo, M. Kanahira, Phys. Chem. Chem. Phys. 2013, 15, 17537.

[174] W. Lv, D. Huang, Y. Chen, Q. Qiu, Z. Luo, Ceram. Int. 2014, 40, 12661.

[175] I.G. Madiba, A. Simo, B. Sone, L. Kotsedi, M. Maaza, Mater. Today Proc. 2015, 2, 4006.

[176] O. Srirodpai, J. Wootthikanokkhan, S. Nawalertpanya, K. Yuwawech, V. Meeyoo, Materials (Basel). 2017, 10, 53.

[177] S. Wu, S. Tian, B. Liu, H. Tao, X. Zhao, R.G. Palgrave, G. Sankar, I.P. Parkin, Sol. Energy Mater. Sol. Cells 2018, $176,427$.

[178] S. Li, Y. Li, K. Qian, S. Ji, H. Luo, Y. Gao, P. Jin, ACS Appl. Mater. Interfaces 2014, 6, 9.

[179] K. Qian, S. Li, S. Ji, W. Li, Y. Li, R. Chen, P. Jin, Ceram. Int. 2014, 40, 14517.

[180] Y. Lu, X. Xiao, Z. Cao, Y. Zhan, H. Cheng, G. Xu, Appl. Surf. Sci. 2017, 425, 233.

[181] Y. Lu, X. Xiao, Y. Zhan, Z. Cao, H. Cheng, C. Huan, S. Qi, G. Xu, Ceram. Int. 2018, 44, 1013.

[182] A. Seeboth, R. Ruhmann, O. Mühling, Materials (Basel). 2010, 3, 5143.

[183] Y. Zhou, Y. Cai, X. Hu, Y. Long, J. Mater. Chem. 2014, 2, 13550.

[184] Y.-S. Yang, Y. Zhou, F.B. Yin Chiang, Y. Long, RSC Adv. 2016, 6, 61449.

[185] X. Xiao, H. Cheng, G. Dong, Y. Yu, L. Chen, L. Miao, G. Xu, CrystEngComm 2013, 15, 1095. 